\title{
Insights into the aging of biomass burning aerosol from satellite observations and 3D atmospheric modeling: evolution of the aerosol optical properties in Siberian wildfire plumes
}

\author{
Igor B. Konovalov ${ }^{1}$, Nikolai A. Golovushkin ${ }^{1}$, Matthias Beekmann ${ }^{2}$, and Meinrat O. Andreae ${ }^{3,4,5}$ \\ ${ }^{1}$ Institute of Applied Physics, Russian Academy of Sciences, Nizhniy Novgorod, Russia \\ ${ }^{2}$ Laboratoire Interuniversitaire des Systèmes Atmosphériques (LISA), UMR 7583, CNRS, Université Paris-Est Créteil, \\ Université de Paris, Institut Pierre Simon Laplace, Créteil, France \\ ${ }^{3}$ Max Planck Institute for Chemistry, Mainz, Germany \\ ${ }^{4}$ Scripps Institution of Oceanography, University of California San Diego, La Jolla, CA 92093, USA \\ ${ }^{5}$ Department of Geology and Geophysics, King Saud University, Riyadh, Saudi Arabia
}

Correspondence: Igor B. Konovalov (konov@ipfran.ru)

Received: 12 June 2020 - Discussion started: 29 June 2020

Revised: 15 November 2020 - Accepted: 24 November 2020 - Published: 14 January 2021

\begin{abstract}
Long-range transport of biomass burning (BB) aerosol from regions affected by wildfires is known to have a significant impact on the radiative balance and air quality in receptor regions. However, the changes that occur in the optical properties of BB aerosol during long-range transport events are insufficiently understood, limiting the adequacy of representations of the aerosol processes in chemistry transport and climate models. Here we introduce a framework to infer and interpret changes in the optical properties of $\mathrm{BB}$ aerosol from satellite observations of multiple BB plumes. Our framework includes (1) a procedure for analysis of available satellite retrievals of the absorption and extinction aerosol optical depths (AAOD and AOD) and singlescattering albedo (SSA) as a function of the BB aerosol photochemical age and (2) a representation of the AAOD and AOD evolution with a chemistry transport model (CTM) involving a simplified volatility basis set (VBS) scheme with a few adjustable parameters. We apply this framework to analyze a large-scale outflow of BB smoke plumes from Siberia toward Europe that occurred in July 2016. We use AAOD and SSA data derived from OMI (Ozone Monitoring Instrument) satellite measurements in the near-UV range along with $550 \mathrm{~nm}$ AOD and carbon monoxide (CO) columns retrieved from MODIS (Moderate Resolution Imaging Spectroradiometer) and IASI (Infrared Atmospheric Sounding Interferometer) satellite observations, respectively, to infer
\end{abstract}

changes in the optical properties of Siberian BB aerosol due to its atmospheric aging and to get insights into the processes underlying these changes. Using the satellite data in combination with simulated data from the CHIMERE CTM, we evaluate the enhancement ratios (EnRs) that allow isolating AAOD and AOD changes due to oxidation and gas-particle partitioning processes from those due to other processes, including transport, deposition, and wet scavenging. The behavior of EnRs for AAOD and AOD is then characterized using nonlinear trend analysis. It is found that the EnR for AOD strongly increases (by about a factor of 2) during the first $20-30 \mathrm{~h}$ of the analyzed evolution period, whereas the EnR for AAOD does not exhibit a statistically significant increase during this period. The increase in AOD is accompanied by a statistically significant enhancement of SSA. Further BB aerosol aging (up to several days) is associated with a strong decrease in EnRs for both AAOD and AOD. Our VBS simulations constrained by the observations are found to be more consistent with satellite observations of strongly aged BB plumes than "tracer" simulations in which atmospheric transformations of BB organic aerosol were disregarded. The simulation results indicate that the upward trends in EnR for AOD and in SSA are mainly due to atmospheric processing of secondary organic aerosol (SOA), leading to an increase in the mass scattering efficiency of BB aerosol. Evaporation and chemical fragmentation of the SOA species, part of which is 
assumed to be absorptive (to contain brown carbon), are identified as likely reasons for the subsequent decrease in the EnR for both AAOD and AOD. Hence, our analysis reveals that the long-range transport of smoke plumes from Siberian fires is associated with major changes in BB aerosol optical properties and chemical composition. Overall, this study demonstrates the feasibility of using available satellite observations for evaluating and improving representations in atmospheric models of the $\mathrm{BB}$ aerosol aging processes in different regions of the world at much larger temporal scales than those typically addressed in aerosol chamber experiments.

\section{Introduction}

Open biomass burning - including wildfires, controlled fires, and agricultural burns - is an important source of aerosol particles that are a key agent in the processes controlling regional and global climate (e.g., Bond et al., 2013; Jacobson, 2014; Sand et al., 2015). Climate effects of biomass burning (BB) aerosol are associated, in particular, with the scattering of solar radiation by organic matter, which is typically a dominant component of BB aerosol (Reid et al., 2005a), as well as with absorption of solar radiation by black carbon $(\mathrm{BC})$ and brown carbon $(\mathrm{BrC})$, which are also ubiquitous components of BB aerosol (Andreae and Gelencsér, 2006) both within the atmosphere and on snow and ice surfaces (Gustafson and Ramanathan, 2016; Jiang et al., 2016; Wang et al., 2016). Acting as cloud condensation nuclei (CCN), BB aerosol particles can affect the formation and radiative characteristics of clouds (e.g., Hobbs et al., 1969; Petters et al., 2009; Lu et al., 2018). Apart from being an important agent in the climate system, BB aerosol is a major contributor to air pollution episodes that have been caused by wildfires worldwide (e.g., Konovalov et al., 2011; Keywood et al., 2013; Gupta et al., 2018) and represent a major human health problem (Lelieveld et al., 2020). These facts highlight the importance of having adequate representations of the physical and chemical properties of BB aerosol in models of various complexities for climate and air pollution studies. However, developing such representations is an extremely challenging task given the high diversity of BB aerosol composition and optical properties (e.g., Reid et al., 2005a, b; Tsigaridis and Kanakidou, 2018), as well as the dynamic, nonlinear nature of the atmospheric evolution of its organic component (e.g., Bian et al., 2017; Konovalov et al., 2019).

The composition of primary BB smoke is strongly dependent on fuel type and highly variable burning conditions (McMeeking et al., 2009; Levin et al., 2010; Liu et al., 2014; Laskin et al., 2015). For example, smoldering fires have been reported to favor higher emissions of organic aerosol (OA) and semi-volatile organic gases, but lower BC emissions, compared to flaming conditions (Jen et al., 2019). In turn, the $\mathrm{BC}$-to-OA ratio has been identified as a key factor controlling the $\mathrm{BrC}$ contribution to light absorption by BB aerosol (Saleh et al., 2014; Lu et al., 2015; Pokhrel et al., 2017; McClure et al., 2020).

Furthermore, results of laboratory and field studies show a very diverse picture of atmospheric transformations of BB aerosol, suggesting that oxidation of volatile and semivolatile organic gases or heterogeneous oxidation of particles can lead, in different cases, to either enhancements or losses of organic matter by BB aerosol (e.g., Yokelson et al., 2009; Cubison et al., 2011; Hennigan et al., 2011; Akagi et al., 2012; Jolleys et al., 2015; Konovalov et al., 2015; Tiitta et al., 2016; Ciarelli et al., 2017; Vakkari et al., 2018). Some observational studies have also reported that atmospheric aging of $\mathrm{BB}$ aerosol did not result in changes in the mass concentration (corrected for dilution) of OA (e.g., May et al., 2015; Sakamoto et al., 2015; Zhou et al., 2017). This diversity, which is presently not well understood and is not reproduced in chemistry transport and climate models, can at least partly be associated with differences in fuel types, burning conditions, initial parameters of BB smoke plumes, and the dilution rate (Hennigan et al., 2011; Ahern et al., 2019; Lim et al., 2019; Hodshire et al., 2019; Konovalov et al., 2019).

There is still no consensus on the patterns of the changes in absorptive properties associated with the brownness of organics in BB aerosol in the real atmosphere, although findings from many laboratory and field studies indicate that these changes can be very significant (e.g., Kumar et al., 2018; Browne et al., 2019; Fan et al., 2019; Li et al., 2019; Sumlin et al., 2017). Based on both a BB aging experiment with an outdoor smog chamber and an analysis of field observations, Zhong and Jang (2014) reported an initial increase in light absorption by $\mathrm{BrC}$ under natural sunlight, followed by a decrease. The same $\mathrm{BrC}$ aging effects (that is, an initial photo-enhancement of $\mathrm{BrC}$ absorption and eventual bleaching of OA under UV irradiation) have also been found in more recent laboratory experiments with water-soluble organic extracts from BB aerosol (Wong et al., 2017, 2019). However, only rapid bleaching of $\mathrm{BrC}$ (on the timescale of 9 to $15 \mathrm{~h}$ ) has been detected in age-resolved aircraft observations of BB aerosol (Forrister et al., 2015). Furthermore, while these aircraft observations suggest that $\mathrm{BrC}$ almost fully disappears from BB aerosol after about $40 \mathrm{~h}$ of atmospheric aging, an analysis of the AErosol RObotic NETwork (AERONET) data by Wang et al. (2016) indicates that a sizeable fraction of $\mathrm{BrC}$ "survives" during a much longer atmospheric exposition. Laboratory data (Di Lorenzo et al., 2017; Wong et al., 2017, 2019; Fleming et al., 2020) indicate that this fraction is likely formed by high-molecular-weight chromophores (while low-molecular-weight chromophores are more rapidly destroyed), suggesting that the atmospheric fate of the $\mathrm{BrC}$ fraction of $\mathrm{BB}$ aerosol is dependent on fuel type and burning conditions. Finally, it should be noted that the atmospheric relevance of various processes, which, according to laboratory studies, can affect formation and bleaching of chromophores in BB aerosol, is so far not sufficiently clear 
(Fleming et al., 2020); this fact constitutes an additional obstacle for developing adequate modeling representations of $\mathrm{BB}$ aerosol aging processes.

The discussion above indicates that the sparse and often contradictory results of field and laboratory studies available so far can hardly provide consistent observational constraints for representations of the effects of atmospheric aging of BB aerosol in chemistry transport and climate models. The general objective of the present study is to find a way to infer statistically reliable information on the impact of aging processes on the optical properties of BB aerosol from available satellite measurements. To this end, we developed an analytical framework enabling the synergetic combination of satellite and model data on BB aerosol optical properties and composition. Unlike the inevitably sparse field observations that are available only for a tiny fraction of wildfires occurring in the world each year, satellite instruments provide abundant observations of BB plumes associated with virtually any major vegetation fire worldwide. Accordingly, satellite observations of BB plumes can enable statistical characterization of the $\mathrm{BB}$ aerosol aging effect in a given region, encompassing a wide range of BB aerosol sources and burning conditions. A similar concept was initially exploited in our previous study (Konovalov et al., 2017a), focusing on the analysis of MODIS (Moderate Resolution Imaging Spectroradiometer) observations of extinction aerosol optical depth (AOD) (Levy et al., 2013) in Siberia. We found, in particular, that after being corrected for dilution, AOD increases almost twofold in BB plumes aged between 15 and $20 \mathrm{~h} \mathrm{com-}$ pared to fresher plumes, indicating strong secondary organic aerosol (SOA) formation. This study substantially extends the scope of the previous one by analyzing satellite observations of both the absorption and extinction characteristics of BB aerosol. Specifically, along with the MODIS AOD observations, we analyze near-UV retrievals of the absorption aerosol optical depth (AAOD) and single-scattering albedo (SSA) from the OMI (Ozone Monitoring Instrument) measurements (Torres et al., 2007, 2013). Taking into account that OMI observations of AAOD at the $388 \mathrm{~nm}$ wavelength are sensitive to the $\mathrm{BrC}$ content in $\mathrm{BB}$ aerosol (Jethva and Torres, 2011; Mok et al., 2016), these observations can be expected to provide useful insights into the changes in the absorptive properties of the organic fraction of BB aerosol. At the same time, the MODIS AOD observations are expected to bring light to a possible role of SOA formation (Saleh et al., 2013) in these changes. Note that the OMI AAOD and MODIS AOD observations were previously found to provide consistent information on $\mathrm{BB}$ aerosol optical properties, enabling their use as observational constraints on $\mathrm{BB}$ emissions of $\mathrm{BC}$ and organic carbon (OC) (Konovalov et al., 2018). The OMI AAOD retrievals were also found to provide useful constraints on anthropogenic $\mathrm{BC}$ emissions over southeastern Asia (Zhang et al., 2015). Similar to Konovalov et al. (2017a), we additionally use CO column amounts retrieved from IASI (Infrared Atmospheric Sounding Interfer- ometer) satellite observations (Clerbaux et al., 2009) to account for the effects of dilution.

To analyze and interpret the satellite observations, we use the CHIMERE chemistry transport model (Mailler et al., 2017) in combination with an external module, OPTSIM (Stromatas et al., 2012), enabling Mie calculations of light absorption and extinction for both core-shell and homogeneous morphologies of particles. Typically, $\mathrm{BrC}$ has been introduced in previous modeling studies as an absorbing fraction of otherwise non-absorbing OA (e.g., Park et al., 2010; Saleh et al., 2015; Jo et al., 2016), with predefined absorptive properties that are not affected by atmospheric aging. More recently, Wang et al. (2018), Brown et al. (2018), and Zhang et al. (2020) assigned empirical estimates of absorption properties for all OA in their global modeling studies and also assumed that the absorption of OA decreases with a constant rate as a function of the BB aerosol photochemical age, irrespective of the simulated evolution of the chemical composition of the particles. In this study, we largely follow the latter approach but take a step further by considering the evolution of $\mathrm{BrC}$ consistently with simulated changes in both primary organic aerosol (POA) and SOA within the volatility basis set (VBS) framework (Robinson et al., 2007). Several parameters of our model are adjusted to meet the observational constraints. Nonetheless, because our representation of BB aerosol aging is highly simplified and associated with large uncertainties, we use our simulations mainly to get insights into the qualitative patterns of $\mathrm{BB}$ aerosol transformations rather than for quantitative characterization of any processes.

Aerosol particles emitted from vegetation fires in Siberia can be transported in the atmosphere over thousands of kilometers and significantly affect atmospheric composition in receptor regions, such as East Asia (Agarwal et al., 2010; Matsui et al, 2013, Ikeda and Tanimoto, 2015; Yasunari et al., 2018), the western USA (Laing et al., 2016), and Alaska (Warneke et al., 2009). Siberian fires have been estimated to contribute, on average, up to $40 \%$ of total BC deposited annually in the Arctic (Evangelio et al., 2016), where BB aerosol can significantly affect the climate processes (Sand et al., 2015) associated with an observed rapid increase in the annual surface temperature in this region (Bekryaev et al., 2010). As the role of fires in boreal regions is projected to increase in a warmer climate (Oris et al., 2014), there is a need for a better quantitative understanding of the climate impact of BB aerosol emitted in these regions, which can be achieved, in particular, through the use of stronger observational constraints to represent $\mathrm{BB}$ aerosol optical properties and their evolution in chemistry transport and climate models. A way to obtain and exploit such constraints is proposed in this paper.

In this study, we analyze aging effects on the evolution of BB aerosol from Siberian fires by considering a relatively short period - from 15 to 31 July 2016. This analysis period is chosen to include a spectacular event of an anomalous outflow of optically dense BB plumes from Siberia to the 
European part of Russia. Different aspects of this event have already been addressed in the scientific literature (e.g., Sitnov et al., 2017, 2020; Gorchakov et al., 2018). It has been shown, in particular, that this event was associated with the formation of a so-called dipole structure of the atmospheric circulation, with the westward transport of air masses being a result of anticyclonic and cyclonic circulations to the north and south of the air transport trajectory, respectively. The outflow of the BB plumes took place in a relatively dry and cloudless atmosphere, providing favorable conditions for observing the evolution of BB smoke plumes from space. Importantly, the geographical isolation of aged and young plumes during this event allows us to minimize the effects of possible uncertainties associated with the estimation of photochemical age.

To the best of our knowledge, this is the first study attempting to constrain simulations of the aging behavior of BB aerosol with satellite observations of both absorption and extinction AODs. Using the constrained simulations, we attempt to get insights into the key physical and chemical processes driving changes in the optical characteristics of $\mathrm{BB}$ aerosol from Siberian wildfires during its long-range transport. By examining the changes in the absorption properties of BB aerosol through the joint analysis of the corresponding satellite retrievals and Mie calculations, this study significantly extends our previous analysis of the evolution of BB aerosols in Siberia (Konovalov et al., 2017a), which was focused on the evolution of only the extinction AOD. Although this study addresses a relatively short period and a specific region, we believe that the analytical framework developed here, as well as insights into the effects of atmospheric aging of BB aerosol during a period spanning its typical lifetime, will be beneficial for other studies involving modeling of aerosol processes and their climate impacts, especially in northern Eurasia and in the Arctic.

\section{Methods and data}

\subsection{Analysis method}

We analyze the atmospheric evolution of BB aerosol by considering the enhancement ratio (EnR), which is defined as the ratio of the enhancement of actual AAOD or AOD due to fire emissions to the corresponding enhancement of an aerosol tracer that represents the atmospheric evolution of a hypothetical BB aerosol in which the organic fraction is composed of inert, non-volatile, and non-hygroscopic matter. Under this definition, the enhancement ratio for AAOD (EnR $\left.\mathrm{abs}_{\mathrm{as}}\right)$ is evaluated as follows:

$\mathrm{EnR}_{\mathrm{abs}}=\eta_{0} \frac{\tau_{\mathrm{abs}}-\tau_{\mathrm{abs}}^{\mathrm{bgr}}}{\tau_{\mathrm{abs}}^{\mathrm{t}}}$,

where $\tau_{\mathrm{abs}}$ is the AAOD retrieval, $\tau_{\mathrm{abs}}^{\mathrm{bgr}}$ is the estimate of the background part of AAOD, $\tau_{\text {abs }}^{\mathrm{t}}$ is the estimate of AAOD associated with the inert aerosol tracer, and $\eta_{0}$ is a constant normalization factor defined below. The enhancement ratio for extinction AOD (EnR ext $)$ is evaluated similarly to $E_{n} R_{a b s}$ by substituting the observed and estimated AOD values ( $\tau_{\mathrm{ext}}$, $\tau_{\mathrm{ext}}^{\mathrm{bgr}}$, and $\tau_{\mathrm{ext}}^{\mathrm{t}}$ ) into Eq. (1) instead of $\tau_{\mathrm{abs}}, \tau_{\mathrm{abs}}^{\mathrm{bgr}}$, and $\tau_{\mathrm{abs}}^{\mathrm{t}}$. The objective of our analysis involving these EnRs is to identify the differences between changes in AAOD or AOD due to aging of $\mathrm{BB}$ aerosol in the real $\mathrm{BB}$ plumes (including the changes that occur due to oxidation and condensationevaporation and can also be indirectly induced by the dry and wet deposition of organic gases and particles) and those in a hypothetical simulation in which the organic fraction of BB aerosol is composed of only non-volatile, inert, and hydrophobic material and SOA formation processes are negligible. In our analysis involving EnRs, we largely follow Konovalov et al. (2017a) and Konovalov et al. (2019), but it should also be noted that the meaning of EnR defined by Eq. (1) is very similar to that of the normalized excess mixing ratio (NEMR), which was employed in previous studies (e.g., Yokelson et al., 2009; Vakkari et al., 2018; Junghenn Noyes et al., 2020) to analyze the evolution of the mass concentrations (or mixing ratios) of aerosol species. In the framework of this study, Eq. (1) is also used to analyze the simulated evolution of BB aerosol. To this end, AAOD (or AOD) retrievals are replaced in Eq. (1) by the corresponding simulated values.

The BB aerosol tracers ( $\tau_{\mathrm{abs}}^{\mathrm{t}}$ and $\left.\tau_{\mathrm{ext}}^{\mathrm{t}}\right)$ are evaluated using AAOD and AOD values obtained from simulations with a chemistry transport model (CTM) as explained in Sect. 2.3. An advantage of the BB aerosol "optical" tracers in comparison with more traditional tracers based on $\mathrm{CO}$ concentration is that they are affected not only by transport and eddy diffusion but also by dry deposition, wet scavenging, and coagulation, thereby representing BB aerosol in the aforementioned hypothetical simulation. Note that coagulation is not considered to be one of the BB aerosol aging processes addressed in this study.

However, the BB aerosol simulated tracers can be affected by model transport errors that can lead to biases in EnRs for both fresh and aged BB plumes observed from satellites (Konovalov et al., 2017a). To address this potential issue, we employ a simple correction procedure involving satellite observations of CO columns. Specifically, we introduce a correction factor, $f_{\mathrm{c}}$, defined as follows:

$f_{\mathrm{c}}=\left([\mathrm{CO}]^{\mathrm{obs}}-[\mathrm{CO}]^{\mathrm{bgr}}\right)\left([\mathrm{CO}]^{\mathrm{mod}}\right)^{-1}$,

where $[\mathrm{CO}]^{\text {obs }}$ and $[\mathrm{CO}]^{\text {mod }}$ are the observed total $\mathrm{CO}$ column amounts and the corresponding modeled contribution of fire emissions to the $\mathrm{CO}$ columns, respectively, and $[\mathrm{CO}]^{\mathrm{bgr}}$ is the background value of $[\mathrm{CO}]$ in the absence of fires. This factor is applied to the simulated tracers. In particular, the simulated values of $\tau_{\mathrm{abs}}^{\mathrm{t}}$ are corrected as follows:

$\tau_{\mathrm{abs}}^{\mathrm{t}}[$ corrected $]=\tau_{\mathrm{abs}}^{\mathrm{t}}[$ simulated $] \times f_{\mathrm{c}}$. 
This correction implies that the simulated $\mathrm{CO}$ column amounts in a BB plume are affected by the same multiplicative transport errors as the $\mathrm{BB}$ aerosol components determining AAOD and AOD. Note that a similar procedure was used in Konovalov et al. (2017a), wherein the advantages of using the observed and simulated $\mathrm{CO}$ columns in the estimation of EnR for AOD are discussed in detail; similar arguments apply for our estimations of EnRs for AAOD and AOD in this study. Estimation of the background values of $\tau_{\mathrm{abs}}, \tau_{\mathrm{ext}}$, and [CO] in this study is described in Sect. 2.3.

The normalization factor $\eta_{0}$ does not affect the results of our analysis and is introduced mainly for illustrative purposes. Here, we define it such that the average of all values of $E_{n} R_{a b s}\left(\right.$ or $E n R_{\text {ext }}$ ) over the ensemble of the data considered is equal to 1 :

$\eta_{0}=\left\langle\frac{\tau_{\mathrm{abs}}-\tau_{\mathrm{abs}}^{\mathrm{bgr}}}{\tau_{\mathrm{abs}}}\right\rangle^{-1}$,

where the angular brackets denote averaging over the data ensemble.

As part of our analysis, we infer trends of EnRs for AAOD and AOD in the process of $\mathrm{BB}$ aerosol aging from the ensemble of available estimates of $E_{n} R_{a b s}$ and $E n R_{\text {ext }}$. To characterize the $\mathrm{BB}$ aerosol age, we evaluate the time, $t_{\mathrm{e}}$, of exposure of a given $\mathrm{BB}$ plume to solar irradiation. In other words, $t_{\mathrm{e}}$ is the integral time of the transport of a given BB plume since emission during daytime hours. Unlike the BB aerosol photochemical age evaluated in Konovalov et al. (2017a), the solar irradiation exposure time - which was previously employed by Forrister et al. (2015) to evaluate the photodegradation of $\mathrm{BrC}$ in observed $\mathrm{BB}$ plumes - is not affected by potential major uncertainties in the simulated $\mathrm{OH}$ concentration. At the same time, $t_{\mathrm{e}}$ also quantifies the exposure of $\mathrm{BB}$ aerosol to the photochemical processing through oxidation by $\mathrm{OH}$ under the assumption that the $\mathrm{OH}$ concentration inside the plumes is constant during daytime and zero during nighttime. We believe that this is a reasonable simplifying assumption in our case, in which observations of $\mathrm{OH}$ are unavailable and the accuracy of the simulated $\mathrm{OH}$ concentration in the BB plumes is unknown. Accordingly, for brevity, we refer below to $t_{\mathrm{e}}$ as the photochemical age of $\mathrm{BB}$ aerosol. Using a photochemical age defined in this way as a predictor for the atmospheric evolution of $\mathrm{BB}$ aerosol in an analysis such as ours has the potential drawback that it can result in losing some observational information about the oxidation processes controlled by $\mathrm{OH}$ and that it disregards possible effects of the nighttime oxidation processes (specifically involving $\mathrm{NO}_{3}$ and $\mathrm{O}_{3}$ as oxidation agents). A concrete method, which is used to evaluate $t_{\mathrm{e}}$ in this study, is detailed in Sect. 2.3.

The trends in $\mathrm{EnR}_{\mathrm{abs}}$ and $\mathrm{EnR}_{\mathrm{ext}}$ (that is, the corresponding dependences on $t_{\mathrm{e}}$ ) are fitted with a nonlinear function, $y$ $\left(t_{\mathrm{e}}\right)$, which is constructed as a sum of sigmoids:

$y\left(t_{\mathrm{e}}\right)=\sum_{k=1}^{N} \frac{w_{k 1}}{\left(1+\exp \left(w_{k 2} t_{\mathrm{e}}+w_{k 3}\right)\right)}+w_{0}$,

where $w_{k 1}, w_{k 2}, w_{k 3}$, and $w_{0}$ are the weight coefficients, and $N$ is the number of sigmoids. In essence, the function $y\left(t_{\mathrm{e}}\right)$ represents a neural network (of the perceptron type), which is known as a universal approximator (Hornik et al., 1989). The optimal values of the weight coefficients are found by minimizing the root mean square difference between the individual values of $E_{n} R_{a b s}$ or $E n R_{\text {ext }}$ and the corresponding values of $y\left(t_{\mathrm{e}}\right)$. Following Konovalov et al. (2010), the optimization of the weight coefficients is achieved using the Nelder-Mead simplex algorithm (Press et al., 1992). Although the number of neurons $(N)$ used for the trend approximation can also be optimized in a regular (albeit more complicated) way (Konovalov et al., 2010), here we simply tried the fits with $N=1$, $N=2$, and $N=3$. We found that while the fits with $N=2$ manifested statistically significant features that are missing in the approximations with $N=1$, the use of three neurons instead of two did not reveal any new statistically significant features of the analyzed trends. Therefore, only results obtained only with $N=2$ are reported in this paper. The nonlinear fit function given by Eq. (5) is also applied to the SSA retrievals described in Sect. 2.2 and to the model data described in Sect. 2.3. Similar to Konovalov et al. (2017a), the confidence intervals for the approximations $y\left(t_{\mathrm{e}}\right)$ were evaluated with the bootstrapping method (Efron and Tibshirani, 1993) involving a random selection of sample estimates. To ensure the reliable evaluation of the confidence intervals in terms of the 95th percentile, the analysis involved 300 random samples. Note that the method employed in this study to approximate the tendencies in the optical properties of BB aerosol is more general and objective than the one used in our previous analysis of AOD observations (Konovalov et al., 2017a). The main technical differences between the analysis procedures used in Konovalov et al. (2017a) and this study are outlined in Supplement Sect. S1.

\subsection{Satellite data}

Our analysis described in the previous section makes use of aerosol optical properties and total CO column amounts, which are retrieved from satellite observations performed by the three satellite instruments: OMI (Levelt et al., 2006), MODIS (Salomonson et al., 1989), and IASI (Clerbaux et al., 2009). Various combinations of these satellite retrievals were used in our previous studies of the atmospheric impacts of Siberian fires (Konovalov et al., 2014, 2017a, 2018) and are only briefly described below. Preprocessing and harmonization of the different satellite datasets are explained in Sect. 2.5. 
Specifically, we used the AAOD and SSA retrievals for the $388 \mathrm{~nm}$ wavelength, which are available as part of the Level-2 OMAERUV (v. 1.8.9.1) data product (Torres et al., 2007, 2013) derived by NASA from the OMI observations onboard the EOS Aura satellite. The OMAERUV algorithm exploits the observed departure of the spectral dependence of the near-UV upwelling radiation at the top of the atmosphere from that of a hypothetical pure molecular atmosphere and derives AAOD, AOD, and SSA following a lookup table approach with assumed aerosol models, aerosol layer height, and surface albedo. Importantly, the OMAERUV data product used in this study accounts for the wavelength-dependent aerosol absorption associated with $\mathrm{BrC}$ (Jethva and Torres, 2011; Torres et al., 2013). While the OMAERUV algorithm identifies one of the three assumed aerosol types (biomass burning, desert dust, and urban-industrial), we consider the AAOD and SSA data only for the first aerosol type. The data are retrieved assuming a set of five different vertical locations of the aerosol center mass: at the surface and 1.5, $3.0,6.0$, and $10 \mathrm{~km}$ above the surface. We also used the "final" AAOD OMAERUV product, which is derived using the OMI-CALIOP (Cloud-Aerosol Lidar with Orthogonal Polarization) joint dataset (Torres et al., 2013) for the monthly climatology of the aerosol layer height. An important feature of the OMAERUV data product is that the AAOD data are less affected by sub-pixel cloud contamination than the AOD and SSA data due to partial cancellation of errors in the AOD and SSA retrievals. Accordingly, the quality-assured AOD and SSA data (which are associated with the quality flag 0 ) are much less abundant than the quality-assured AAOD data (which are associated with the quality flags 0 and 1 ).

Both AOD and SSA data were found to be in good agreement with corresponding AERONET data worldwide (Ahn et al., 2014; Jethva et al., 2014), indicating that the AAOD data associated with the quality flag 0 are also sufficiently accurate. In our previous study (Konovalov et al., 2018), CTM simulations based on BB black carbon (BC) and organic carbon (OC) emissions in Siberia, which were inferred from the OMI AAOD data associated with the quality flags 0 and 1 and from the MODIS AOD observations, were found to be consistent with AERONET, aircraft, and in situ aerosol measurements. Furthermore, the relationship between AAOD and AOD values retrieved from the OMI and MODIS satellite observations, respectively, was found to be virtually the same as that between AAOD and AOD values derived from the AERONET measurements in Siberia, confirming that sub-pixel cloud contamination, which can affect the less reliable retrievals (with the quality flag 1), is not likely to result in serious biases in the OMI AAOD retrievals. Therefore, the previous results provide evidence for the reliability of the OMAERUV AAOD data corresponding to both values of the quality flag.

We also used AOD at $550 \mathrm{~nm}$ derived from the MODIS observations onboard the Aqua and Terra satellites (Levy et al., 2013). The AOD data are obtained as the merged "dark target" and "deep blue" AOD retrievals from the Collection 6.1 MYD04 and MOD04 Level-2 data products (Levy and Hsu, 2015). Validation studies (e.g., Levy et al., 2010) indicated the high quality of the MODIS AOD data, with multiplicative and additive errors of MODIS-retrieved AOD of $\sim 15 \%$ and 0.05 (or less), respectively.

In this study, the OMI AAOD and MODIS AOD retrievals are analyzed independently as described in Sect. 2.1. A similar analysis was performed for the SSA estimates obtained by combining the AAOD and AOD data as follows:

$\omega_{0}=\frac{\tau_{\mathrm{ext}}^{\text {inferred }}-\tau_{\mathrm{abs}}}{\tau_{\mathrm{ext}}^{\text {inferred }}}$,

where $\omega_{0}$ is an estimate of SSA at $388 \mathrm{~nm}, \tau_{\mathrm{abs}}$ is AAOD retrieved from the OMI measurements, and $\tau_{\mathrm{ext}}^{\text {inferred }}$ is AOD at $388 \mathrm{~nm}$ inferred from the MODIS observations at $550 \mathrm{~nm}$ using a power-law approximation. The extinction Ångström exponent necessary for this calculation was estimated in two ways. First, it was evaluated as the average ratio of the logarithms of the $388 \mathrm{~nm}$ AOD and $550 \mathrm{~nm}$ AOD retrievals from the matching OMI and MODIS satellite observations, respectively. Since the OMI AOD data correspond to the quality flag 0 and are therefore very sparse, the Ångström exponent could be estimated only as a constant number independent of the BB aerosol age. The different AOD retrievals were matched in space and time as described below in Sect. 2.5. Second, the Ångström exponent was calculated using the simulated AOD values (see Sect. 2.3) matching both the AAOD and AOD observations. The advantage of the second approach is that it allowed us to take into account the dependence of the Ångström exponent on the BB aerosol photochemical age, but an obvious drawback of the model estimates is that they can be affected by various model errors.

The total CO columns used in our analysis were retrieved using the FORLI (Fast Optimal Retrievals on Layers for IASI) algorithm (Hurtmans et al., 2012) from the IASI observations onboard the METOP-A satellite (Clerbaux et al., 2009) and are provided by LATMOS/CNRS and ULB (ESPRI, 2020). Following Konovalov et al. (2014, 2016, 2017a), the IASI CO data were preselected based on the degree of freedom of the signal (DOFS), which is considered an indicator of the IASI sensitivity to $\mathrm{CO}$ in the boundary layer (George et al., 2009): we only considered the CO observations with DOFS exceeding 1.7.

In addition to the satellite observations of aerosol and $\mathrm{CO}$, we use MODIS retrievals of fire radiative power (FRP), which are available as the Collection 6 Level-2 MYD14/MOD14 data products (Giglio and Justice, 2015a, b). Following Konovalov et al. (2018), these FRP data were used to evaluate fire emissions, as briefly explained in the next section. 


\subsection{Chemistry transport model simulations: basic configuration and fire emissions}

The chemistry transport model (CTM) is a key component of our analytical framework, serving three main objectives. First, we use the model to evaluate the BB aerosol tracers and photochemical age. Second, it is used to characterize the background conditions for aerosol and CO. Third, simulations of $\mathrm{BB}$ aerosol evolution help interpret the results of the satellite data analysis.

The simulations are performed with the CHIMERE CTM version 2017 (Mailler et al., 2017). The same version of this model was successfully used in our previous analysis of satellite observations of BB aerosol (Konovalov et al., 2018). Previous versions of the CHIMERE model proved to be useful in other studies of BB aerosol and fire emissions (e.g., Hodzic et al., 2010; Konovalov et al., 2012; Péré et al., 2014; Majdi et al., 2019). In this study, the configuration of the model was almost the same as that in Konovalov et al. (2018), although there are some differences, mainly concerning the representations of the organic fraction and optical properties of BB aerosol. These model representations are described in Sect. 2.4. The basic features of the model configuration used in this study are outlined later in this section.

Specifically, the chemical transformations of gaseous species, including $\mathrm{OH}$, are simulated with the MELCHIOR2 chemical mechanism (Schmidt et al., 2001). Photolysis rates are computed with the FAST-JX module (Wild et al., 2000; Bian and Prather, 2002), taking into account the attenuation of solar radiation by both clouds and aerosols. The representation of dry deposition follows Zhang et al. (2001). Wet scavenging and coagulation of aerosol particles are simulated using the standard parameterizations described in Mailler et al. (2017) and Menut et al. (2013). The formation of SOA from biogenic emissions of isoprene and terpenes is simulated with an oxidation scheme based on Kroll et al. (2006) and Zhang et al. (2007). Anthropogenic SOA is represented as a result of the oxidation of a few specific volatile SOA precursors (Bessagnet et al., 2008). The anthropogenic emissions of gaseous and aerosol species are specified using the Hemispheric Transport of Air Pollution (HTAP) v2 global emission inventory (Janssens-Maenhout et al., 2015). Biogenic emissions of several organic gases and NO are calculated using the Model of Emissions of Gases and Aerosols from Nature (MEGAN v2.04) (Guenther et al., 2006).

Fire emissions are derived from satellite FRP data following the methodology detailed in Konovalov et al. (2014, 2017a, 2018). Briefly, the rate of emission of a given aerosol or gaseous species from fires per unit area is assumed to be proportional to the FRP density. The proportionality coefficients include, in particular, the emission factor (depending on a vegetation land cover type), the empirical factor relating FRP to the BB rate, and the adjustable correction factor $\left(F_{s}\right)$, which is allowed to take different values for different species $s$. The emission factors for gaseous species are spec-
Table 1. Parameters of the species representing the evolution of BB OA in the framework of the simplified VBS scheme.

\begin{tabular}{lrrr}
\hline $\begin{array}{l}\text { Species } \\
\text { name }\end{array}$ & $\begin{array}{r}\text { Volatility, } \\
C^{*}\left(\mu \mathrm{g} \mathrm{m}^{-3}\right)\end{array}$ & $\begin{array}{r}\text { Molar } \\
\text { mass }\end{array}$ & $\begin{array}{r}\text { Enthalpy of } \\
\text { evaporation, } \\
\Delta \mathrm{H}_{\text {vap }} \\
\left(\mathrm{kJ} \mathrm{mol}^{-1}\right)\end{array}$ \\
\hline LV-POA & $10^{0}$ & 216 & 85 \\
MV-POA & $10^{2}$ & 216 & 77 \\
LV-SOA & $10^{0}$ & 144 & 85 \\
MV-SOA & $10^{2}$ & 135 & 77 \\
HV-SOA & $10^{3}$ & 131 & 73 \\
NTVOCs & $\infty$ & 113 & - \\
\hline
\end{tabular}

ified using the data from Andreae (2019). However, to simplify the auxiliary - for the given study - task of optimizing BB aerosol emissions, the BC and organic carbon (OC) emission factors are taken to be the same as in Konovalov et al. (2018; see Table 1 therein). The emission rates are modulated with the diurnal profile of BB emissions, which was derived directly from the MODIS FRP data (Konovalov et al., 2014, 2015). The correction factors are adjusted against the satellite data as explained in Sect. 2.6.

Following Konovalov et al. (2018), the maximum injection heights of BB emissions are calculated for each FRP pixel using the "two-step" parameterization of Sofiev et al. (2012) as a function of the observed FRP, the boundary layer height, and the Brunt-Väisälä frequency. The calculations of the injection heights of the BB emissions were validated by Sofiev et al. $(2012,2013)$ against vertical profiles of BB plumes derived from satellite observations by the Multi-angle Imaging SpectroRadiometer (MISR) and CALIOP instruments (Mazzoni et al., 2007; Omar et al., 2009) and were found to be in reasonable quantitative agreement with these observations. In our simulations, the emissions for the given model layer are computed proportionally to the weighted number of pixels yielding the maximum injection height corresponding to this layer, with the weight of each pixel evaluated proportionally to the corresponding FRP. Konovalov et al. (2018) found that $\mathrm{BB}$ aerosol simulations that were constrained by the OMI and MODIS satellite observations of AAOD and AOD were consistent with in situ measurements of BC and OC (Mikhailov et al., 2017) at the $300 \mathrm{~m}$ tall mast at the Zotino Tall Tower Observatory (ZOTTO) situated at a remote location in central Siberia (within our study region). Taking into account that the AAOD and AOD observations provide constraints to only columnar concentrations of $\mathrm{BC}$ and $\mathrm{OC}$, this finding can be regarded as indirect evidence that the calculated $\mathrm{BB}$ emission vertical profiles within the boundary layer are reliable.

To estimate the BB aerosol photochemical age (or, more strictly speaking, the solar radiation exposure time as defined in Sect. 2.1), the chemical mechanism in CHIMERE 
is extended to include two gaseous tracers that have the same emissions as BB OC. One of the tracers, $T_{1}$, is treated as an inert gas, while another tracer, $T_{2}$, decays with time but only when the local solar zenith angle is less than $90^{\circ}$. The decay rate, $k_{T}$, is set to be equal to $2.3 \times 10^{-5} \mathrm{~s}^{-1}$ to represent - for definiteness - the mid-range of the half-lives for the decay of $\mathrm{BrC}$ in $\mathrm{BB}$ aerosol (12 h) according to the observational estimates by Forrister et al. (2015). Using the columnar mass concentrations of the tracers, $\left[T_{1}\right]$ and $\left[T_{2}\right]$, the BB aerosol photochemical age (or, more strictly speaking, the solar radiation exposure time as explained in Sect. 2.1), $t_{\mathrm{e}}$, is estimated as follows:

$t_{\mathrm{e}}=k_{T}^{-1} \ln \left(\left[T_{1}\right]\left[T_{2}\right]^{-1}\right)$.

The simulations are performed using a 1 by $1^{\circ}$ model mesh covering a major part of northern Eurasia $\left(22.5-136.5^{\circ} \mathrm{E}\right.$; $38.5-75.5^{\circ} \mathrm{N}$ ) with 12 non-equidistant model layers in the vertical. The top of the upper layer is fixed at the $200 \mathrm{hPa}$ pressure level. The model was run for the period from 28 May to 15 August 2016, but the first 18 d (until 15 June) are withheld as the spin-up period. Note that BB aerosol evolution in 2016 was not addressed in our previous studies mentioned above. The CHIMERE simulations are driven with meteorological data from the WRF (Weather Research and Forecasting; version 3.9) model (Skamarock et al., 2008) simulations with nudging toward the FNL (Final) reanalysis (NCEP, 2017).

Similar to Konovalov et al. $(2015,2017 \mathrm{a})$, the simulations considered in this study are performed for three main scenarios. The first and second main scenarios (labeled here as bb_vbs and bb_trc, respectively) represent the conditions with predominating air pollution from fire emissions. For these scenarios, all sources of gases and aerosol, except for those due to fire emissions inside the CHIMERE domain, were disregarded. The bb_vbs scenario corresponds to the BB OA representation formulated within the VBS framework as described in Sect. 2.4. In the bb_trc scenario, which is ancillary in the framework of the given study, the BB OA representation largely follows that for anthropogenic OA in the "standard" version of CHIMERE (Menut et al., 2013), presuming, in particular, that primary OA consists of non-volatile material. In this study, this representation is further simplified by entirely neglecting SOA formation, which turned out to be negligible anyway in our previous BB aerosol simulations with the standard version of CHIMERE (Konovalov et al., 2015, 2017a, 2018). The simulations for the bb_trc scenario are used to evaluate the BB aerosol tracers involved in Eq. (1). For both scenarios, particulate fire emissions of $\mathrm{OC}$ were distributed following a fine-mode lognormal distribution with a mass median diameter (MMD) of $0.3 \mu \mathrm{m}$ and a geometric standard deviation of 1.6 (Reid et al., 2005a) among 10 size sections. A smaller value of MMD of $0.25 \mu \mathrm{m}$ was assumed for BC emissions, partly based on the recent measurements by Morgan et al. (2020). Taking into account that a contribution of the coarse mode of aerosol particles to the optical properties of BB aerosol at the UV and visual wavelengths is likely negligible (Reid et al., 2005b), this mode was disregarded in our simulations. This simplification allows us to avoid large uncertainties associated with the representation of emissions and the evolution of coarse particles.

The third scenario (labeled below as bgr) represents the hypothetical conditions that are background with respect to the air pollution caused by fire emissions. The corresponding simulations were made with anthropogenic and biogenic emissions of particles and gases but without fire emissions. Monthly climatology for gas and aerosol concentrations from the LMDZ-INCA chemistry transport model (Folberth et al., 2006) was used for the boundary conditions. The AOD values in our analysis were computed in CHIMERE under the assumption that particle components are homogeneously mixed. The AAOD background values have not been evaluated in this study. As discussed in Konovalov et al. (2018), the main reason is that it is not known how the background part can be accounted for in the OMI AAOD retrievals for the biomass burning type of aerosol. Furthermore, the CHIMERE simulations of AAOD at $388 \mathrm{~nm}$ for the scenes dominated by anthropogenic pollution are probably highly uncertain, particularly due to poorly known and variable values of the imaginary refractive index for OA. Hence, a contribution of the background part of AAOD to the OMI AAOD retrievals is effectively neglected and is disregarded (unless indicated otherwise) in the analysis involving Eq. (1). To evaluate the total $\mathrm{CO}$ columns and AOD representative of all sources (anthropogenic, biogenic, and pyrogenic) of gases and aerosol, the corresponding values for the bb_vbs or bb_trc scenarios are summed up with values for the bgr scenario. Note that by doing so we disregard any effects of anthropogenic emissions on the evolution of BB aerosol: according to our simulations, concentrations of aerosol and reactive gases in the analyzed situation are predominantly determined by fire emissions. Our computations of the optical properties of $\mathrm{BB}$ aerosol are explained in the next section.

In addition, we performed supplementary simulations for a test scenario (referred below to as bb_poa) in which all the oxidation reactions that were taken into account in the simulations for the bb_vbs scenario were turned off but POA was still assumed to be composed of semi-volatile species. Some further details on this scenario are provided below in Sect. 3.3.

Figure 1 shows the model domain and illustrates the fire emissions used in our simulations by presenting the density of the total BB emissions of particulate matter (PM) according to the bb_vbs scenario in the analysis period of 1531 July 2016 (see the Introduction). The same figure also introduces the study region that covers the western and central parts of Siberia - where (as evident from the figure) major fires occurred during the analysis period - and also a part of 


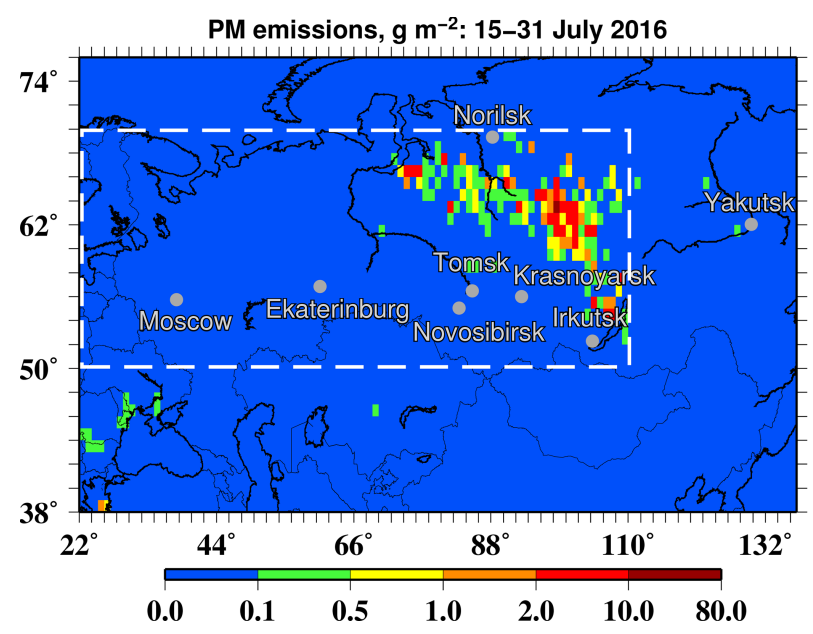

Figure 1. Spatial distribution of the total emissions $\left(\mathrm{g} \mathrm{m}^{-2}\right)$ of particulate matter from fires in the period from 15 to 31 July 2016. The emissions were computed using the MODIS FRP data (see Sect. 2.3) and are shown over the CHIMERE domain specified in this study. A dashed white rectangle indicates the study region.

eastern Europe, including the European territory of Russia and territories of several eastern European countries.

\subsection{Model representation of the evolution and optical properties of $\mathrm{BB}$ aerosol}

As noted above, one of the goals of our BB aerosol simulations is to interpret the evolution of $\mathrm{BB}$ aerosol optical properties that can be inferred from satellite observations as described in the previous section. However, there is currently no uniform way to represent atmospheric transformations of BB organic aerosol (OA) and its optical properties in CTMs. Typically, model representations of the evolution of OA aerosol involve organic aerosol (OA) oxidation schemes that are designed using the volatility basis set (VBS) framework (Donahue et al., 2006; Robinson et al., 2007), but it is challenging to choose an appropriate VBS scheme among those suggested in the literature. Furthermore, differences between the available VBS schemes (e.g., Shrivastava et al., 2015; Konovalov et al., 2015; Ciarelli et al., 2017; Tsimpidi et al., 2018), which have been proposed for simulations of BB OA aerosol and are to some extent constrained by observational or experimental data, have been shown to result in major quantitative and even qualitative differences in the simulated multi-day evolution of BB OA mass concentration (Konovalov et al., 2019). Therefore, it is not given that any of the available schemes can adequately describe the BB aerosol evolution, specifically in Siberia.

Taking into account that the real BB aerosol evolution depends on numerous variable factors, most of which cannot presently be constrained by available observations in Siberia, we do not attempt to represent the many interrelated aging processes that can affect the BB aerosol evolution in a quantitatively accurate way. Instead of choosing any concrete OA oxidation scheme among those previously described in the literature, we designed a highly simplified VBS scheme, which takes into account only basic processes driving the OA evolution and can be fitted to the satellite observations by adjusting a few parameters. This scheme was used in our simulations for the bb_vbs scenario.

As the basis for our OA oxidation scheme, we used a relatively simple 1.5-dimensional VBS scheme proposed and described in detail by Ciarelli et al. (2017) (abbreviated below as C17). The original scheme addresses the evolution of several surrogate organic species, each of which is given the volatility, molecular weight, and oxidation state. More specifically, all semi-volatile organic compounds (SVOCs) are split into three sets, such as (1) the POA set, (2) the set of SOA species formed as a result of oxidation of the POA species, and (3) the SOA set containing products of oxidation of volatile organic compounds (VOCs) or intermediatevolatility organic compounds (IVOCs). Real VOC and IVOC species are represented by surrogate species referred to as NTVOCs ("non-traditional" VOCs). Some parameters of the C17 scheme, including the mass ratio of NTVOC and SVOC emissions and the enthalpies of vaporization for SVOCs, were constrained with mass-spectrometric measurements of organic gases and particles from the combustion of beech logs in a residential wood burner. The SVOC species are split into five volatility classes, with the volatilities $\left(C^{*}\right)$ ranging from $10^{-1}$ to $10^{3} \mathrm{\mu g} \mathrm{m}^{-3}$. The constrained VBS scheme yielded good agreement of the measurements with corresponding box-model simulations under $\mathrm{OH}$ exposures that are equivalent to about 10 to $15 \mathrm{~h}$ of evolution under typical atmospheric conditions (Ciarelli et al., 2017).

Our simplified oxidation scheme includes only two aggregated volatility classes of the POA species, one of which aggregates the three original classes of organic compounds with relatively low volatility $(\mathrm{LV})\left(C^{*} \in\left[10^{-1} ; 1\right] \mu \mathrm{g} \mathrm{m}^{-3}\right)$, and another represents mostly medium-volatility (MV) primary compounds with volatilities ranging from $10^{1}$ to $10^{2} \mu \mathrm{g} \mathrm{m}^{-3}$. The corresponding model species are denoted below as LVPOA and MV-POA. The volatilities of LV-POA and MVPOA were set in our simulations at 1 and $10^{2} \mu \mathrm{g} \mathrm{m}^{-3}$, respectively. Note that the gas-particle partitioning of MV-POA emissions in our simulation may be similar to that of more volatile organic species since small but dense BB plumes are effectively diluted over the size of a grid cell. Box-model simulations performed with varying initial size and density of the BB plume indicated that such artificial dilution can unrealistically enhance SOA formation (Konovalov et al., 2019). For these reasons, the BB emissions of SVOCs species with a volatility of $\sim 10^{3} \mathrm{\mu g} \mathrm{m}^{-3}$ are assumed to also be represented by MV-POA. The fire emissions of POA were split between LV-POA and MV-POA species based on a ratio of 3 to 4 following the estimates by May et al. (2013).

In our simulations, we merged the two SOA sets that was originally introduced in C17. Similar to primary or- 
ganic compounds, secondary compounds with volatilities lower than or equal to $1 \mu \mathrm{g} \mathrm{m}^{-3}$ are aggregated as one model species, LV-SOA. To allow for a more realistic representation of the multi-generation aging of SOA, we retained a distinct SOA species with a relatively high volatility (HV) of $10^{3} \mathrm{\mu g} \mathrm{m}^{-3}$. Our scheme also involves an MV-SOA species with a volatility of $10^{2} \mu \mathrm{g} \mathrm{m}^{-3}$. The POA and SOA species were given the same molecular weight as their respective analogs from the second, fourth, and fifth volatility classes of the SVOC sets 1 and 3 from the original C17 scheme. The properties of the VBS species in our model are listed in Table 1.

The reactions representing the evolution of BB OA within our simplified VBS scheme are specified in Table 2. Specifically, the POA species in the gas phase are assumed to undergo Reactions (R1) and (R2), whereby the stoichiometric factor of 1.3 is introduced to account for the difference between the molecular weights for SOA from the second volatility class of set 2 of the $\mathrm{C} 17$ scheme and the merged SOA set in our model (189 and $144 \mathrm{~g} \mathrm{~mol}^{-1}$, respectively). Following $\mathrm{C} 17$, we assume that apart from the oxidation of POA, SOA species are produced from the oxidation of NTVOCs (see Reaction R3). However, we simplified the SOA yields: the direct oxidation of NTVOCs is assumed to result in the formation of only HV-SOA and LV-SOA, while the formation of MV-SOA is disregarded. The SOA yields for HV-SOA and LV-SOA are defined to retain the same total yield of SOA mass from the oxidation of NTVOCs as in $\mathrm{C} 17\left(\sim 43 \mathrm{~g} \mathrm{~mol}^{-1}\right)$. The stoichiometric coefficients for these yields are determined by factors ( 0.33 and 0.30 ) accounting for the difference between the molar masses of HV-SOA and LV-SOA $(131 / 144 \cong 0.30 / 0.33)$ and by the adjustable parameter $\xi_{1}$, which was varied in our test simulations to enable consistency of our simulations with the satellite observations considered (see Sect. 2.6). The simulation results presented in this paper were obtained with $\xi_{1}$ equal to 0.85 .

Oxidation of gas-phase HV-SOA is assumed to yield MVSOA (Reaction R4). Since the molecular weight of MV-SOA is larger than that of HV-SOA (see Table 1), functionalization is presumed to effectively dominate - although only slightly - over fragmentation in the oxidation of high-volatility organic species. However, fragmentation is assumed to dominate over functionalization in the oxidation of both MV-SOA and LV-SOA in Reactions (R5) and (R6): the reaction yield is controlled by another adjustable parameter, $\xi_{2}$, which is set in our simulations at the small value of 0.15 (see Sect. 2.6 for the adjustment procedure). This means that $\mathrm{OH}$ oxidation of MV-SOA and LV-SOA yields $15 \%$ of LV-SOA through a functionalization pathway, while the fragmentation pathway accounts for $85 \%$ of products that are considered volatile and do not contribute to SOA formation. Lower volatility of the SOA species is associated with a higher $\mathrm{O} / \mathrm{C}$ ratio (see $\mathrm{C} 17$ ), thus making less volatile species more prone to fragmentation. The reaction rates $\left(k_{\mathrm{OH}}\right)$ for Reactions $(\mathrm{R} 1)-(\mathrm{R} 4)$ are taken to be the same as those for similar reactions in $\mathrm{C} 17$, but a smaller rate is set for Reactions (R5) and (R6), presuming that they represent multi-generation fragmentation processes.

One more adjustable parameter $-\xi_{3}-$ in our simplified VBS scheme is the emission ratio of the mass concentration of NTVOCs to the sum of mass concentrations of the POA species, which was set at 14.2. The same parameter was estimated in C17: its optimal value was found to be 4.75 (that is, 3 times less than in our case), although a much larger value (up to 9.8) was found to also be consistent with the measurements analyzed in $\mathrm{C} 17$. As noted above, the results of the experiments performed in $\mathrm{C} 17$ do not directly apply to the case of BB aerosol from Siberian fires. Hence, it does not seem infeasible that oxidation of VOC emissions from Siberian fires indeed effectively yields more SOA than oxidation of VOCs from the combustion of beech logs.

Enthalpies of vaporization $\left(\Delta \mathrm{H}_{\mathrm{vap}}\right)$ of the surrogate OA species are evaluated using the estimates derived by May et al. (2013) from thermodenuder measurements of fresh BB aerosol. The same $\Delta \mathrm{H}_{\mathrm{vap}}$ values (depending on the volatility) are used for both POA and SOA species. Following C17, we assume, for definiteness and simplicity, that all organic species within particles form a well-mixed, liquid, and inviscid solution. This assumption implies, in particular, that POA species can affect the partitioning of SOA species according to Raoult's law and vice versa.

To get a tentative idea about whether or not our simplified VBS scheme enables a sufficiently realistic representation of the BB aerosol evolution (especially during the first few hours, which, as is discussed below, are not represented in satellite observations), we simulated the BB OA evolution under the conditions of chamber experiments reported in $\mathrm{C} 17$ by using the microphysical box model described in Konovalov et al. (2019) with both the simplified and original (C17) VBS schemes. The simulations are described in Supplement Sect. S2, and the results are presented in Fig. S1 in comparison with available chamber measurements. These results indicate that the simulations of the BB OA evolutions with our simplified scheme are physically reasonable (see Sect. S2 for details).

The optical properties of BB aerosol particles (for both bb_vbs and bb_trc scenarios) are evaluated using the OPTSIM software (Stromatas et al., 2012) under the assumption that any particle is composed of a spherical BC core surrounded by a concentric shell consisting of homogeneously mixed organic components, inorganic ions, and water. Given the simulated size-resolved mass concentration and composition of BB aerosol particles, as well as the complex refractive index for each particle component, the scattering and absorbing efficiencies for the particles are computed for the coreshell mixing scenario with a Mie code based on the formulations proposed by Toon and Ackerman (1981). The scattering and absorption efficiencies are then used to compute both the AOD and AAOD values. Note that Mie core-shell models in which a $\mathrm{BC}$ core is represented as a perfect sphere are prone to underestimation of the fractional contribution of 
Table 2. Reactions representing the evolution of BB OA in the simplified VBS scheme and their $\mathrm{OH}$ reaction rates $\left(k_{\mathrm{OH}}\right)$.

\begin{tabular}{lll}
\hline Reaction & & $\begin{array}{l}k_{\mathrm{OH}} \\
\left(\mathrm{cm}^{3} \mathrm{molec}^{-1} \mathrm{~s}^{-1}\right)\end{array}$ \\
\hline (R1) & MV-POA $+\mathrm{OH} \rightarrow 1.3 \mathrm{LV}-\mathrm{SOA}+\mathrm{OH}$ & $4 \times 10^{-11}$ \\
$(\mathrm{R} 2)$ & $\mathrm{LV}-\mathrm{POA}+\mathrm{OH} \rightarrow 1.3 \mathrm{LV}-\mathrm{SOA}+\mathrm{OH}$ & $4 \times 10^{-11}$ \\
$(\mathrm{R} 3)$ & $\mathrm{NTVOC}+\mathrm{OH} \rightarrow \xi_{1}^{*} 0.33 \mathrm{HV}-\mathrm{SOA}+\left(1-\xi_{1}\right) 0.30 \mathrm{LV}-\mathrm{SOA}+\mathrm{OH}$ & $4 \times 10^{-11}$ \\
$(\mathrm{R} 4)$ & $\mathrm{HV}-\mathrm{SOA}+\mathrm{OH} \rightarrow \mathrm{MV}-\mathrm{SOA}+\mathrm{OH}$ & $4 \times 10^{-11}$ \\
$(\mathrm{R} 5)$ & $\mathrm{MV}-\mathrm{SOA}+\mathrm{OH} \rightarrow \xi_{2}^{*} \mathrm{LV}-\mathrm{SOA}+\mathrm{OH}$ & $1 \times 10^{-11}$ \\
$(\mathrm{R} 6)$ & $\mathrm{LV}-\mathrm{SOA}+\mathrm{OH} \rightarrow \xi_{2} \mathrm{LV}-\mathrm{SOA}+\mathrm{OH}$ & $1 \times 10^{-11}$ \\
\hline
\end{tabular}

$* \xi_{1}$ and $\xi_{2}$ are adjustable parameters, which have been evaluated as $\xi_{1}=0.85$ and $\xi_{2}=0.15$.

$\mathrm{BC}$ to absorption at near-UV wavelengths in cases in which the coating is relatively thin (with the shell-core mass ratio less than 3) as a result of the fact that actual BC particles are typically non-spherical aggregates (Liu et al., 2017; Taylor et al., 2020). However, this potential underestimation is unlikely to be significant in our simulations representing typical Siberian BB aerosol, which features typical OC-BC mass ratios almost as large as 30 (Mikhailov et al., 2017).

The real part of the refractive index for all of the BB aerosol components resolved in our simulation (see Sect. 2.3), as well as the imaginary part of the refractive index for the inorganic components (including BC), was taken in our computations to be the same as that given in Stromatas et al. (2012) for the $532 \mathrm{~nm}$ wavelength (see Table 3 therein) and is assumed for simplicity to be the same for both the 388 and $550 \mathrm{~nm}$ wavelengths considered here. In the bb_trc simulation, BB aerosol absorption was calculated under the assumption that the organic shell is non-absorbing. Evaluation of the imaginary part of the refractive indexes for the POA and SOA species, $k_{\text {poa }}$ and $k_{\text {soa }}$, in our simulations for the bb_vbs scenario involved the following assumptions.

First, based on the experimental findings (Saleh et al., 2014) that almost all BrC absorption of fresh BB aerosol is associated with extremely low-volatility organic compounds, we assumed that MV-POA is not absorbing. Based on the estimates of the imaginary refractive index of fresh $\mathrm{OA}, k_{\mathrm{OA}}$, and their uncertainties, which have been reported by $\mathrm{Lu}$ et al. (2015) as a function of the BC-to-OA ratio, and assuming average values of the $\mathrm{BC}$-to-OC and POA-to-OC ratios for Siberian BB aerosol to be about 0.04 and 1.8, respectively (Mikhailov et al., 2017; Konovalov et al., 2017b), we conservatively estimated $k_{\mathrm{OA}}$ to be 0.013 . This estimate, which is in the lower range of the corresponding $k_{\mathrm{OA}}$ values $\left(k_{\mathrm{OA}} \approx 0.025 \pm 50 \%\right)$ given by Lu et al. (2015), is expected to ensure that the contribution of POA to BB aerosol absorption in our simulations is not overestimated. Accordingly, taking into account the assumed MV-POA / LV-POA emission ratio (see above), we estimated $k_{\text {poa }}$ (for LV-POA) to be 0.03 .

Second, we assumed that, as a result of UV photodegradation, $k_{\text {poa }}$ decreases exponentially with the BB aerosol photochemical age $\left(t_{\mathrm{e}}\right)$. Taking into account the laboratory results by Fleming et al. (2020), we assumed the lifetime of $\mathrm{BrC}$ chromophores in the LV-POA species to UV photodegradation to be $82 \mathrm{~h}$. This lifetime represents the lowest part of the range of the experimental values reported by Fleming et al. (2020, see Table 3 therein).

Third, we assumed that in contrast to POA, the lowvolatility SOA, LV-SOA, is not absorbing. This assumption does not contradict the aforementioned experimental findings (Saleh et al., 2014) that indicated high absorptivity of lowvolatility organic compounds, since the contributions of POA and SOA species to the absorption were not isolated in these experiments, and the effect of SOA addition was found to be comparable to measurement uncertainties. Furthermore, if low-volatility SOA remaining after more rapid atmospheric processing of higher-volatility SOA were strongly absorbing, it would be difficult to explain an almost total loss of $\mathrm{BrC}$ absorption of aging BB aerosol (Forrister et al., 2015), during which POA is typically replaced by oxidized species (e.g., May et al., 2015). While oxidation of low-volatility POA is likely to yield absorptive components (Wong et al., 2017), chemical processing of LV-POA in our simulations is very slow (as shown below), so the corresponding source of $\mathrm{BrC}$ is disregarded. For simplicity, the HV-SOA and MV-SOA species are assumed to have the same constant values of the imaginary refractive index, $k_{\mathrm{soa}}$. This value was adjusted in our simulations for the bb_vbs scenario (see Sect. 2.6) and is taken to be equal to 0.009 for the $388 \mathrm{~nm}$ wavelength. Photochemical processing of HV-SOA and MV-SOA resulting in the formation of non-absorbing LV-SOA implicitly accounts in our simulations for the destruction of $\mathrm{BrC}$ chromophores through all possible mechanisms, including gas-phase and heterogeneous oxidation as well as UV photodegradation. To the best of our knowledge, estimates of the imaginary refractive index for SOA formed from photo-oxidation of BB emissions have so far been reported only by Saleh et al. (2013) based on the analysis of smog chamber experiments. According to these estimates, the imaginary refractive index (at $388 \mathrm{~nm}$ ) for SOA is at least 0.04 (as in the case of SOA from pocosin pine) or even much larger. However, these estimates correspond to a very initial stage of BB aerosol aging (when the UV exposure time is less than $1.5 \mathrm{~h}$ ), which is not ad- 
Table 3. Key features of the configuration of the simulations with the CHIMERE model.

\begin{tabular}{|c|c|}
\hline $\begin{array}{l}\text { Simulation } \\
\text { scenario }\end{array}$ & Key features \\
\hline \multirow[t]{5}{*}{ bb_vbs } & $\begin{array}{l}\text { - POA and SOA processing is represented using a simplified six-component VBS scheme (see Tables } 1 \text { and 2) with } \\
\text { two adjustable parameters. }\end{array}$ \\
\hline & $\begin{array}{l}\text { - Gas-particle partitioning of the POA and SOA species is calculated assuming these species to form an ideal inviscid } \\
\text { liquid solution. }\end{array}$ \\
\hline & $\begin{array}{l}\text { - BB POA and BC emissions are derived from the FRP measurements and constrained by the AOD and AAOD } \\
\text { satellite observations with the injection heights parameterized }{ }^{\mathrm{a}} \text { as a function of FRP; the mass emission ratio of } \\
\text { NTVOCs to POAs is an adjustable parameter estimated as } 14.2 \text {. }\end{array}$ \\
\hline & $\begin{array}{l}\text { - A spherical core-shell structure of particles, with BC forming the core and the other (homogeneously mixed) } \\
\text { components forming the shell, is assumed to calculate the BB aerosol optical properties using the OPTSIM module }\end{array}$ \\
\hline & $\begin{array}{l}\text { - Light absorption by LV-POA, HV-SOA, and MV-SOA with } k_{\text {poa }}^{\mathrm{c}}=0.03 \times \exp \left(-t_{\mathrm{e}} / 82\right) \text { (where } t_{\mathrm{e}} \text { is the BB aerosol } \\
\text { photochemical age in hours) and } k_{\text {soa }}^{\mathrm{c}} \text { estimated as } 9 \times 10^{-3} \text { is taken into account, while MV-POA and LV-SOA are } \\
\text { treated as non-absorbing species. }\end{array}$ \\
\hline
\end{tabular}

- Uptake of water by SOA is computed ${ }^{\mathrm{d}}$ assuming the hygroscopicity parameter $\kappa_{\mathrm{org}}$ of 0.2 , whereas BC and POA are assumed to be hydrophobic.

- The photochemical age of BB aerosol is estimated using two model tracers, one of which is inert and another is decaying with a constant rate.

- Biogenic and anthropogenic emissions of aerosols and gases are turned off.

- Zero concentrations are taken for the boundary conditions.

bb_trc - SOA formation is turned off and the organic fraction of BB aerosol is treated as being chemically inert, refractory, non-absorbing, and hydrophobic.

- Other features and assumptions are the same as in the bb_vbs scenario.

bgr $\quad-$ BB emissions are turned off but both the biogenic and anthropogenic emissions of aerosols and gases are taken into account using the HTAP ${ }^{\mathrm{e}}$ and MEGAN ${ }^{\mathrm{f}}$ emission inventories, respectively.

- SOA formation from both the anthropogenic and biogenic precursors is taken into account using simplified representations ${ }^{\mathrm{g}}$ provided in the standard version of CHIMERE.

- AOD is calculated with the built-in FAST-JX module ${ }^{\mathrm{h}}$ of CHIMERE with the standard settings ${ }^{\mathrm{i}}$.

- Boundary conditions for aerosol and gaseous components are specified using the monthly climatology from the LMDZ-INCA global model $\mathrm{j}^{\mathrm{j}}$.

bb_poa - SOA formation is turned off but POA is treated in the same way as in the bb_vbs scenario except that POA is (a test scenario) assumed to be hydrophilic $\left(\kappa_{\text {org }}=0.2\right)$.

- Other features and assumptions are the same as in the bb_vbs scenario.

All $\quad-$ Simulations are performed on a $1^{\circ} \times 1^{\circ}$ model grid with 12 non-equidistant layers extending up to the $200 \mathrm{hPa}$ scenarios pressure level.

- Gas-phase chemical processes are simulated using the MELCHIOR2 chemical mechanism (built into CHIMERE).

- Dry deposition of gases as well as wet scavenging of aerosol and gases are taken into account using parameterizations implemented in the standard version of CHIMERE ${ }^{\mathrm{i}}$.

- Meteorological fields are computed "offline" with the WRF (version 3.9) model $^{\mathrm{k}}$.

${ }^{\text {a }}$ According to Sofiev et al. (2012); ${ }^{\mathrm{b}}$ Stromatas et al. (2012); ${ }^{\mathrm{c}} k_{\text {poa }}$ and $k_{\mathrm{soa}}$ are the imaginary parts of the refractive indexes (at $388 \mathrm{~nm}$ ) for the POA and SOA species, respectively; ${ }^{\mathrm{d}}$ according to Petters and Kreidenweis et al. (2007); ${ }^{\mathrm{e}}$ Janssens-Maenhout et al. (2015); ${ }^{\mathrm{f}}$ Guenther et al. (2006); ${ }^{\mathrm{g}}$ Kroll et al. (2006), Zhang et al. (2007), Bessagnet et al. (2008); ${ }^{\mathrm{h}}$ Wild et al., (2000); ${ }^{\mathrm{i}}$ Mailler et al. (2017); ${ }^{\mathrm{j}}$ Folberth et al. (2006); ${ }^{\mathrm{k}}$ Skamarock et al. (2008). 
dressed in our analysis and therefore may not be applicable to the more oxidized SOA compounds that are probably dominating aged BB aerosol particles.

Overall, except for a slow degradation of BrC by UV in primary aerosol particles, we assume that each molecule of any given SVOC species contains a constant fraction (that can be different for different species) of chromophores and that atmospheric evolution of $\mathrm{BrC}$ within $\mathrm{BB}$ aerosol particles is determined by the condensation or evaporation of the different primary and secondary organic compounds forming BB aerosol particles. This approach allows us to parameterize the evolution of the optical properties of $\mathrm{BB}$ aerosol within the CTM and the evolution of its chemical composition consistently.

To characterize the effects of water uptake by BB aerosol particles on our computations of their optical properties, we evaluated the hygroscopicity parameter $\kappa_{\text {org }}$ (Petters and Kreidenweis, 2007) for BB OA by assuming that all the SOA species feature a constant $\kappa_{\text {org }}$ of 0.2 and that the POA species are hydrophobic. The chosen value of $\kappa_{\text {org }}$ for SOA is representative of the mid-range of the set of $\kappa_{\text {org }}$ measurements for oxidized organic compounds generated in a flow reactor (Lambe et al., 2011). Also, we took into account the water uptake by inorganic species using the equilibrium concentrations calculated in CHIMERE with the ISORROPIA module (Nenes et al., 1998). The main features of our simulations for the different modeling scenarios defined in Sect. 2.3 are summarized in Table 3.

Finally, we would like to emphasize once again that our simplified parameterization of the physical, chemical, and optical properties of BB aerosol is not aimed at a quantitatively accurate representation of the actual very complex processes. We believe that a quantitatively accurate representation of the BB aerosol properties and their evolution in CTMs is presently not feasible in a general case due to the lack of the necessary observational constraints. However, we consider our study to be a step forward towards the development of a simple and robust yet physically sound parameterization ensuring adequate simulation of BB aerosol properties and evolution in chemistry transport and climate models.

\subsection{Preprocessing and harmonization of the satellite and model data}

At the preparatory stage of our analysis, the Level-2 (orbital) AAOD, AOD, and CO satellite data were projected onto the model grid with an hourly temporal resolution (corresponding to the temporal resolution of the output data from CHIMERE). Different pixels falling into the same grid cell were averaged and matched to the corresponding simulated value. To select a particular AAOD retrieval among those corresponding to the different altitudes of the aerosol center mass (see Sect. 2.2), the altitude of an observed BB plume was estimated using the mass concentration of the total particulate matter from the CHIMERE simulations for the bb_vbs scenario. In this way, we harmonized the OMI AAOD retrievals with the corresponding simulations (similar to Zhang et al., 2015; Konovalov et al., 2018). As noted in Sect. 2.2, we also used the final AAOD retrieval product, which is not affected by possible errors of our model but still may not be free of biases due to differences between the actual and assumed "climatological" heights of the BB plumes.

For our analysis of $\mathrm{EnR}_{\mathrm{abs}}$ or EnR $\mathrm{Ext}_{\mathrm{ex}}$, the MODIS and IASI observations collocated - at the scale of a model grid cell with the OMI observations were selected by requiring that the absolute value of the time difference between the measurements taken by OMI and MODIS as well as by OMI and IASI is as small as possible and does not exceed $2 \mathrm{~h}$. The observed BB plumes are assumed to be mostly of a large spatial scale (tens of kilometers) and slowly evolving at a scale of a few hours. Accordingly, the temporal and spatial inconsistencies between the different satellite data are expected to result mostly in random uncertainties in our estimates of $E_{n} R_{a b s}$ or EnR $_{\text {ext }}$, which can be taken into account by the corresponding confidence intervals. For the ancillary analysis that does not involve the OMI AAOD observations (which are much sparser than the MODIS AOD and IASI CO observations), we matched only the available AOD and CO observations, again requiring that the absolute value of the time difference between these observations does not exceed $2 \mathrm{~h}$.

The simulated AAOD, AOD, and CO data were matched in both space and time to the corresponding satellite data. The simulated 3D concentration fields of $\mathrm{CO}$ were first processed to compute the total CO columns using the IASI averaging kernels as described in Konovalov et al. (2014, 2016). As an additional step towards the harmonization of the satellite and simulation data, we introduced a selection criterion for the simulated data, which accounts for the fact that the OMI AAOD data considered in this study are representative only of the scenes strongly affected by fire emissions. In the framework of the OMAERUV retrieval algorithm (Torres et al., 2013), such scenes were selected based on realtime AIRS (Atmospheric Infrared Sounder) retrievals of CO. Accordingly, the grid cells for which the OMAERUV data are available correspond to larger magnitudes of the retrieved CO columns than the grid cells for which the OMAERUV data are not provided. However, due to errors in the fire emissions and computations of the air pollution transport, the observed "hot spots" in the CO columns do not necessarily correspond to similarly elevated values in the simulated CO columns, AAOD, and AOD. Such a mismatch between the OMAERUV data and simulations can result in systematic biases in estimates of $\mathrm{EnR}_{\mathrm{abs}}$. To avoid these possible biases, we first arranged (ranked) the retrieved CO columns with respect to their magnitudes. A similar ranking was performed for the simulated $\mathrm{CO}$ columns. Then we required that the simulated CO data (and the simulated AOD and AAOD data matching the $\mathrm{CO}$ columns in space and time) selected for our analysis have the same ranks as the retrieved $\mathrm{CO}$ columns. Using this criterion, we tried to mimic the selec- 
(a)

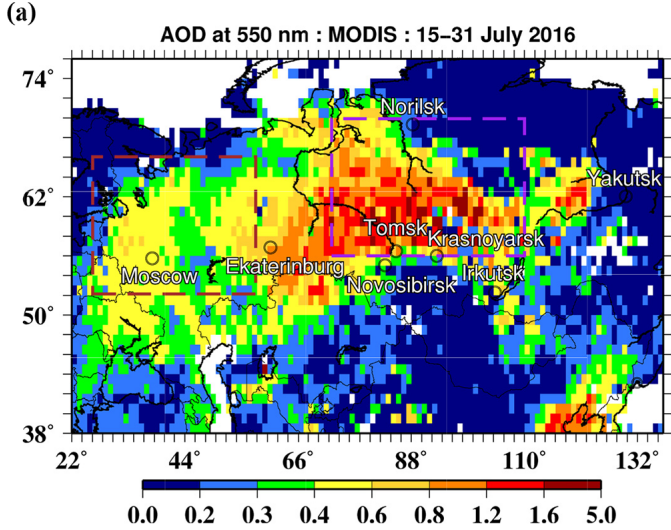

(c)

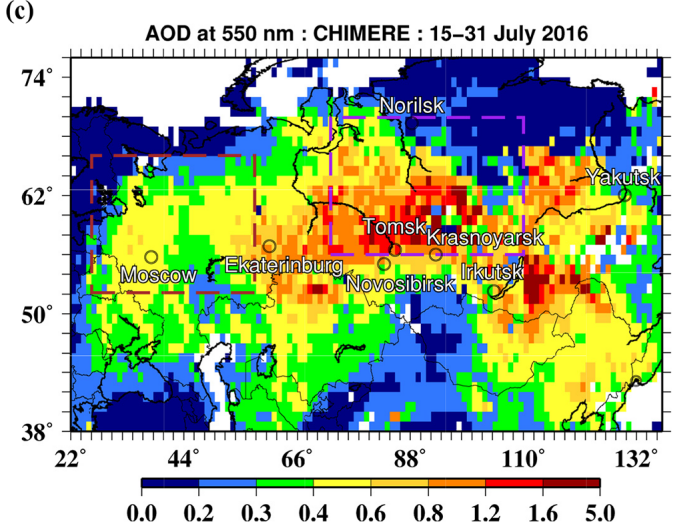

(b)

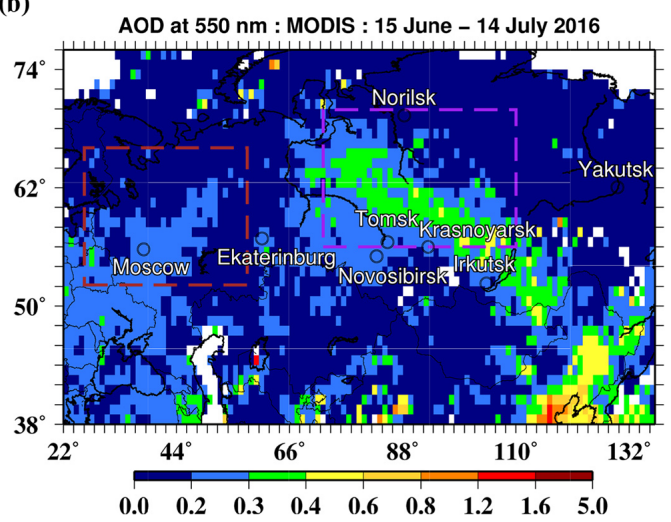

(d)

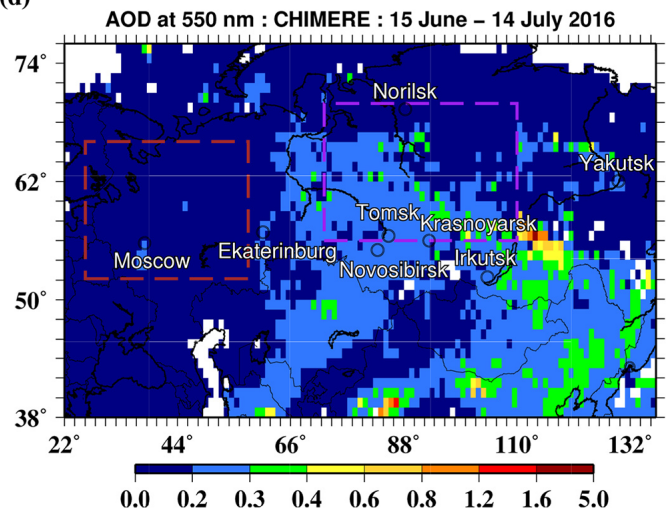

Figure 2. Spatial distributions of the temporal averages of AOD (at $550 \mathrm{~nm}$ ) in the periods (a, c) from 15 to $31 \mathrm{July} 2016$ and (b, d) from 15 June to 14 July 2016 according to (a, b) the MODIS observations and (c, d) the combined CHIMERE simulations for the bb_vbs and bgr scenarios. The distributions represent the ancillary sets of AOD data that were selected irrespective of the availability of the corresponding AAOD retrievals. The rectangles depict the source (purple lines) and receptor (dark red lines) regions covering parts of Siberia and (mostly) the European territory of Russia, respectively.

tion procedure that was applied to the OMI observations in the framework of the OMAERUV algorithm in the case of the simulated data. An advantage of this selection procedure is that it does not involve any subjective quantitative criteria and its outcome is rather insensitive to the mean level of the $\mathrm{CO}$ fire emissions in the model. Finally, some outliers (values of $E_{n} R_{a b s}$ and $E n R_{\text {ext }}$ that were too large or too small) were removed using the three-sigma rule.

Applying all the selection criteria left us with a sufficiently large number (1156) of data points (in the main dataset) suitable for our statistical analysis using the method outlined in Sect. 2.1. As the OMI SSA retrievals are very sparse compared to the AAOD retrievals, we did not apply any selection criteria to the SSA data except for the common spatial and temporal windows.

Note that the harmonization procedure described above presumes that satellite retrievals available only for clear-sky conditions are sufficiently representative of a whole grid cell, part of which can be covered by clouds. The underlying assumption is that in the analyzed period in the middle of summer, when there was little precipitation in the study region, the fire emissions and the corresponding atmospheric loading of BB aerosol were independent, in the statistical sense, of the cloud coverage in a given location. To ensure that the masking out of cloudy scenes in the satellite retrievals does not entail any major systematic discrepancies between the retrievals and simulations, we examined the difference of the observed and retrieved values of AOD in a given grid cell in the study region and period as a function of the number of available retrievals per grid cell and did not find any considerable relationship between the two characteristics.

Figure 2 illustrates the "ancillary" (see above) datasets of AOD observations and simulations. In addition, Fig. S2 in the Supplement shows similar data for the CO columns. More specifically, these figures show the AOD and CO spatial distributions averaged over the analysis period (1531 July 2016) in comparison to similar distributions for the preceding period (15 June-14 July 2016) when there were no strong fire emissions in the study region. These figures also introduce two special regions used in our analysis; one (referred to below as the source region) includes the locations of major Siberian fires that emitted BB plumes transported 
afterward to the eastern European part of Russia and is expected to contain relatively fresh BB aerosol, and another (referred to below as the receptor region) is expected to represent aged BB aerosol. The spatial distributions shown indicate that the Siberian fires caused strong enhancements of the concentrations of $\mathrm{BB}$ aerosol and $\mathrm{CO}$ in the troposphere over a big part of eastern Europe, which is further discussed in Sect. 3.

A final step in our procedure aimed at harmonizing the satellite and simulation data involved the estimation of probable biases in the background values of $\mathrm{CO}$ columns and AOD. (It may be useful to recall that the background part of AAOD is neglected in our analysis.) Similar to our previous studies mentioned above, these biases were estimated by averaging the differences between the simulated and observed data representative of background conditions. A given scene was assumed to be representative of the background conditions with respect to a given characteristic (CO columns or AOD) if a corresponding simulated value for the "fires" scenario did not exceed $10 \%$ of the respective value for the bgr scenario. In this study, the averaging is done over the period from 15 June to 15 August 2016 separately for the source region, the receptor region, and the rest of the study region. The estimated biases are then applied to the simulations of AOD and CO columns for the corresponding regions under the bgr scenario.

\subsection{Adjustment of the model parameters}

As explained above (see Sect. 2.4), our model representation of the BB aerosol aging processes for the VBS scenario involves the three adjustable parameters, $\xi_{1}-\xi_{3}$, controlling the evolution of the POA and SOA species, and the imaginary refractive index, $k_{\text {soa }}$, controlling the absorptive properties of SOA. We need to adjust the correction factors, $F_{S}$ (see Sect. 2.3), specifically those controlling the fire emissions of $\mathrm{BC}, \mathrm{POA}$, and $\mathrm{CO}$. Note that the correction factor for $\mathrm{CO}$ emissions, $F_{\mathrm{CO}}$, is applied to the emissions of all other gaseous species, except for those of NTVOCs (which were determined by scaling the POA emissions). Taking into account that AAOD for BB aerosol in Siberia is typically an order of magnitude smaller than AOD (e.g., Konovalov et al., 2018), we expected that the modeled evolution of AOD is not sensitive to $k_{\text {soa }}$ and also not sensitive to the correction factor for $\mathrm{BC}$ emission, $F_{\mathrm{BC}}$. Therefore, the parameters $\xi_{1}-\xi_{3}$, as well as the correction factors for the POA and CO emissions from fires, can be adjusted independently of $k_{\text {soa }}$ and $F_{\mathrm{BC}}$. Specifically, we required that the nonlinear trend (see Eq. 5) in EnR for the simulated AOD be consistent with the corresponding nonlinear trend in the MODIS observations:

$$
\begin{aligned}
& \left|y_{\mathrm{ext}}^{\mathrm{obs}}\left(t_{\mathrm{e}}\right)-y_{\mathrm{ext}}^{\mathrm{sim}}\left(t_{\mathrm{e}}\right)\right|<\Delta_{\mathrm{ext}}^{\mathrm{obs}}\left(t_{\mathrm{e}}\right)+\Delta_{\mathrm{ext}}^{\mathrm{sim}}\left(t_{\mathrm{e}}\right), \\
& \quad t_{\mathrm{e}} \in\left[t_{\mathrm{e}}^{\mathrm{min}} ; t_{\mathrm{e}}^{\mathrm{max}}\right]
\end{aligned}
$$

where $y_{\mathrm{ext}}^{\mathrm{obs}}\left(t_{\mathrm{e}}\right)$ is the approximation of $\mathrm{EnR}_{\mathrm{ext}}$ for the AOD observations, $y_{\mathrm{ext}}^{\mathrm{sim}}\left(t_{\mathrm{e}}\right)$ is a similar approximation for the AOD simulations, $\Delta_{\mathrm{ext}}^{\mathrm{obs}}$ and $\Delta_{\mathrm{ext}}^{\mathrm{sim}}$ are the $95 \%$ confidence intervals for $y_{\mathrm{ext}}^{\mathrm{obs}}$ and $y_{\mathrm{ext}}^{\mathrm{sim}}$, respectively, and $t_{\mathrm{e}}^{\min }$ and $t_{\mathrm{e}}^{\max }$ are the minimum and maximum values of the photochemical age in the selected dataset.

In the presence of significant nonlinear variations of $y_{\mathrm{ext}}^{\mathrm{obs}}$, the condition given by Eq. (8) can provide sufficiently strong observational constraints to the three parameters $\xi_{1}-\xi_{3}$ of our VBS scheme. To optimize the fire emissions for POA by adjusting the corresponding correction factor $\left(F_{\mathrm{POA}}\right)$, we further required (following Konovalov et al., 2018) that the average values of the AOD simulated using an optimal value of $F_{\mathrm{POA}}, \tau_{\mathrm{ext}}^{\text {sim }}$, and the AOD derived from MODIS observations, $\tau_{\mathrm{ext}}^{\mathrm{obs}}$, be approximately equal:

$\left|\left\langle\tau_{\mathrm{ext}}^{\mathrm{sim}}\right\rangle-\left\langle\tau_{\mathrm{ext}}^{\mathrm{obs}}\right\rangle\right|\left\langle\tau_{\mathrm{ext}}^{\mathrm{obs}}\right\rangle^{-1}<o$,

where the angular brackets denote the averaging performed over (only) the source region and analysis period, and $o$ is the relative error, which is set to be equal to 0.05 in this study.

Similar conditions providing observational constraints to $k_{\text {soa }}$ and $F_{\mathrm{BC}}$ apply to the simulations of AAOD:

$$
\begin{aligned}
& \left|y_{\mathrm{abs}}^{\mathrm{sim}}\left(t_{\mathrm{e}}\right)-y_{\mathrm{abs}}^{\mathrm{obs}}\left(t_{\mathrm{e}}\right)\right|<\Delta_{\mathrm{abs}}^{\mathrm{sim}}\left(t_{\mathrm{e}}\right)+\Delta_{\mathrm{abs}}^{\mathrm{obs}}\left(t_{\mathrm{e}}\right), \\
& t_{\mathrm{e}} \in\left[t_{\mathrm{e}}^{\mathrm{min}} ; t_{\mathrm{e}}^{\mathrm{max}}\right], \\
& \left|\left\langle\tau_{\mathrm{abs}}^{\mathrm{sim}}\right\rangle-\left\langle\tau_{\mathrm{abs}}^{\mathrm{obs}}\right\rangle\right|\left\langle\tau_{\mathrm{abs}}^{\mathrm{obs}}\right\rangle^{-1}<o .
\end{aligned}
$$

Note that the trend $y_{\mathrm{abs}}^{\mathrm{sim}}\left(t_{\mathrm{e}}\right)$ involved in Eq. (10) is expected to depend on both the correction factor $F_{\mathrm{BC}}$ and the imaginary refractive indexes $k_{\text {poa }}$ (which is fixed) and $k_{\text {soa. }}$. Taking into account Eq. (11), larger values of $F_{\mathrm{BC}}$ would require smaller values of $k_{\text {soa }}$. In turn, smaller values of $k_{\text {soa }}$ would suppress the variability of $y_{\mathrm{abs}}^{\mathrm{sim}}\left(t_{\mathrm{e}}\right)$ (which is expected to depend also on parameters $\xi_{1}-\xi_{3}$ ), and therefore the condition in Eq. (10) would require a smaller value of $F_{\mathrm{BC}}$. Such reasoning shows that if $y_{\mathrm{abs}}^{\mathrm{obs}}$ exhibits significant changes with $t_{\mathrm{e}}$, then the conditions in Eqs. (10) and (11) allow for constraining each of the two parameters, $k_{\mathrm{soa}}$ and $F_{\mathrm{BC}}$, independently.

It should be noted that Eqs. (8)-(11) do not imply a rigorous minimization procedure but impose only approximate constraints on the parameters. Indeed, constraining the six parameters controlling our simulations of AAOD and AOD within the VBS framework is a challenging (although not infeasible) computational task. On the other hand, the relatively loose constraints defined above allowed us to manually adjust the parameter values with reasonable accuracy by running the model multiple times and iteratively varying the parameter values using the trial-and-error method. More specifically, starting from a priori estimates of $F_{\mathrm{POA}}$ and $F_{\mathrm{BC}}$ based on our previous studies and estimates of $\xi_{1}-\xi_{3}$ based on Ciarelli et al. (2017), we first adjusted the parameters $\xi_{1}$ $\xi_{3}$ and $F_{\mathrm{POA}}$ in an iterative process. At the next iteration cy- 
cle, using the optimized values of $\xi_{1}-\xi_{3}$ and $F_{\mathrm{POA}}$, we adjusted the parameters $k_{\mathrm{soa}}$ and $F_{\mathrm{BC}}$. These iteration cycles were repeated to ensure the consistency of all the parameters. The optimized values for $\xi_{1}-\xi_{3}$ and $k_{\text {soa }}$ are indicated above in Sect. 2.4 and in Tables 2 and 3.

A similar but much simpler optimization procedure was realized in the case of the simulations with the standard version of CHIMERE (that is, for the bb_trc scenario). Specifically, the parameters of the VBS scheme did not need to be adjusted by definition, and only a pair of iterations was needed to adjust the correction factors $F_{\mathrm{POA}}$ and $F_{\mathrm{BC}}$ under the conditions in Eqs. (8) and (11). The $\mathrm{CO}$ emissions from fires were optimized in the same way as the POA and BC emissions for the bb_trc scenario.

For the bb_vbs scenario, the optimized values of $F_{\mathrm{POA}}$ and $F_{\mathrm{BC}}$ were found to be 0.9 and 1.5 , respectively. With these factors, the bb_vbs simulation yields a mean ratio of $\mathrm{BC}$ and OC mass concentrations of 0.035 , which is a quite realistic value given the estimate $(0.036 \pm 0.009)$ previously derived by Konovalov et al. (2017b) from the AERONET measurements and the average value (0.038) of the highly variable $\mathrm{BC}-\mathrm{OC}$ ratios observed for BB aerosol in central Siberia (Mikhailov et al., 2017). This finding indicates that the absorption closure carried out in our numerical experiments is sufficiently adequate. The optimized value of $F_{\mathrm{BC}}$ is consistent with the $F_{\mathrm{BC}}$ estimate $(1.5 \pm 0.5)$ obtained in Konovalov et al. (2018) for the Siberian fires that occurred in July 2012. However, $F_{\mathrm{POA}}$ is much smaller than the corresponding estimate of $F_{\mathrm{OC}}(2.3 \pm 0.6)$, which was also reported in Konovalov et al. (2018). This difference accounts for the strong SOA formation in our simulations for the bb_vbs scenario, which was essentially disregarded in the simulations performed in Konovalov et al. (2018) (wherein BrC absorption, on the other hand, was implicitly taken into account using an empirical parameterization). For the bb_trc scenario, the optimized values of $F_{\mathrm{POA}}$ and $F_{\mathrm{BC}}$ were found to be 2.8 and 2.9 , respectively. The difference between the optimal values of $F_{\mathrm{POA}}$ for the two scenarios is qualitatively consistent with similar findings from our previous studies (Konovalov et al., $2015,2017 \mathrm{a}$ ) and with underestimation of AOD by simulations in which SOA formation was treated as a minor process (e.g., Petrenko et al., 2012; Tosca et al., 2013; Reddington et al., 2016). A much larger value of $F_{\mathrm{BC}}$ in the bb_trc scenario compared to that in the in bb_vbs is indicative of a major contribution of $\mathrm{BrC}$ to $\mathrm{BB}$ aerosol absorption in the bb_vbs scenario, since the organic matter was assumed to be nonabsorbing in the bb_trc simulation. The $F_{\mathrm{CO}}$ factor was set to 1.9 for both bb_vbs and bb_trc scenarios.

The optimized correction factors allow us to obtain topdown estimates of the total amounts of OC and BC emissions from fires in the study region. Specifically, the total emissions of OC (in particles) in the study region in July are found to be 1.0 and $2.8 \mathrm{Tg}$, respectively, for the bb_vbs and bb_trc scenarios. The big difference between the estimates reflects a strong dependence of the top-down esti- mates of the BB OA emissions on a model representation of the OA processes (Konovalov et al., 2015). The corresponding $\mathrm{BC}$ emissions are estimated as 70 and $136 \mathrm{Gg}$. As noted above, the difference between the $\mathrm{BC}$ emission estimates is mainly due to a missing contribution of $\mathrm{BrC}$ to the absorption in the simulations for the bb_trc scenario. For comparison, according to the GFED4.1s inventory (van der Werf et al., 2017), the same fires emitted $0.96 \mathrm{Tg}$ OC and $51 \mathrm{Gg} \mathrm{BC}$. These bottom-up estimates are evidently much closer to our estimates for the bb_vbs scenario than for the bb_trc one. The good agreement of the bottom-up and top-down estimates of the OC emissions is not necessarily meaningful: as argued in Konovalov et al. (2015), the consistency of top-down and bottom-up estimates of BB OA emissions should be examined by taking into account the partitioning of the measured OC emissions between gases and particles, but the necessary data are not provided as part of emission inventories. Our estimate of the $\mathrm{BC}$ emissions for the bb_vbs scenario is indicative of the underestimation of the Siberian BB BC emissions in the GFES4.1s emission inventory, consistent with the findings of previous analyses (Hao et al., 2016; Konovalov et al., 2018). Note, however, that the present study is not designed to evaluate the uncertainties in top-down emissions estimates. As indicated by the more detailed analysis in Konovalov et al. (2018), the uncertainty in our estimate of the $\mathrm{BC}$ emissions is likely at least $35 \%$. Accordingly, the top-down emission estimates reported above do not allow us to make any certain conclusions about the accuracy of the $\mathrm{BC}$ or OC emission estimates provided by the GFED4.1s inventory.

\section{Results}

\subsection{Analysis using the two-region approach}

In this section, we provide some preliminary characterization of the input data for our analysis, specifically by considering the spatial distributions and time series of both the satellite observations and corresponding simulations. We also examine the aging-driven changes in the optical properties of BB aerosol by considering the satellite and simulated data for the two regions (source and receptor) introduced above (see Sect. 2.5 and Fig. 2). The source region includes the locations of major Siberian fires, and the receptor region was affected by the aged BB plumes transported from the source region (see Figs. 2 and S2). Spatial averaging of the observed characteristics over a big region suppresses the variability associated with individual air masses.

The analysis presented in this section allows us to get some preliminary insights into the effects of atmospheric aging on the BB aerosol optical properties. The advantage of this analysis is that it does not rely on any quantitative estimates (which may be inaccurate) of the BB aerosol photochemical age and is more "transparent" than the more general analysis 
presented in Sect. 3.2. However, such an analysis has serious limitations, as it can provide only crude snapshots of the evolving BB plumes and does not involve the characterization of statistical uncertainties.

The spatial distributions of the simulated average values of AOD and CO columns in the study region during the analyzed period are in reasonable (although not perfect) agreement with the corresponding fields of the satellite data in both Siberia and Europe (see Figs. 2a, c and S2a, c). Specifically, the satellite and model data (both for AOD and CO) exhibit similar big enhancements in the source region and also similar smaller but still considerable enhancements in the receptor region (compared to the period without strong BB emissions in the study region; see Figs. 2b, d and S2b, d). It is noticeable, however, that CHIMERE yields AOD values that are too high compared to MODIS in the eastern and southeastern parts of the model domain (see Fig. 2a and c), where, in contrast, the simulated $\mathrm{CO}$ columns tend to be lower than those retrieved from the IASI observations in the same parts of the domain. We suppose that these differences (which do not significantly affect the results of our analysis because the affected grid cells are mostly outside the study region) may be caused by the spatial variations in several factors and parameters involved in our simulations, including the emission factors for aerosol and gaseous species, volatility distributions of the POA emissions, and the relationship between FRP and the BB rate. In turn, these variations may be due to the inhomogeneity in the spatial distribution of the vegetation species across the region covered by the model domain: in particular, while the dominant tree species in the forest of western Siberia are pine, spruce, fir, birch, and aspen, the most abundant tree species in eastern Siberia (including the eastern part of the study region) is larch (Schepaschenko et al., 2011). According to available measurements (May et al., 2014; Hennigan et al., 2011), both BB OA emission factors and SOA formation for different tree species exhibit strong diversity, while the relationship between FRP and the BB rate can be affected by the relative prevalence of crown and ground fires, which differs in forests dominated by different tree species (Schulze et al., 2012).

The time series corresponding to the spatial distributions shown in Figs. 2 and S2 are presented and discussed in the Supplement (see Sect. S3, Figs. S3 and S4). Similar to the spatial distributions, the time series of the simulations taking fire emissions into account are found to be in good agreement with the observations in both the source and receptor regions, with the correlation coefficient for the spatially averaged daily values of the observations and simulations exceeding 0.85 . Taking into account that $\mathrm{CO}$ has a relatively long lifetime typically exceeding $15 \mathrm{~d}$ in the troposphere over continental regions in summer (Holloway et al., 2000), we consider the results of the comparison of the simulated and retrieved CO columns to be an indication of the good performance of CHIMERE in capturing both the emissions and transport of the BB plumes during the studied period. Fur- thermore, taking into account that satellite retrievals of $\mathrm{CO}$ columns are known to be sensitive to the $\mathrm{CO}$ vertical distribution (e.g., George et al., 2009) (and, as noted in Sect. 2.5, this sensitivity has been addressed in our simulations by applying the averaging kernels), this comparison is also indicative of the adequacy of the simulated vertical profiles of the BB plumes.

The spatial distributions of the OMI AAOD observations and corresponding simulations (for the bb_vbs scenario) for the study region and analysis period are shown in Fig. 3. Note again that the AAOD data analyzed in this study represent only BB aerosol. Qualitatively, these distributions are similar to the corresponding distributions of AOD and $\mathrm{CO}$ (see Figs. 2a, c and S2a, c), but the data are much more sparse, especially in the receptor region. Nonetheless, both the AAOD observations and simulations show numerous hot spots of AAOD in the source region and are also indicative of the major outflow of BB plumes from Siberia into the European territory of Russia.

Figure 4 shows the time series of the spatially averaged AAOD values according to the OMI observations and our simulations for the bb_vbs and bb_trc scenarios. It should be recalled that the background AAOD values were not computed in our simulations and are thus not shown. As the OMI AAOD data representing BB aerosol are almost absent for both regions outside the analysis period, only the data for the analysis period are presented in Fig. 4. Note that for the receptor region, there are not enough data to cover the whole analysis period. The time series for the corresponding $A O D$ and $C O$ values (that were selected consistently with the AAOD observations) are also shown in Fig. 4.

It can be seen that the simulations for both bb_vbs and bb_trc scenarios are in good agreement with the AAOD observations in the source region. In the receptor region, however, the simulations for the bb_trc scenario overestimate AAOD on all $4 \mathrm{~d}$ for which the data are available and are biased high by $\sim 22 \%$ on average. The AOD simulations for the same scenario also tend to overestimate the observations, although the bias is smaller $(\sim 16 \%)$. In contrast, the corresponding simulations of the $\mathrm{CO}$ columns are practically unbiased. These results indicate that the decrease in the observed values of both AAOD and AOD in the receptor region compared to the source region cannot be fully explained by the processes (such as dilution, dry and wet deposition, and coagulation) included in the simulations for the bb_trc scenario. As argued below (see Sect. 3.3), these additional changes in AAOD and AOD are primarily caused by losses of the medium-volatility fraction of SOA due to fragmentation. It is noteworthy that the simulations for the bb_vbs scenario, which take into account BB aerosol aging, do not exhibit any bias in the case of AOD and show only a minor negative bias of $\sim 4 \%$ in the case of AAOD. Note that the magnitude of the biases is not quite properly illustrated in Fig. 4a because different "daily" points represent significantly different numbers of spatial grid cells. Overall, the analysis presented in 
(a)

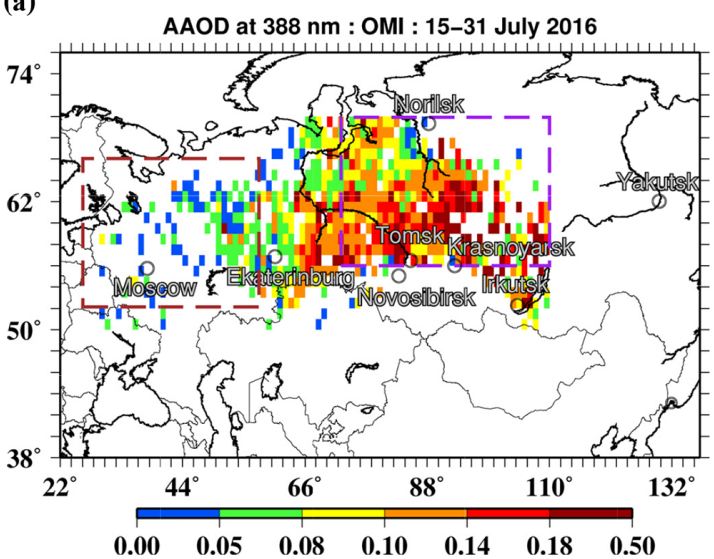

(b)

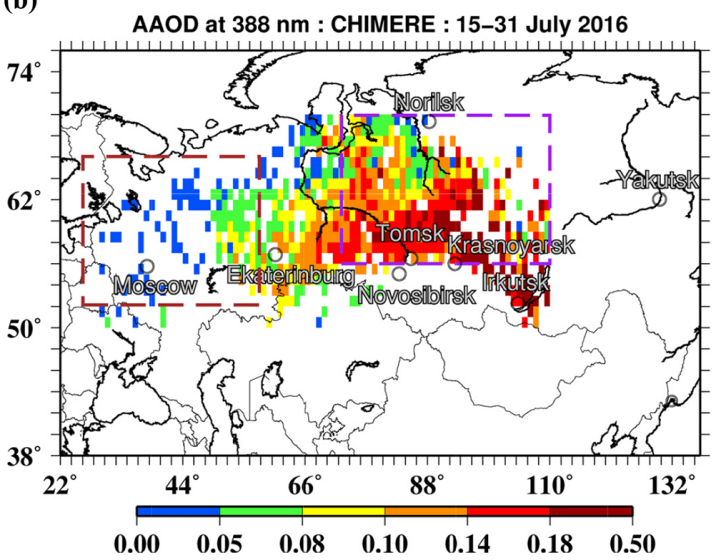

Figure 3. Spatial distributions of temporal averages of AAOD (at $388 \mathrm{~nm}$ ) in the period from 15 to 31 July 2016 according to (a) the OMI observations and (b) CHIMERE simulations for the bb_vbs scenario. The AAOD data represent only BB aerosol in the study region according to the selection criterion specified in the OMAERUV data product. The rectangles depict the source and receptor regions as in Fig. 2.

this section indicates (i) that BB aerosol transported from the source region to the receptor region was affected by aging processes that resulted in reductions of both AAOD and AOD and (ii) that our simulations, which have been designed to account for these processes, reproduce these reductions rather adequately.

\subsection{Analysis of EnRs for the AAOD and AOD observations as a function of the $\mathrm{BB}$ aerosol photochemical age}

The results of the application of our analysis method, which is described in Sect. 2.1, to the AAOD, AOD, and SSA data retrieved from the OMI and MODIS measurements are presented in Fig. 5. Different panels show the nonlinear approximations (trends) of EnRs for AAOD and AOD (Fig. 5a and b) as a function of the BB aerosol photochemical age, as well as similar nonlinear approximations for the SSA values that are either inferred from the OMI AAOD and MODIS AOD observations (Fig. 5c) or available directly from the OMAERUV data product (Fig. 5d). Along with the nonlinear trends for EnRs and SSA, we show the running averages over every 15 corresponding data points (for EnRs or SSA) that were preliminarily arranged with respect to the $\mathrm{BB}$ aerosol photochemical age. The averaging is done for illustrative purposes, as the scatter of the original data points is typically large at the scale of the trends. Note that in the special situation addressed in this study, there is a strong association between the photochemical age of BB aerosol and the geographical location (specifically, the longitude) of the BB plumes transported westward (see Fig. 6). In particular, the $\mathrm{BB}$ aerosol photochemical age ranges from 6 to $42 \mathrm{~h}$ in the source region and from 70 to $106 \mathrm{~h}$ in the receptor region. This association facilitates the interpretation of the results of our analysis and also confirms the reliability of our model estimates of the BB aerosol photochemical age.

The nonlinear trend for AAOD (Fig. 5a) reveals a statistically significant decrease in $\mathrm{EnR}_{\mathrm{abs}}$ (up to $\sim 45 \%$ ) corresponding to the photochemical age $\left(t_{\mathrm{e}}\right)$ period from about 25 to $60 \mathrm{~h}$. The changes in $\mathrm{EnR}_{\mathrm{abs}}$ corresponding to both fresher and older BB aerosol are not statistically significant. This trend indicates that if AAOD were simulated for the given situation without taking into account any $\mathrm{BB}$ aging processes (except for coagulation) and were fitted to the AAOD observations corresponding to BB aerosol aged less than $40 \mathrm{~h}$, the simulated AAOD corresponding to the aged BB plumes $\left(t_{\mathrm{e}}>60 \mathrm{~h}\right)$ would be overestimated by $\sim 30 \%$. This rough estimate is in tentative agreement with the results from the tworegion analysis discussed above (see Fig. 4), taking into account the ranges of the $\mathrm{BB}$ aerosol age in the source and the receptor region (see Fig. 6) and the uncertainty of the trends.

Variations in EnR for AOD (EnR $\mathrm{Ext})$ are more pronounced (see Fig. 5b). Specifically, $E_{n R} R_{\text {ext }}$ increases by more than a factor of 2 during the initial $30 \mathrm{~h}$ of the daytime evolution (since $t_{\mathrm{e}}$ of about $6 \mathrm{~h}$ ) but then decreases by $\sim 40 \%$. This non-monotonic behavior is not contradictory to the relatively minor overestimation of AOD in the receptor region in our simulations for the bb_trc scenario, taking into account that the major part of the increase in $E_{n} R_{\text {ext }}$ occurs inside the source region, which includes BB aerosol with photochemical ages of less than $40 \mathrm{~h}$. Interestingly, the decreasing part of the trend in EnR $_{\text {ext }}$ almost coincides in time with the decreasing part of the trend in $\mathrm{EnR}_{\mathrm{abs}}$ (see Fig. 5a and b). This observation suggests that the reductions in both $\mathrm{EnR}_{\mathrm{abs}}$ and $\mathrm{EnR}_{\text {ext }}$ may be driven by the same processes.

It is noteworthy that a similar increase (by a factor of 2) in EnR for AOD as a result of the atmospheric evolution of aerosol from Siberian fires was reported in our previous 

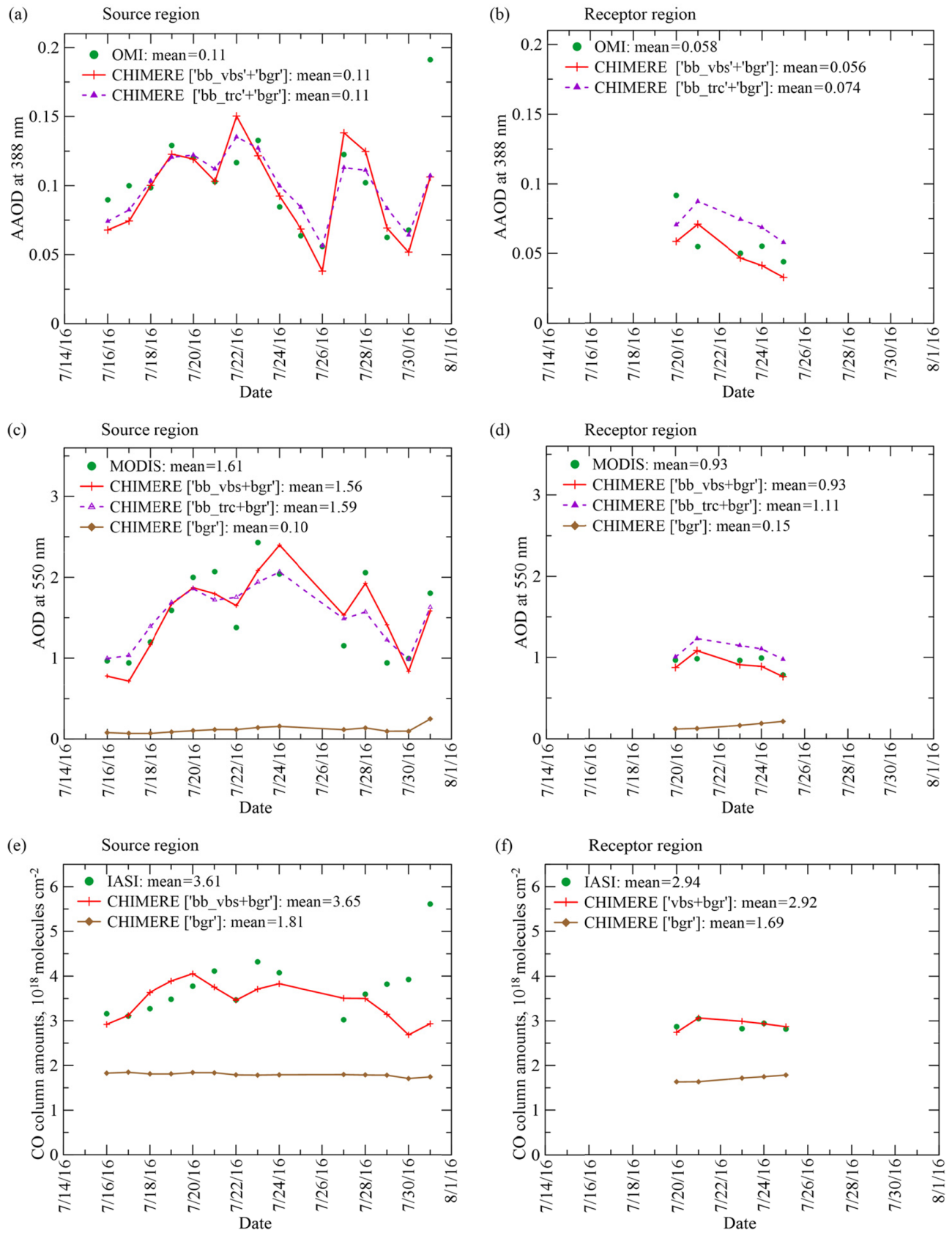

Figure 4. Time series of the daily $(\mathbf{a}, \mathbf{b}) \mathrm{AAOD},(\mathbf{c}, \mathbf{d}) \mathrm{AOD}$, and $(\mathbf{e}, \mathbf{f}) \mathrm{CO}$ values averaged over the study region according to the satellite observations and the CHIMERE simulations under the different model scenarios for the (a, c, e) source and (b, d, f) receptor regions indicated in Fig. 2. All the data were selected consistently. Note that the simulations for the bgr (background) scenario are shown after applying the de-biasing procedure (see Sect. 2.5). The background AAOD is not evaluated in this study and therefore not shown. Taking into account that the time series are very short, the correlation coefficient has not been evaluated (as its values are not sufficiently robust).

study (Konovalov et al., 2017a) despite the differences in the region, period, and method of analysis compared to those in the present study. Furthermore, the previous analysis indicated the presence of a decreasing part in the dependence of EnR $_{\text {ext }}$ on the BB aerosol photochemical age, but the statistical significance of that feature was not evaluated. The quantitative difference between the BB aerosol photochemical ages corresponding to the $\mathrm{EnR}_{\text {ext }}$ maximum $(\sim 30 \mathrm{~h}$ in this study and $\sim 15 \mathrm{~h}$ in Konovalov et al., 2017a) may partly be due to the different definitions of the photochemical age. To the best of our knowledge, this is the first study reporting simultaneous decreases in both the AAOD and AOD (both corrected for dilution) in strongly aged BB plumes. 

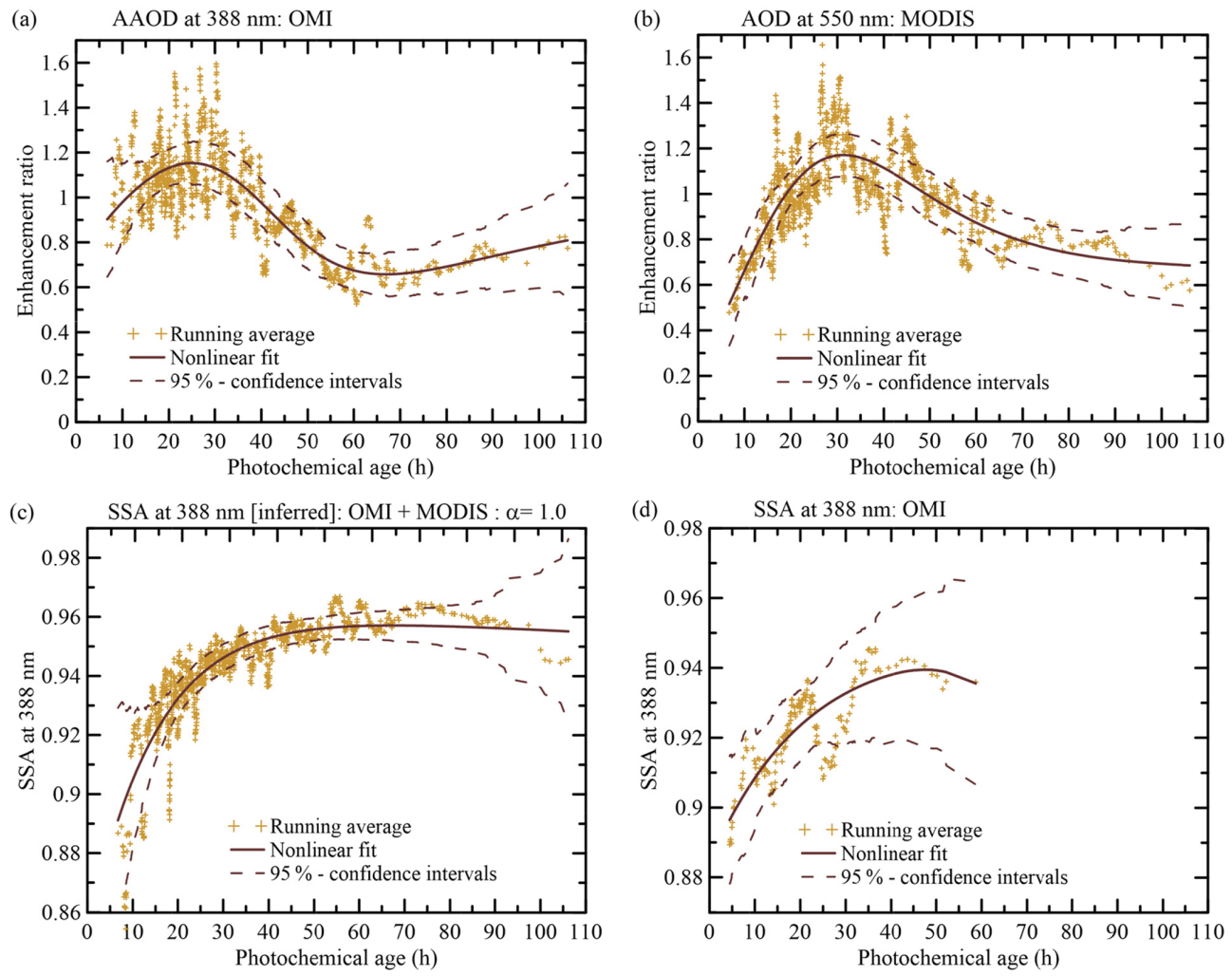

Figure 5. Nonlinear approximations (see Eq. 5) of the dependencies of (a, b) EnRs for AAOD (388 nm), AOD (550 nm), and (c, d) SSA $(388 \mathrm{~nm})$ on the photochemical age of BB aerosol. Also shown are the running averages over every 15 consecutive data points (for EnRs or SSA) arranged with respect to the photochemical age and the $95 \%$ confidence intervals for the approximations. The SSA values approximated in panel (c) are inferred from the OMI AAOD and MODIS AOD observations, while those presented in panel (d) are provided directly in the OMAERUV data product.

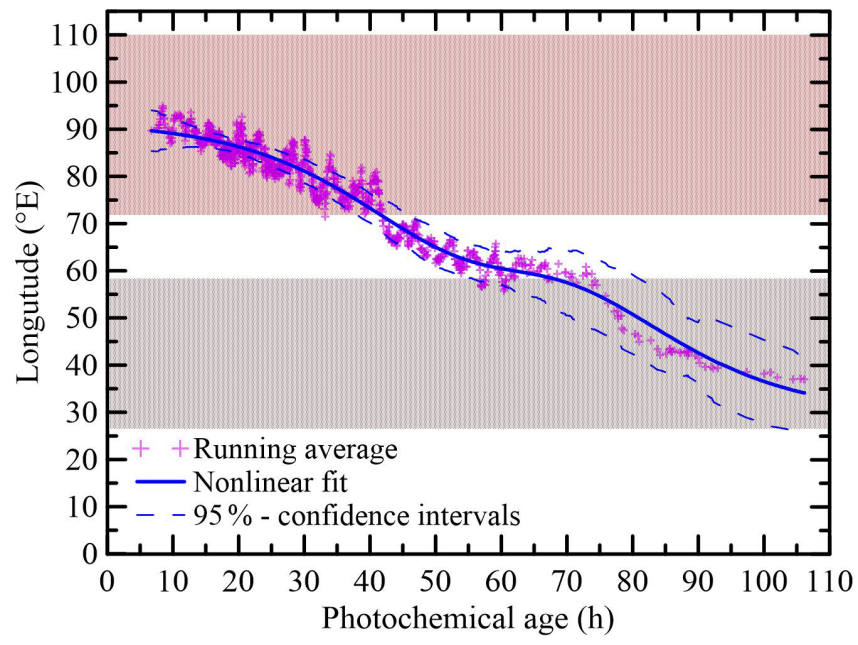

Figure 6. Dependence of the longitude of the instant location of a given BB plume on its photochemical age. The shaded areas indicate the ranges of longitudes of the source (red shade) and receptor (brown shade) regions shown in Fig. 2.
It seems reasonable to expect that the major increase in $\mathrm{EnR}_{\text {ext }}$ in the absence of a similarly strong increase in $\mathrm{EnR}_{\mathrm{abs}}$ is likely to signify an increase in SSA. Figure $5 c$ and $d$ indicate that there is indeed a significant increase in SSA (at $388 \mathrm{~nm}$ ) during the first $20-30 \mathrm{~h}$ of the daytime evolution. According to the SSA estimates inferred from both the OMI AOD and MODIS AAOD data (Fig. 5c) under the assumption that the Ångström exponent is constant (see Sect. 2.2) and equal (in the given case) to 1.0, SSA increased with a decreasing rate from $\sim 0.89$ to almost 0.95 during the first $25 \mathrm{~h}$ and then continued to increase much more slowly, reaching a maximum after $67 \mathrm{~h}$ of the BB aerosol evolution. This assumption, however, may be too strong because whatever processes might significantly affect AAOD and AOD will also likely affect the size distribution of the particles and the Ångström exponent. As an alternative, we also estimated variable values of the Angström exponent for the 388 and $550 \mathrm{~nm}$ wavelengths by using the corresponding AOD from our simulations for the bb_vbs scenario. The dependence of the derived SSA estimates on the photochemical age is found to be qualitatively similar to the dependence shown in Fig. 5c, although the amplitude of the SSA changes in the test case is smaller than in the base case (see Fig. S5). 
Importantly, a growing dependence on $t_{\mathrm{e}}$ is also found for the direct SSA retrievals (see Fig. 5d). In this case, SSA increases from about 0.9 to almost 0.94 , and the increase is statistically significant. These direct SSA retrievals are, however, very sparse, resulting in a large uncertainty of the derived trend, and have not been selected consistently with the AAOD and AOD data (see Sect. 2.5). Although the inferred SSA increase associated with the BB aerosol aging may look relatively small, it can be regarded as an indication of major changes in the optical properties of BB aerosol. For example, an increase in SSA from 0.91 to 0.95 under a constant value of AAOD would result in an enhancement of the aerosol scattering of the solar radiation by almost a factor of 2 . Such an enhancement can likely have serious implications for the radiative effects of $\mathrm{BB}$ aerosol.

Note that the freshest BB aerosol considered in our analysis has already been exposed to atmospheric processing for several hours. So, on the one hand, in the context of most BB aerosol aging experiments in smog chambers (e.g., Hennigan et al., 2011; Tiitta et al., 2016; Ciarelli et al., 2017) such an aerosol would be considered already aged. On the other hand, these experiments do not usually examine changes in BB aerosol optical properties, especially at the long timescales addressed in this study. Therefore, a comparison of the results of our analysis with available results of laboratory experiments is not straightforward, and it goes beyond the scope of this study. However, the increase in SSA in our analysis is qualitatively consistent with the persistent enhancements of SSA of BB aerosol particles after $24 \mathrm{~h}$ of atmospheric aging according to a recent analysis of AERONET data (Shi et al., 2019). Significant increases in the BB aerosol mass scattering efficiency and SSA as a result of the BB aerosol aging were observed by Kleinman et al. (2020) in near-field observations of BB plumes, consistent with an earlier observation (Akagi et al., 2012) of a major increase in aerosol light scattering in BB plumes. To the best of our knowledge, the simultaneous increase in both SSA and AOD (corrected for dilution) is reported here for the first time.

\subsection{Interpretation of the inferred changes in the BB aerosol optical properties}

In this section, we employ our simulations with the CHIMERE CTM to interpret the qualitative features of the BB aerosol evolution inferred from the satellite observations. It should be noted that our interpretation is not unambiguous, especially with respect to the quantitative aspects of the effects considered. However, to the best of our knowledge, this interpretation is the first attempt to reconcile the major changes in both absorption and scattering characteristics of $\mathrm{BB}$ aerosol due to multi-day atmospheric aging with the available knowledge of the atmospheric transformations of $\mathrm{BB}$ aerosol by using numerical simulations with a CTM. The analysis presented below may have implications for devel- oping adequate and robust parameterizations of BB aerosol aging processes in chemistry transport and climate models.

Figure 7 shows the nonlinear approximations for the AAOD and AOD enhancement ratios calculated using the simulations for the bb_vbs scenario. The corresponding approximations based on the analysis of the satellite data are also shown for comparison. Evidently, based on the criteria given by Eqs. (8) and (10), EnR $\mathrm{abs}_{\mathrm{ab}}$ and EnR $\mathrm{ext}_{\mathrm{ext}}$ from the simulations are overall consistent with their counterparts from the observations (see Fig. 5a, b). This fact gives credence to the representation of the BB aerosol evolution in our model.

Further insights into the processes, leading to the nonlinear trends in EnR $R_{\text {ext }}$ and EnR $R_{a b s}$ according to our simulations, are provided by the results presented in Figs. 8-10. Specifically, Fig. 8 illustrates the evolution of the chemical composition of BB aerosol in the simulations for the bb_vbs scenario, presenting the fractional contributions of the model species in the mass columnar concentration of BB aerosol (Fig. 8a) and the normalized EnRs for the columnar concentrations of organic species in the particulate phase (Fig. 8b). These EnRs were evaluated similarly to Eq. (1) as the normalized ratio of the columnar concentration of the given component originating from fires to the columnar concentration of $\mathrm{BB} \mathrm{BC}$ (which was considered a passive tracer). Figure $8 \mathrm{~b}$ also presents the evolution of EnR for OA in the sixth section $(310-630 \mathrm{~nm})$ of the particle size distribution assumed in our simulations. Figure 9 shows the evolution of the mass absorption and mass scattering efficiencies, and Fig. 10 demonstrates several sensitivity tests (explained below) aimed at a better understanding of the factors governing the evolution of EnR $\mathrm{abs}_{\mathrm{abs}}$. Additionally, several characteristics that can affect gas-particle partitioning and oxidation processes as well as AAOD and AOD enhancement ratios are discussed in Sect. S4 (see also Fig. S6).

According to Fig. 8a, the $\mathrm{BB}$ aerosol composition is dominated by SOA species from the very beginning of the $\mathrm{BB}$ aerosol aging period addressed in our analysis (that is, from $t_{\mathrm{e}}$ bigger than about $6 \mathrm{~h}$ ). This is not quite surprising, as the typical lifetime of NTVOCs, which is the major source of SOA in our simulations, is just $\sim 2 \mathrm{~h}$ (with $k_{\mathrm{OH}}$ of $4 \times 10 \mathrm{~cm}^{3}$ molec. ${ }^{-1} \mathrm{~s}^{-1}$ and $\mathrm{OH}$ concentration of $\sim 4 \times 10^{6} \mathrm{~cm}^{-3}$; see Fig. S6b). The same lifetime is characteristic of the gaseous fractions of POA (but note that the gaseous fraction of LV-POA is relatively very small) and HVSOA. During the next $30 \mathrm{~h}$ or so, the remains of MV-POA and HV-SOA are evaporated and converted into LV-SOA and MV-SOA. At this stage, the SOA fraction remains nearly constant $(\sim 78 \%)$, as the effects of evaporation and fragmentation are overall counterbalanced by the effects of condensation and functionalization. It is worth noticing, however, that while the MV-SOA fraction also remains nearly constant, the LV-SOA fraction increases by more than $20 \%$, and the ratio of the LV-SOA and LV-POA fractions increases quite significantly by about $45 \%$. After about $40 \mathrm{~h}$, the main processes governing the evolution of SOA are the evaporation (facili- 

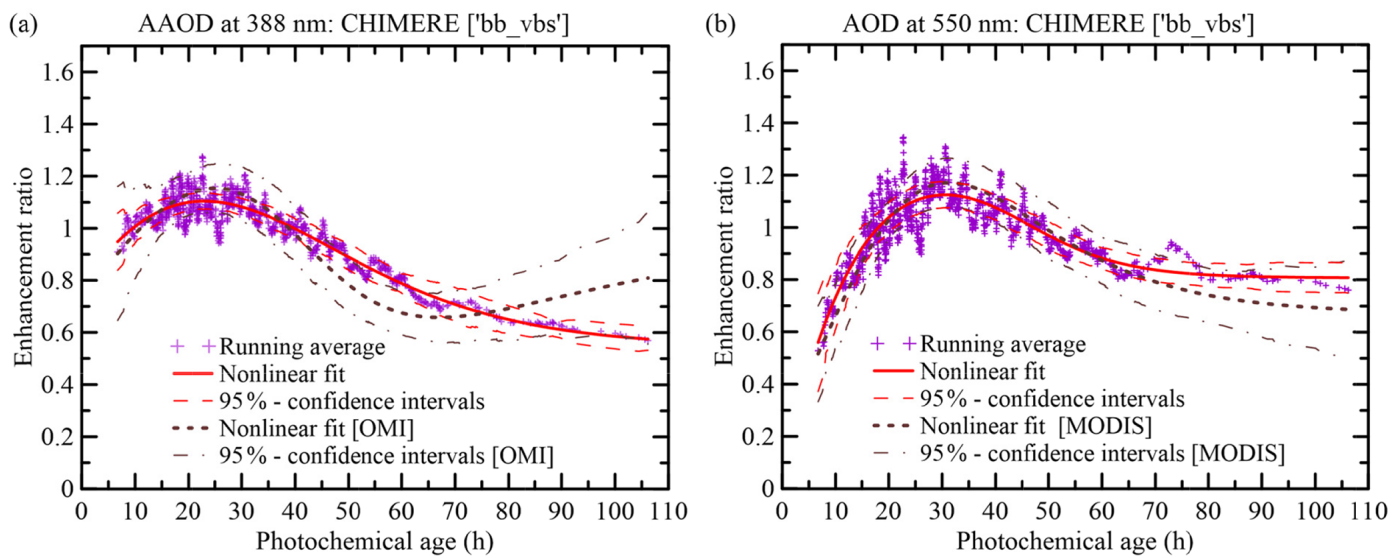

Figure 7. The same as in Fig. 5a-b but obtained using the CHIMERE simulations for the bb_vbs scenario. The dependencies from Fig. 5a-b and their confidence intervals are also shown for comparison.
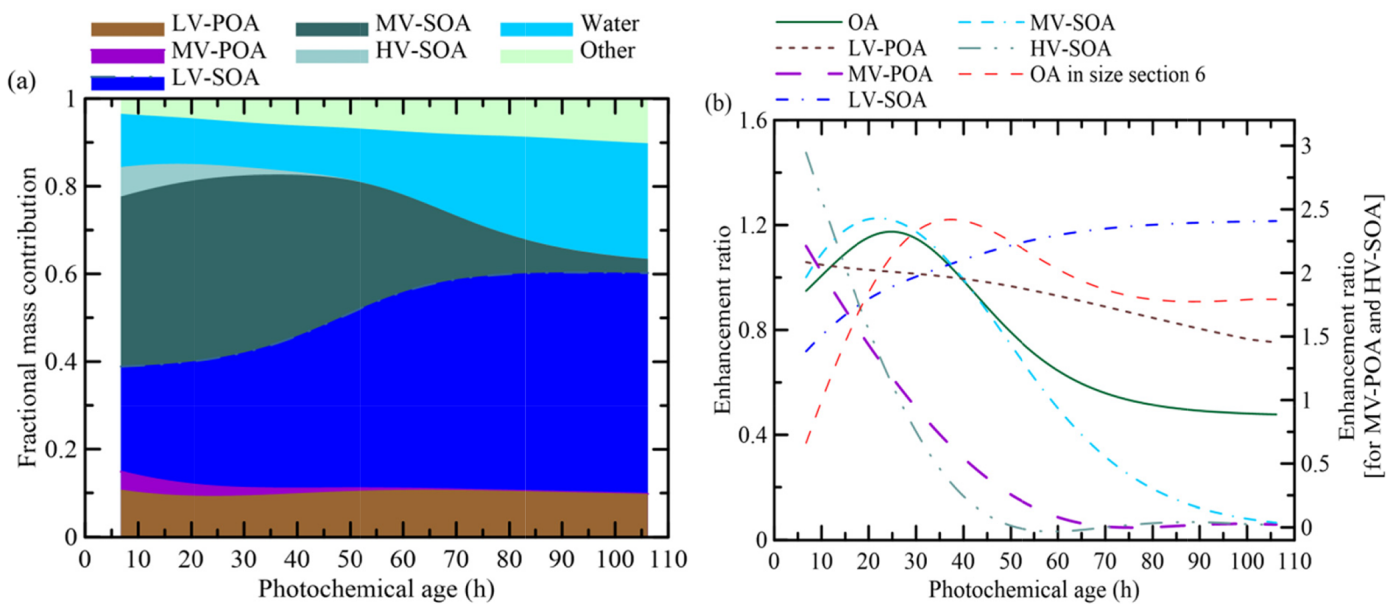

Figure 8. Evolution of the key model species determining the composition of BB aerosol in the CHIMERE simulation for the bb_vbs scenario: (a) fractional contributions of the model species to the mass columnar concentration of BB aerosol; (b) the normalized EnRs of columnar concentrations of organic species in the particulate phase in the simulations for the bb_vbs scenario with respect to the OA concentration in the simulations for the bb_trc scenario, along with similar enhancement ratios for the total columnar OA concentration and OA concentration in the sixth bin $(310-630 \mathrm{~nm})$ of the particle size distribution in CHIMERE. Note that the EnRs for MV-POA and HV-SOA are presented using the right ordinate axis.

tated by dilution; see Fig. S6c) of MV-SOA, its subsequent conversion into LV-SOA, and relatively slow evaporation and gas-phase fragmentation of the latter. Consequently, the MVSOA fraction shrinks from $44 \%$ to merely $5 \%$, whereas the LV-SOA fraction increases twofold. The contribution of the inorganic fraction to the BB aerosol is initially small (16\%), but it increases up to $37 \%$ (see Fig. 8a) following the increase in relative humidity (see Fig. S6a) from about $40 \%$ to $65 \%$. The predominant inorganic compound in particles is water, whose fraction remains below $15 \%$ before $60 \mathrm{~h}$ and eventually rises to $26 \%$. Similar to non-absorbing organic compounds, inorganic ions and water increase the scattering cross section of BB aerosol particles, thereby increasing AOD and SSA, although the contribution of a unit mass of water to the scattering efficiency is considerably smaller in our simula- tions than that of the organic matter because the real component of the refractive index for water (1.33) is substantially smaller than for the organic species (1.63). It is noteworthy that the substantial increase in the water uptake occurs only after $60 \mathrm{~h}$, and therefore it could not contribute significantly to the strong increase in $\mathrm{EnR}_{\text {ext }}$ before $30 \mathrm{~h}$. The water uptake by the organic shell of the particles can also contribute to the lensing effect, thereby increasing AAOD, but as argued in this section below, the lensing effect does not play a key role in the evolution of EnR $\mathrm{R}_{\mathrm{abs}}$.

Consistent with the results shown in Fig. 8a, the EnRs for both MV-POA and HV-SOA decrease rapidly and become negligible after about $60 \mathrm{~h}$ (see Fig. 8b). In contrast, the EnR for LV-SOA exhibits a growing tendency during the whole period of evolution, increasing by $\sim 70 \%$ but becom- 


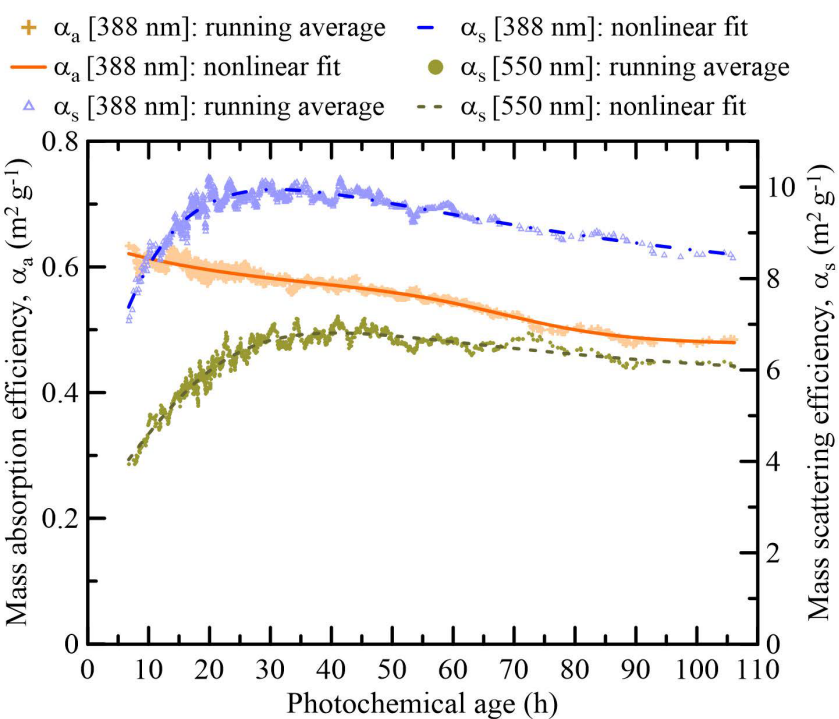

Figure 9. Evolution of the mass absorption efficiency at $388 \mathrm{~nm}$ (left axis) and mass scattering efficiency at 388 and $550 \mathrm{~nm}$ (right axis) according to the simulations with the CHIMERE CTM and OPTSIM module for the bb_vbs scenario.

ing nearly stable after about $70 \mathrm{~h}$. A growing tendency is also manifested in the evolution of the EnR for MV-SOA and total OA but only during the initial $25 \mathrm{~h}$, after which the EnRs for both MV-SOA and total OA start to decrease. Since the BB OA concentration is typically much higher than $1 \mu \mathrm{g} \mathrm{m}^{-3}$ (see Fig. S6c), LV-POA evaporates slowly, with its EnR decreasing by $30 \%$ during the whole analysis period. The evaporation of LV-POA can be mainly driven by the loss of its gas-phase fraction due to Reaction (R2).

It may be puzzling why $\mathrm{EnR}_{\text {ext }}$ increases twofold in the period until $30 \mathrm{~h}$ (see Fig. 7b), whereas no similar strong increase is demonstrated by the EnRs for any of the organic species. However, Fig. 8b also shows that the EnR for OA in particles with sizes from 310 to $630 \mathrm{~nm}$ increases more than 3 times during the same period when $E_{n} R_{\text {ext }}$ increases twofold. According to Mie theory, this section corresponds to the particle diameters with the maximum scattering and extinction efficiencies at $550 \mathrm{~nm}$. Hence, it is not surprising that the gain of mass by particles in this section of the accumulation mode results in an enhancement of AOD. Furthermore, Fig. 9 shows that the mass scattering efficiency (which is the main contributor to the mass extinction efficiency in our case) at the $550 \mathrm{~nm}$ wavelength increases by a comparable amount (almost by $70 \%$ ) in the same initial period of evolution. A similar, although relatively smaller, increase $(\sim 25 \%)$ takes place in the mass scattering efficiency at $388 \mathrm{~nm}$. In contrast, the mass absorption efficiency at $388 \mathrm{~nm}$ (also shown in Fig. 9) gradually decreases during the whole period of the evolution. Therefore, according to our simulation, the changes in the mass scattering and absorption efficiencies are the key drivers for the increases in both EnR for AOD at $550 \mathrm{~nm}$ and SSA at $388 \mathrm{~nm}$. Our further analysis indicates that the changes in the mass absorption and scattering efficiencies are indeed associated with changes in the size distribution of BB particles. Specifically, the particle size distribution shifts toward larger particles (see Fig. S7) as the BB aerosol ages. Such a shift is apparently due to a complex interplay between the evaporation process (predominantly affecting smaller particles having a larger surfaceto-volume ratio) and the dominating condensation process (which can also significantly affect bigger particles, especially in the situation when smaller particles are partially evaporated). In the diluting plumes, condensation of organic material onto the particles occurs primarily as a result of oxidation processes driving the SOA formation. The growth of particles can also be caused by the uptake of water by both organic and inorganic components of the aerosol.

To get further insights into the role of SOA formation in the analyzed evolution of the optical properties of BB aerosol, we also performed simulations for a test scenario (bb_poa), which has been briefly introduced in Sect. 2.3. In these simulations, the POA emissions had to be strongly (by a factor of 4.3) increased to keep the agreement between the observed and simulated AOD. The bb_poa simulations were performed by assuming that POA is hydrophilic with $\kappa$ of 0.2 (whereas it was assumed to be hydrophobic in the bb_vbs scenario). The corresponding results are presented in Sect. S5 and Fig. S8. Importantly, we found that neither EnR ext nor the mass scattering efficiency considerably increases during the period until $30 \mathrm{~h}$, in striking contrast to the behavior of the same characteristics in the base case simulation. Changes in $E_{n} R_{\text {ext }}$, which are due to the combined effect of evaporation of MV-POA and the uptake of water, are small (less than $15 \%$ ) and negative during the whole period of evolution. There are decreasing trends in the mass absorption efficiency and $E R_{a b s}$ and a gradual increase in SSA, which are apparently due to the limited lifetime of $\mathrm{BrC}$ in LV-POA. Overall, the simulations for the bb_poa scenario confirm that the oxidation processes are the main driving force behind the major features in the retrieved evolution of AOD and SSA.

As could be expected, the simulated evolution of $E R_{a b s}$ is also found to be driven by condensation and evaporation processes, but the impact of these processes on $E_{n} R_{a b s}$ is mediated by several additional factors. In particular, one should take into account that AAOD is determined by BC, POA, and SOA species, each of which is characterized by a different value of the imaginary refractive index, and therefore equal relative changes in the mass concentrations of these components will have different impacts on AAOD. Furthermore, changes in the POA and SOA mass concentrations can affect AAOD through the lensing effect (Lack and Cappa, 2010). To examine these factors, we ran the OPTSIM module for several limiting cases representing different optical properties of the individual components of BB aerosol simulated within the bb_vbs scenario. The main results are presented in Fig. 10, where the evolution of $\mathrm{EnR}_{\mathrm{abs}}$ simulated 
(a) AAOD at $388 \mathrm{~nm}$ : CHIMERE ['bb vbs']: 'only BC'

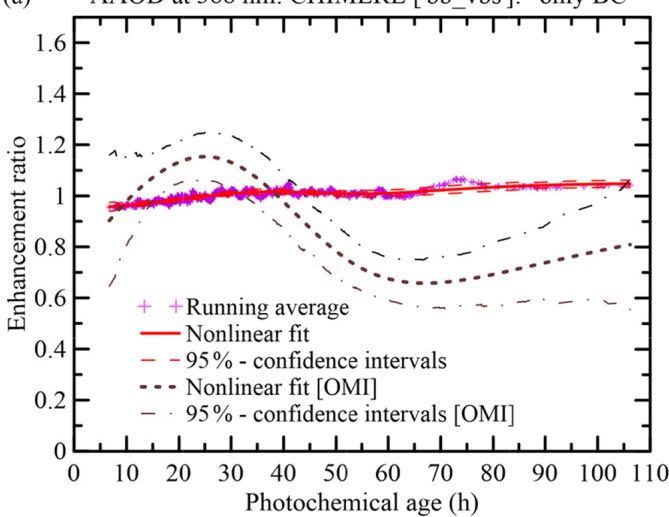

(c) AAOD at $388 \mathrm{~nm}$ : CHIMERE ['bb vbs']: 'BC+clear shell'

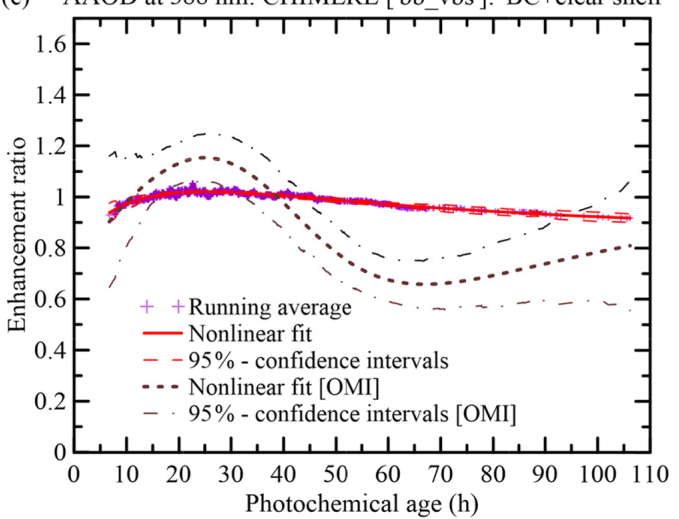

(b) AAOD at $388 \mathrm{~nm}$ : CHIMERE ['bb vbs']: 'only $\mathrm{BrC}$ '

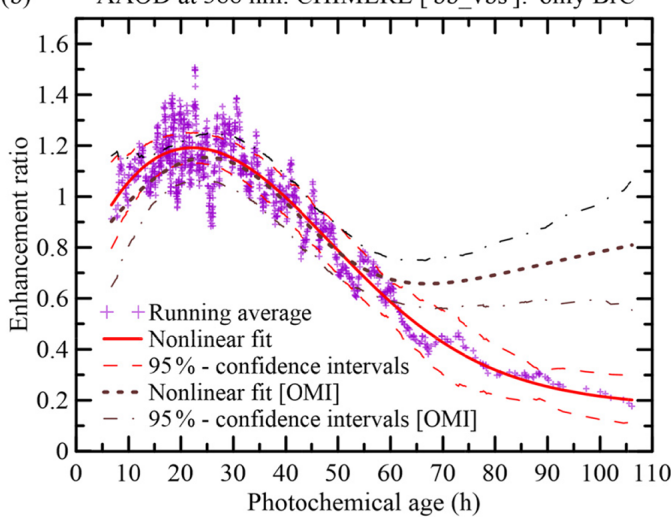

(d) AAOD at $388 \mathrm{~nm}$ : CHIMERE ['bb_vbs'] : 'clear SOA'

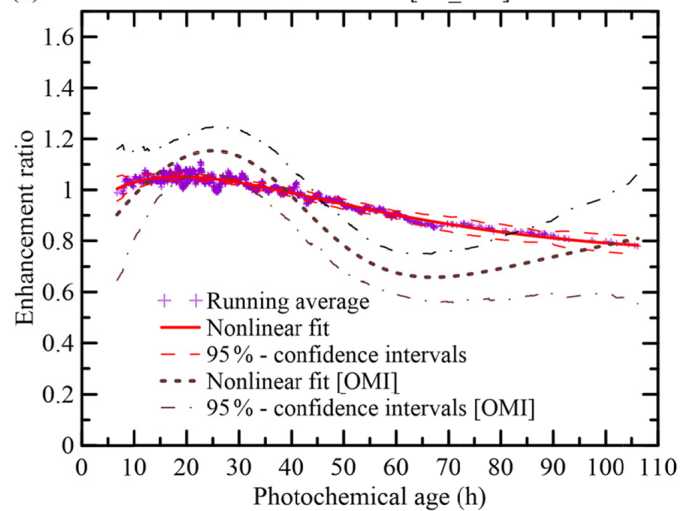

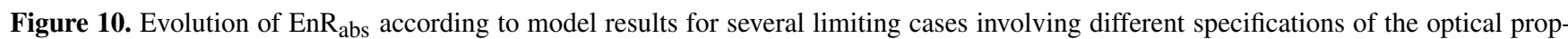
erties of the individual components of $\mathrm{BB}$ aerosol: (a) absorption is determined only by $\mathrm{BC}$, (b) absorption is determined only by BrC, (c) absorption is determined only by the BC core surrounded by the non-absorbing shell, and (d) absorption is determined by both the BC core and OA shell, but SOA is non-absorbing. The trends in $\mathrm{EnR}_{\mathrm{abs}}$ according to the analysis of satellite observations (Fig. 5a) and the confidence intervals are also shown for comparison. The corresponding model results for the base case in which the BC core is surrounded by the absorbing shell are shown in Fig. 7a.

under the different assumptions is compared with the corresponding trends derived from the OMI observations. Based on these results, we also evaluated the relative contribution of several factors to the BB aerosol absorption (see Sect. S6 and Fig. S9).

Specifically, Fig. 10a shows the trend in $\mathrm{EnR}_{\mathrm{abs}}$ for the sensitivity test in which the refractive index of the shell of $\mathrm{BB}$ particles approaches that of ambient air. This is a relatively trivial case because the size distribution of BC particles should not be affected by evaporation and condensation of the POA and SOA species, and therefore AAOD associated with such particles is expected to behave almost as an inert tracer. And indeed, $\mathrm{EnR}_{\mathrm{abs}}$ computed for this case is found to be nearly constant (Fig. 10a). A minor increase in the $E_{n} R_{a b s}$ is likely due to different effects of dry deposition and coagulation on the size distribution of BB aerosol particles in the bb_vbs and bb_trc scenarios. Despite looking trivial, this test confirms the integrity of our simulations and indicates that the evolution of AAOD in our simulations is al- most fully determined by transformations of the organic fraction of BB aerosol. Note that in this case, the average AAOD in the selected dataset is much lower than in the base case: we estimated that "pure" BC (without the lensing effect) accounts on average for only $31 \%$ of the total absorption (see Sect. S6).

Figure $10 \mathrm{~b}$ presents results for the opposite sensitivity test, in which the contribution of $\mathrm{BC}$ to the $\mathrm{BB}$ aerosol absorption was disregarded. In other words, AAOD was computed under the assumption that $\mathrm{BC}$ is not absorbing. In this case, the evolution of EnR $\mathrm{R}_{\mathrm{abs}}$ is similar to that in the base case (see Fig. 7a), except that the amplitude of a variation in the nonlinear approximation is much larger in the test case. This test case further confirms a pivotal role played by OA in the simulated evolution of AAOD. As could be expected, constant BC absorption (see Fig. 10a) dampens, to a significant extent, the AAOD changes caused by the OA.

In principle, one would also expect that variations in the thickness of the organic shell, which are associated with the 
evolution of EnR $R_{\text {ext }}$, lead to changes in $E_{n} R_{a b s}$ due to the lensing effect associated with the non-absorbing fraction of OA. To test this possibility, we set the imaginary refractive index for both POA and SOA to zero. The results of the corresponding computations are shown in Fig. 10c. According to these results, the lensing effect does not significantly contribute to the $\mathrm{EnR}_{\mathrm{abs}}$ variations in the base case. This can be due to the saturation of the absorption enhancement by a clear coating (Wu et al., 2018) and also because the dilutioncorrected variations in the OA concentration in our simulations are relatively small (see Fig. 8b).

The test computations shown in Fig. 10a-c clearly indicate that the key factor responsible for the changes in $E_{n} R_{a b s}$ in our simulation is the variable $\mathrm{BrC}$ absorption. Further insights into the mechanism of these changes are provided by a computation under the assumption that SOA is nonabsorbing (while POA is still absorbing). The results of these computations are shown in Fig. 10d. Similar to the base case, $\mathrm{EnR}_{\mathrm{abs}}$ decreases with $t_{\mathrm{e}}$ but at a much lower rate. Hence, we can conclude that the evolution of the aerosol absorption properties in our simulations is mainly driven by the formation and transformations of the SOA species.

Taking the entirety of the results of our analysis into account, we suggest the following qualitative interpretation of the main processes driving the evolution of $E_{n} R_{a b s}$ and $\mathrm{EnR}_{\mathrm{ext}}$ in our simulations and, ultimately, in the real atmosphere. First, fast oxidation of NTVOCs results in the production of HV-SOA and MV-SOA. HV-SOA is mostly oxidized into MV-SOA and then LV-SOA during the initial period of a few hours, which is not represented in the satellite observations considered here. Oxidation of POA provides an additional source of both MV-SOA and LV-SOA. Evaporation (and subsequent transformation) of POA and HV-SOA as well as formation and condensation of LV-SOA and MVSOA lead to a major increase in $\mathrm{EnR}_{\mathrm{ext}}$, mainly as a result of an increase in the mass scattering efficiency at $550 \mathrm{~nm}$ due to a shift of the size distribution towards bigger particles. In contrast, the mass absorption efficiency at $388 \mathrm{~nm}$ is not strongly affected by the indicated processes, and there is only a minor increase in $E_{n} R_{a b s}$, which is caused by the formation of MV-SOA (as LV-SOA is assumed to be non-absorbing). As the sources of MV-SOA are depleted, its concentration decreases due to the oxidation Reaction (R5). Since the fragmentation pathway is assumed to be dominating in this reaction, the depletion of MV-SOA is not compensated for by the production of LV-SOA, so the total concentration of the SOA species also decreases. This process can explain the decreasing stage in both the EnR $R_{a b s}$ and EnR $R_{\text {ext }}$ evolution. The decrease in the total SOA concentration - and the decrease in $E_{n} R_{a b s}$ and $E_{n} R_{\text {ext }}$ - slows down as the MV-SOA concentration decreases. Eventually, the BB aerosol consists predominantly of the lower-volatility fractions of POA and SOA. This agrees with observations of low-volatility aged BB aerosols in field campaigns (Clarke and Kapustin, 2010; Thornberry et al., 2010; Andreae et al., 2018).

\subsection{Discussion of the uncertainties}

In this section, we discuss possible sources of systematic errors in our retrieval and interpretation of the evolution of the optical properties of BB aerosol, which are associated with both our analysis of satellite data and CTM simulations. Random uncertainties (due to the spatial and temporal variability of satellite and model data corresponding to the same photochemical age of BB aerosol) in the retrieved tendencies are taken into account in the confidence intervals as explained in Sect. 2.1.

To examine the main potential sources of systematic errors in our analysis of the satellite data, we performed several sensitivity tests. These tests and the corresponding results are presented in Supplement Sect. S7 and Figs. S10-S12.

First, we tried to ensure that the major features in the retrieved evolution of the BB aerosol absorption properties are not sensitive to possible biases in the simulated vertical profiles of BB aerosol, keeping in mind that such biases can affect the processing of the OMAERUV retrievals, which are provided for five different altitudes of the aerosol center of mass (see Sect. 2.2). For this reason, we repeated our analysis with the final OMAERUV retrievals, which means without involving the simulated heights of the BB plumes. We found that the trends in $\mathrm{EnR}_{\mathrm{abs}}$ and SSA obtained with the final retrievals (see Fig. S10a, b) are only slightly different from those for the base case (see Fig. 5a, d, respectively).

Second, we examined to what extent our analysis is sensitive to the satellite and modeled data for the CO columns involved in the estimation of the correction factor $f_{\mathrm{c}}$ (see Eqs. 2 and 3) intended to compensate for possible model transport errors but possibly having biases of its own (see Sect. S7). To this end, we repeated our analysis of the satellite data with $f_{\mathrm{c}}$ equal to 1 . The derived trends (see Fig. S11) retained the main qualitative features of the tendencies obtained for the base case (see Fig. 5a, b). It is noteworthy that the tendency in EnR for AOD has wider confidence intervals corresponding to photochemical ages larger than $70 \mathrm{~h}$ in the test case than in the base case, thereby indicating that the application of the $\mathrm{CO}$ columns is indeed helpful in reducing the uncertainties associated with model transport and BB emission errors in the simulations of the strongly aged BB plumes. This sensitivity test therefore provides strong evidence that the main derived qualitative features of the evolution of the BB aerosol optical characteristics are not an artifact of the model errors in the transport and BB emissions.

Third, we evaluated the sensitivity of the inferred tendencies in $E_{n} R_{\text {ext }}$ and $E_{n R} R_{a b s}$ to the assumptions regarding the background AOD and AAOD values (see Eq. 1) by neglecting the background AOD and assuming a constant value of 0.018 (based on the daily Level-3 OMAERUV data) for the background AAOD. This test indicated (see Fig. S12) that neither the increasing part in the trend in $\mathrm{EnR}_{\mathrm{ext}}$ nor the decreasing parts in the trends in both $E_{n} R_{\text {ext }}$ and $E n R_{a b s}$ is due to possible biases in the background AOD and AAOD values. 
Overall, these tests confirm that our major qualitative findings obtained as a result of the analysis of the satellite data are not artifacts of the analysis procedure or model errors.

Potential systematic errors in the inferred tendencies in $E_{\text {ext }}$ and EnR $_{\text {abs }}$ can also be associated with biases in the satellite retrievals. However, as noted above (see Sect. 2.2), previous validation studies and analyses involving both the MODIS AOD and OMI AAOD retrievals for Siberian BB plumes did not reveal indications that these data are significantly biased. Accordingly, we have reason to assume that the corresponding systematic errors in the inferred tendencies are relatively small in comparison to random errors and are covered by the estimated confidence intervals. Nonetheless, the lack of in situ measurements in Siberia does not allow us to properly evaluate and definitely rule out any effects of potential biases in the satellite retrievals on the results of our analysis. Validation of the satellite retrievals, especially ones distinguishing between fresh and aged BB aerosol, requires further dedicated studies.

As pointed out in the Introduction and Sect. 2.4, our interpretation of the inferred evolution of the BB aerosol optical properties is based on the use of a highly simplified representation of the evolution of the organic fraction of $\mathrm{BB}$ aerosol. Accordingly, our analysis of the simulated data (see Sect. 3.3) was intended to identify only basic possible mechanisms underlying the main qualitative feature of the inferred tendencies and does not allow us to make any quantitative assessments. Although - based on our knowledge - we cannot propose any plausible alternative to oxidation processes associated with SOA formation and transformation as driving forces behind the major changes in the enhancement ratios for both AOD and AAOD, our interpretation involves considerable uncertainties with respect to many important features of these processes.

For example, the evolution of the mass scattering efficiency $\left(\alpha_{\mathrm{S}}\right)$ is likely to depend on the initial size distribution of the $\mathrm{BB}$ aerosol particles, which may be very variable (Reid et al., 2005a). A smaller increase in $\alpha_{\mathrm{s}}$ would need to be compensated for by a larger enhancement of the OA concentration (and vice versa). This could be achieved in our simulations by assuming a larger weight for the functionalization (or, alternatively, fragmentation) pathway of the oxidation reactions. The evolution of POA and SOA can also depend on the phase state and viscosity of the particles. While we assume in our simulations that particles are liquid and inviscid, the critical temperature for the transition between the liquid and glassy states of the particles is estimated to be in the range of ambient temperatures in the boundary layer over Siberia (Shiraiwa et al., 2017), which is a complex function of ambient relative humidity and particle composition. Slow diffusion of organic molecules within highly viscous glassy or semi-solid particles could limit gas-particle interactions, thereby slowing down the POA and SOA evaporation (e.g., Kim et al., 2019; Vaden et al., 2011) but also effectively exposing larger quantities of SOA species to gas-phase photo- chemical processing. The gas-particle partitioning and evolution of organic species forming $\mathrm{BB}$ aerosol can also depend on the mixing state of POA and SOA species. While there is experimental evidence supporting our simplifying assumption that POA and SOA species form a well-mixed solution (Asa-Awuku et al., 2009), there is also evidence (Song et al., 2007) that POA and SOA form external mixtures. If POA and SOA species do not mix in the real BB aerosol and form two separate organic phases (as assumed, e.g., in Shrivastava et al., 2015), then our model is likely prone to overestimate the concentrations of both POA and SOA species in particles. Taking the phase state transition processes, particle viscosity, and possible scenarios concerning mixing of organic solutions into account would result in significant extensions of our simplified representation of BB aerosol aging. These extensions, which cannot be sufficiently constrained by available observations in Siberia, would probably require changes in the optimal values of the adjustable parameters and some other modifications (e.g., changes in the assumed volatility distribution or enthalpies of evaporation). However, we see no evidence in the literature that a more complex representation of $\mathrm{BB}$ aerosol could produce qualitative changes in the simulated dynamics of BB aerosol, and thus an application of such a representation would not likely invalidate the proposed qualitative interpretation of the "observed" changes in the BB aerosol optical properties.

One more potentially important factor that can affect the BB aerosol evolution in the real atmosphere but is not taken into account in our simulations is the photolysis of SOA species, especially in particles. Based on a very limited amount of experimental data on the quantum yields for photolytic reactions of organic species in the particle phase, Hodzic et al. (2015) estimated the in-particle photolysis rate of SOA as $0.04 \%$ of the photolysis rate of $\mathrm{NO}_{2}$ and found as a result of a global model simulation - that SOA photolysis can remove aerosol from the troposphere on timescales of several days. Although this mechanism of SOA removal is very uncertain, we cannot rule out the possibility that it significantly contributed to the SOA depletion in the analyzed situation. If that was the case, then the SOA fragmentation rate in our simulations is likely overestimated. However, it should be noted that if the in-particle SOA photolysis were a primary driver for the decrease in AOD in our analysis (see Fig. 5b), then the rate of the decrease in $E_{n R}$ ext would not be expected to strongly decelerate after about $70 \mathrm{~h}$, as it does according to Fig. 5b (presuming that SOA and linked water are actually predominant components of aged BB aerosol). Hence, a brief inspection of our results suggests that inparticle SOA photolysis could hardly be a principal cause for the decreasing part of the trend in EnR $\mathrm{ext}_{\text {. }}$.

The evolution of the imaginary refractive index of $\mathrm{BB}$ aerosol is also represented in our simulations in a very simplified way. Although we differentiate between several model species with respect to these properties, both primary and secondary real organic compounds are likely to feature a 
much wider spectrum of absorptive properties. Nonetheless, our interpretation will likely hold if the low-volatility SOA species formed in the real atmosphere from VOCs and POA as a result of a long chain of oxidation processes are much less absorptive than relatively fresh (and more volatile) SOA species. This assumption is supported by field observations (Forrister et al., 2015; Selimovic et al., 2019) and numerous laboratory experiments (e.g., Browne et al., 2019; Fan et al., 2019, Wong et al., 2017; 2019) indicating eventual bleaching of $\mathrm{BrC}$ in $\mathrm{BB}$ aerosol as a result of its exposure to atmospheric oxidation processes and UV radiation. One more important simplifying assumption involved in our simulations concerns the evolution of the optical properties of the SOA species: as noted above, we assume that the imaginary refractive index for a given "virtual" SOA species, which represents the molecular weight and volatility of its real counterparts, does not change as long as this species exists. This assumption is not true in a general case because the destruction of chromophores by UV irradiation or as aqueous heterogeneous oxidation is not necessarily associated with significant changes in the volatility or molecular weight of the affected compound. However, on the one hand, there is experimental evidence noted above (Fleming et al., 2020) that direct photodegradation of $\mathrm{BrC}$ in $\mathrm{BB}$ aerosol is a slow process with a characteristic timescale of at least several days, even though this observation, strictly speaking, applies only to fresh primary BB aerosol. On the other hand, aqueous heterogeneous oxidation can hardly be a significant process in our situation, in which water uptake by particles - as discussed above is typically small, although the effect of ambient relative humidity on the atmospheric evolution of $\mathrm{BrC}$ in $\mathrm{BB}$ aerosol has yet to be investigated.

Overall, this discussion suggests that although our model representation of $\mathrm{BB}$ aerosol evolution involves strong assumptions (which need to be verified in future research), our qualitative interpretation of the inferred major changes in the optical properties of BB aerosol in Siberia is sufficiently robust and realistic. In turn, the applicability of this interpretation corroborates the reliability of our major findings from the analysis of the satellite observations.

\section{Conclusions}

We have presented an analytical framework designed to advance the knowledge of changes in the optical properties of $\mathrm{BB}$ aerosol due to its atmospheric aging by using retrievals of AAOD, AOD, and SSA from satellite observations of BB plumes. This framework includes a method to evaluate nonlinear trends in the optical properties of BB aerosol due to oxidation and gas-particle partitioning processes at the temporal scale (typically, several days) associated with long-range transport of BB plumes. It also involves using adjustable simulations of the sources and atmospheric evolution of $\mathrm{BB}$ aerosol with a chemistry transport model to reproduce and interpret the inferred trends.

We used this framework to get insights into the evolution of BB aerosol optical properties during a pronounced episode of a large-scale outflow of BB smoke plumes from Siberia towards Europe that occurred in July 2016. The analysis was based on the use of OMI AAOD and SSA retrievals combined with MODIS AOD retrievals. These retrievals were used together with BB aerosol simulations and the $\mathrm{CO}$ columns derived from IASI observations to evaluate the enhancement ratios (EnRs) for AAOD and AOD, which allows for isolating the effects of oxidation and gas-particle partitioning processes from those of other processes, including transport, deposition, and wet scavenging. The simulations were performed with the CHIMERE chemistry transport model combined with the OPTSIM module, enabling evaluation of the BB aerosol optical properties under the assumption of a core-shell morphology of the particles. The $\mathrm{OA}$ oxidation and gas-particle partitioning processes were represented in the simulation in the framework of a highly simplified but adjustable VBS scheme. Importantly, the evolution of $\mathrm{BrC}$ was simulated consistently with the evolution of the POA and SOA species based on the assumptions that the POA species are much more absorptive in the near-UV wavelength range than the SOA species and that the imaginary refractive index for a given SOA virtual species is constant. The EnR estimates and SSA data were analyzed as a function of model-based estimates of the BB aerosol photochemical age, which in the situation considered is found to be strongly associated with the geographical location of a BB plume.

We found that, while the EnR for AAOD does not change significantly during the first $20-30 \mathrm{~h}$ of daytime evolution, the EnR for AOD strongly (by more than a factor of 2) increases during the same period. The increase in EnR for AOD is accompanied by a statistically significant increase in SSA. Note that the first few hours of the atmospheric evolution of BB aerosol are not covered by our analysis. Further atmospheric processing of BB aerosol (up to a photochemical age of about $100 \mathrm{~h}$ ) is found to be associated with statistically significant decreases (of about $45 \%$ ) in EnRs for both AAOD and AOD and insignificant changes in SSA. Note that while a similar increase in EnR for AOD was reported previously (Konovalov et al., 2017a), our findings concerning the simultaneous changes in both the absorption and extinction characteristics of BB aerosol are novel.

By adjusting the imaginary refractive indexes for the SOA species, a few parameters of the simplified VBS scheme, and the emission factors, our simulations were brought into close agreement with the observed AAOD and AOD values and with the trends in EnRs for both AAOD and AOD. The analysis of our simulation results suggests that the upward trend in EnR for AOD (which is associated with the initial increase in SSA) could be due to SOA formation and POA evaporation, leading to a major increase in the mass scattering effi- 
ciency of BB aerosol through modulation of the particle size distribution. Evaporation of semi-volatile SOA is indicated as a likely reason for the subsequent decrease in the EnR for both AAOD and AOD. We suggest that despite a highly simplified character of our representation of BB aerosol in our simulations, our conclusions regarding the basic factors behind the observed BB aerosol evolution are sufficiently robust. These factors need to be adequately taken into account in chemistry transport and climate models to ensure reliable simulations of the BB aerosol optical properties and accurate estimates of associated radiative effects, specifically in northern Eurasia. The proposed simplified representation of BB aerosol evolution can contribute to achieving such a goal, suggesting a reasonable compromise between overcomplexity unconstrained by available observations and oversimplicity leading to major biases in the simulation results.

Overall, this study has demonstrated that the presented analytical framework can help identify and interpret manifestations of the BB aerosol aging processes far beyond the timescales that can currently be addressed in aerosol chamber experiments. Although the application of the framework in the present study has been limited to a concrete episode of long-range transport of BB plumes, the proposed methods are sufficiently general that they can be used in many other studies of BB aerosol and applied to different sets of satellite data, including, for example, multi-spectral retrievals of aerosol absorptive properties from MISR (Multi-angle Imaging SpectroRadiometer) measurements (Junghenn Noyes et al., 2020). The framework was also shown to enable validation and optimization of model representations of BB aerosol evolution. Therefore, its future applications can help address current challenges associated with the representation of the evolution and optical properties of BB aerosol and its components in regional and global models (Shrivastava et al., 2017; Samset et al., 2018; Tsigaridis and Kanakidou, 2018; Konovalov et al., 2019).

Data availability. The OMAERUV data product (Torres, 2006) as well as the MOD04/MYD04 (Levy and Hsu, 2015) and MYD14/MOD14 datasets (Giglio and Justice, 2015a, b) are available from https://search.earthdata.nasa.gov/ (last access: 9 January 2021, NASA EarthData portal team, 2021). The CO column amounts retrieved from the IASI measurements (Clerbaux et al., 2009) are available from the ESPRI data center (http://cds-espri. ipsl.fr/etherTypo/index.php?id=1707\&L=1, last access: 9 January 2021, IASI team, 2021). The CHIMERE chemistry transport model (CHIMERE-2017) is available at http://www.lmd.polytechnique.fr/ chimere/ (last access: 30 October 2020, Menut, 2020), and the OPTSIM software is available at https://www.lmd.polytechnique. fr/optsim/ (last access: 9 January 2021, Menut, 2021 ).

Supplement. The supplement related to this article is available online at: https://doi.org/10.5194/acp-21-357-2021-supplement.
Author contributions. IBK and MB designed the study. IBK also designed the method to analyze satellite observations, contributed to the analysis of satellite and model data, and prepared the paper. $\mathrm{MB}$ also contributed to the discussion of the results and to the preparation of the paper. NAG contributed to the analysis of satellite observations and conducted part of the numerical experiments. MOA contributed to the discussion of the results and the preparation of the paper.

Competing interests. The authors declare that they have no conflict of interest.

Special issue statement. This article is part of the special issue "Pan-Eurasian Experiment (PEEX) - Part II". It is not associated with a conference.

Acknowledgements. The authors thank the anonymous reviewers for their helpful comments.

Financial support. The analysis and simulations of the BB aerosol evolution were supported by the Russian Science Foundation (grant agreement no. 19-77-20109). The development and validation of the simplified VBS scheme were performed with support from the Russian Foundation for Basic Research (grant no. 18-05-00911).

Review statement. This paper was edited by Sergey A. Nizkorodov and reviewed by three anonymous referees.

\section{References}

Agarwal, S., Aggarwal, S. G., Okuzawa, K., and Kawamura, K.: Size distributions of dicarboxylic acids, ketoacids, $\alpha$ dicarbonyls, sugars, WSOC, OC, EC and inorganic ions in atmospheric particles over Northern Japan: implication for long-range transport of Siberian biomass burning and East Asian polluted aerosols, Atmos. Chem. Phys., 10, 5839-5858, https://doi.org/10.5194/acp-10-5839-2010, 2010.

Ahern, A. T., Robinson, E. S., Tkacik, D. S., Saleh, R., Hatch, L. E., Barsanti, K. C., Stockwell, C. E., Yokelson, R. J., Presto, A. A., Robinson, A. L., Sullivan, R. C., and Donahue, N. M.: Production of secondary organic aerosol during aging of biomass burning smoke from fresh fuels and its relationship to VOC precursors, J. Geophys. Res., 124, 3583-3606, https://doi.org/10.1029/2018JD029068, 2019.

Ahn, C., Torres, O., and Jethva, H.: Assessment of OMI near-U aerosol optical depth over land, J. Geophys. Res.-Atmos., 119, 2457-2473, https://doi.org/10.1002/2013JD020188, 2014.

Akagi, S. K., Craven, J. S., Taylor, J. W., McMeeking, G. R., Yokelson, R. J., Burling, I. R., Urbanski, S. P., Wold, C. E., Seinfeld, J. H., Coe, H., Alvarado, M. J., and Weise, D. R.: Evolution of trace gases and particles emitted by a chaparral fire in California, At- 
mos. Chem. Phys., 12, 1397-1421, https://doi.org/10.5194/acp12-1397-2012, 2012.

Andreae, M. O. and Gelencsér, A.: Black carbon or brown carbon? The nature of light-absorbing carbonaceous aerosols, Atmos. Chem. Phys., 6, 3131-3148, https://doi.org/10.5194/acp-63131-2006, 2006.

Andreae, M. O., Afchine, A., Albrecht, R., Holanda, B. A., Artaxo, P., Barbosa, H. M. J., Borrmann, S., Cecchini, M. A., Costa, A., Dollner, M., Fütterer, D., Järvinen, E., Jurkat, T., Klimach, T., Konemann, T., Knote, C., Krämer, M., Krisna, T., Machado, L. A. T., Mertes, S., Minikin, A., Pöhlker, C., Pöhlker, M. L., Pöschl, U., Rosenfeld, D., Sauer, D., Schlager, H., Schnaiter, M., Schneider, J., Schulz, C., Spanu, A., Sperling, V. B., Voigt, C., Walser, A., Wang, J., Weinzierl, B., Wendisch, M., and Ziereis, H.: Aerosol characteristics and particle production in the upper troposphere over the Amazon Basin, Atmos. Chem. Phys., 18, 921-961, https://doi.org/10.5194/acp-18-921-2018, 2018.

Andreae, M. O.: Emission of trace gases and aerosols from biomass burning - an updated assessment, Atmos. Chem. Phys., 19, 8523-8546, https://doi.org/10.5194/acp-19-8523-2019, 2019.

Asa-Awuku, A., Miracolo, M. A., Kroll, J. H., Robinson, A. L., and Donahue, N. M.: Mixing and phase partitioning of primary and secondary organic aerosols, Geophys. Res. Lett., 36, L15827, https://doi.org/10.1029/2009GL039301, 2009.

Bekryaev, R. V., Polyakov, I. V., and Alexeev, V. A.: Role of polar amplification in long-term surface air temperature variations and modern Arctic warming, J. Clim., 23, 3888-3906, https://doi.org/10.1175/2010jcli3297.1, 2010.

Bessagnet, B., Menut, L., Curci, G., Hodzic, A., Guillaume, B., Liousse, C., Moukhtar, S., Pun, B., Seigneur, C., and Schulz, M.: Regional modeling of carbonaceous aerosols over Europe - Focus on Secondary Organic Aerosols, J. Atmos. Chem., 61, 175202, https://doi.org/10.1007/s10874-009-9129-2, 2008.

Bian, H. and Prather, M.: Fast-J2: Accurate simulation of stratospheric photolysis in global chemical models, J. Atmos. Chem., 41, 281-296, https://doi.org/10.1023/A:1014980619462, 2002.

Bian, Q., Jathar, S. H., Kodros, J. K., Barsanti, K. C., Hatch, L. E., May, A. A., Kreidenweis, S. M., and Pierce, J. R.: Secondary organic aerosol formation in biomass-burning plumes: theoretical analysis of lab studies and ambient plumes, Atmos. Chem. Phys., 17, 5459-5475, https://doi.org/10.5194/acp17-5459-2017, 2017.

Bond, T. C., Doherty, S. J., Fahey, D. W., Forster, P. M., Berntsen, T., DeAngelo, B. J., Flanner, M. G., Ghan, S., Kärcher, B., Koch, D., Kinne, S., Kondo, Y., Quinn, P. K., Sarofim, M. C., Schultz, M. G., Schulz, M., Venkataraman, C., Zhang, H., Zhang, S., Bellouin, N., Guttikunda, S. K., Hopke, P. K., Jacobson, M. Z., Kaiser, J. W., Klimont, Z., Lohmann, U., Schwarz, J. P., Shindell, D., Storelvmo, T., Warren, S. G., and Zender, C. S.: Bounding the role of black carbon in the climate system: A scientific assessment, J. Geophys. Res.-Atmos., 118, 5380-5552, https://doi.org/10.1002/jgrd.50171, 2013.

Brown, H., Liu, X., Feng, Y., Jiang, Y., Wu, M., Lu, Z., Wu, C., Murphy, S., and Pokhrel, R.: Radiative effect and climate impacts of brown carbon with the Community Atmosphere Model (CAM5), Atmos. Chem. Phys., 18, 17745-17768, https://doi.org/10.5194/acp-18-17745-2018, 2018.

Browne, E. C., Zhang, X., Franklin, J. P., Ridley, K. J., Kirchstetter, T. W., Wilson, K. R., Cappa, C. D., and Kroll, J. H.,
Effect of heterogeneous oxidative aging on light absorption by biomass burning organic aerosol, Aerosol Sci. Tech., 53, 663674, https://doi.org/10.1080/02786826.2019.1599321, 2019.

Ciarelli, G., El Haddad, I., Bruns, E., Aksoyoglu, S., Möhler, O., Baltensperger, U., and Prévôt, A. S. H.: Constraining a hybrid volatility basis-set model for aging of wood-burning emissions using smog chamber experiments: a box-model study based on the VBS scheme of the CAMx model (v5.40), Geosci. Model Dev., 10, 2303-2320, https://doi.org/10.5194/gmd-102303-2017, 2017.

Clarke, A. and Kapustin, V.: Hemispheric aerosol vertical profiles: Anthropogenic impacts on optical depth and cloud nuclei, Science, 329, 1488-1492, https://doi.org/10.1126/science.1188838, 2010.

Clerbaux, C., Boynard, A., Clarisse, L., George, M., Hadji-Lazaro, J., Herbin, H., Hurtmans, D., Pommier, M., Razavi, A., Turquety, S., Wespes, C., and Coheur, P.-F.: Monitoring of atmospheric composition using the thermal infrared IASI/MetOp sounder, Atmos. Chem. Phys., 9, 6041-6054, https://doi.org/10.5194/acp-96041-2009, 2009.

Cubison, M. J., Ortega, A. M., Hayes, P. L., Farmer, D. K., Day, D., Lechner, M. J., Brune, W. H., Apel, E., Diskin, G. S., Fisher, J. A., Fuelberg, H. E., Hecobian, A., Knapp, D. J., Mikoviny, T., Riemer, D., Sachse, G. W., Sessions, W., Weber, R. J., Weinheimer, A. J., Wisthaler, A., and Jimenez, J. L.: Effects of aging on organic aerosol from open biomass burning smoke in aircraft and laboratory studies, Atmos. Chem. Phys., 11, 12049-12064, https://doi.org/10.5194/acp-11-12049-2011, 2011.

Di Lorenzo, R. A., Washenfelder, R. A., Attwood, A. R., Guo, H., Xu, L., Ng, N. L., Weber, R. J., Baumann, K., Edgerton, E., and Young, C. J.: Molecular-size-separated brown carbon absorption for biomass-burning aerosol at multiple field sites, Environ. Sci. Technol., 51, 3128-3137, https://doi.org/10.1021/acs.est.6b06160, 2017.

Donahue, N. M., Robinson, A. L., Stanier, C. O., and Pandis, S. N.: Coupled partitioning, dilution, and chemical aging of semivolatile organics, Environ. Sci. Technol., 40, 2635-2643, https://doi.org/10.1021/es052297c, 2006.

Efron, B. and Tibshirani, R. J.: An introduction to the bootstrap, Chapman \& Hall, New York, 1993.

ESPRI: IASI retrievals, available at: http://cds-espri.ipsl.fr/ etherTypo/index.php?id=1707\&L=1, last access: 15 April 2020.

Evangeliou, N., Balkanski, Y., Hao, W. M., Petkov, A., Silverstein, R. P., Corley, R., Nordgren, B. L., Urbanski, S. P., Eckhardt, S., Stohl, A., Tunved, P., Crepinsek, S., Jefferson, A., Sharma, S., Nøjgaard, J. K., and Skov, H.: Wildfires in northern Eurasia affect the budget of black carbon in the Arctic - a 12-year retrospective synopsis (2002-2013), Atmos. Chem. Phys., 16, 75877604, https://doi.org/10.5194/acp-16-7587-2016, 2016.

Fan, X., Yu, X., Wang, Y., Xiao, X., Li, F., Xie, Y., Wei, S., Song, J., and Peng, P.: The aging behaviors of chromophoric biomass burning brown carbon during dark aqueous hydroxyl radical oxidation processes in laboratory studies, Atmos. Environ., 205, 918, https://doi.org/10.1016/j.atmosenv.2019.02.039, 2019.

Fleming, L. T., Lin, P., Roberts, J. M., Selimovic, V., Yokelson, R., Laskin, J., Laskin, A., and Nizkorodov, S. A.: Molecular composition and photochemical lifetimes of brown carbon chromophores in biomass burning organic aerosol, Atmos. 
Chem. Phys., 20, 1105-1129, https://doi.org/10.5194/acp-201105-2020, 2020.

Folberth, G. A., Hauglustaine, D. A., Lathière, J., and Brocheton, F.: Interactive chemistry in the Laboratoire de Météorologie Dynamique general circulation model: model description and impact analysis of biogenic hydrocarbons on tropospheric chemistry, Atmos. Chem. Phys., 6, 2273-2319, https://doi.org/10.5194/acp-6-2273-2006, 2006.

Forrister, H., Liu, J., Scheuer, E., Dibb, J., Ziemba, L., Thornhill, K. L., Anderson, B., Diskin, G., Perring, A. E., Schwarz, J. P., Campuzano-Jost, P., Day, D. A., Palm, B. B., Jimenez, J. L., Nenes, A., and Weber, R. J.: Evolution of brown carbon in wildfire plumes, Geophys. Res. Lett., 42, 4623-4630, https://doi.org/10.1002/2015GL063897, 2015.

George, M., Clerbaux, C., Hurtmans, D., Turquety, S., Coheur, P.F., Pommier, M., Hadji-Lazaro, J., Edwards, D. P., Worden, H., Luo, M., Rinsland, C., and McMillan, W.: Carbon monoxide distributions from the IASI/METOP mission: evaluation with other space-borne remote sensors, Atmos. Chem. Phys., 9, 8317-8330, https://doi.org/10.5194/acp-9-8317-2009, 2009.

Giglio, L. and Justice, C.: MOD14 MODIS/Terra Thermal Anomalies/ Fire 5-Min L2 Swath 1km V006 [Data set], NASA EOSDIS LP DAAC, https://doi.org/10.5067/MODIS/MOD14.006, 2015a.

Giglio, L. and Justice, C.: MYD14 MODIS/Aqua Therma Anomalies/Fire 5-Min L2 Swath $1 \mathrm{~km}$ V006 [Data set], NASA EOSDIS Land Processes DAAC, https://doi.org/10.5067/MODIS/MYD14.006, 2015b.

Gorchakov, G. I., Golitsyn, G. S., Sitnov, S. A., Karpov, A. V., Gorchakova, I. A., Gushchin, R. A., and Datsenko, O. I.: LargeScale Haze over Eurasia in July 2016, Dokl. Earth Sc., 482, 1212, https://doi.org/10.1134/S1028334X1809012X, 2018.

Guenther, A., Karl, T., Harley, P., Wiedinmyer, C., Palmer, P. I., and Geron, C.: Estimates of global terrestrial isoprene emissions using MEGAN (Model of Emissions of Gases and Aerosols from Nature), Atmos. Chem. Phys., 6, 3181-3210, https://doi.org/10.5194/acp-6-3181-2006, 2006.

Gupta, P., Doraiswamy, P., Levy, R., Pikelnaya, O., Maibach, J., Feenstra, B., Polidori, A., Kiros, F., and Mills, K. C.: Impact of California fires on local and regional air quality: the role of a low-cost sensor network and satellite observations, GeoHealth, 2, 172-181, https://doi.org/10.1029/2018GH000136, 2018.

Gustafsson, Ö. and Ramanathan, V.: Convergence on climate warming by black carbon aerosols, P. Natl. Acad. Sci. USA, 113, 4243-4245, https://doi.org/10.1073/pnas.1603570113, 2016.

Hao, W. M., Petkov, A., Nordgren, B. L., Corley, R. E., Silverstein, R. P., Urbanski, S. P., Evangeliou, N., Balkanski, Y., and Kinder, B. L.: Daily black carbon emissions from fires in northern Eurasia for 2002-2015, Geosci. Model Dev., 9, 4461-4474, https://doi.org/10.5194/gmd-9-4461-2016, 2016.

Hennigan, C. J., Miracolo, M. A., Engelhart, G. J., May, A. A., Presto, A. A., Lee, T., Sullivan, A. P., McMeeking, G. R., Coe, H., Wold, C. E., Hao, W.-M., Gilman, J. B., Kuster, W. C., de Gouw, J., Schichtel, B. A., Collett Jr., J. L., Kreidenweis, S. M., and Robinson, A. L.: Chemical and physical transformations of organic aerosol from the photo-oxidation of open biomass burning emissions in an environmental chamber, Atmos. Chem. Phys., 11, 7669-7686, https://doi.org/10.5194/acp11-7669-2011, 2011.
Hobbs, P. V. and Radke, L. F.: Cloud Condensation Nuclei from a Simulated Forest Fire, Science, 163, 279-280 https://doi.org/10.1126/science.163.3864.279, 1969

Hodshire, A. L., Bian, Q., Ramnarine, E., Lonsdale, C. R., Alvarado, M. J., Kreidenweis, S. M., Jathar, S. H., and Pierce, J. R.: More than emissions and chemistry: Fire size, dilution, and background aerosol also greatly influence near-field biomass burning aerosol aging, J. Geophys. Res.-Atmos., 124, 5589-5611, https://doi.org/10.1029/2018JD029674, 2019.

Hodzic, A., Jimenez, J. L., Madronich, S., Canagaratna, M. R., DeCarlo, P. F., Kleinman, L., and Fast, J.: Modeling organic aerosols in a megacity: potential contribution of semi-volatile and intermediate volatility primary organic compounds to secondary organic aerosol formation, Atmos. Chem. Phys., 10, 5491-5514, https://doi.org/10.5194/acp-10-5491-2010, 2010.

Hodzic, A., Madronich, S., Kasibhatla, P. S., Tyndall, G., Aumont, B., Jimenez, J. L., Lee-Taylor, J., and Orlando, J.: Organic photolysis reactions in tropospheric aerosols: effect on secondary organic aerosol formation and lifetime, Atmos. Chem. Phys., 15, 9253-9269, https://doi.org/10.5194/acp-15-9253-2015, 2015.

Holloway, T., Levy, H., and Kasibhatla, P.: Global distribution of carbon monoxide, J. Geophys. Res., 105, 12123-12147, https://doi.org/10.1029/1999JD901173, 2000.

Hornik, K., Stinchcombe, M., and White, H.: Multilayer feedforward networks are universal approximators, Neural Networks, 2, 359-366, 1989.

Hurtmans, D., Coheur, P.-F., Wespes, C., Clarisse, L., Scharf, O., Clerbaux, C., Hadji-Lazaro, J., George, M., and Turquety, S.: FORLI radiative transfer and retrieval code for IASI, J. Quant. Spectrosc. Ra., 113, 1391-1408, 2012, https://doi.org/10.1016/j.jqsrt.2012.02.036.

IASI Team: FORLI-CO, available at: https://cds-espri.ipsl.upmc.fr, last access: 9 January 2021.

Ikeda, K. and Tanimoto, H.: Exceedances of air quality standard level of PM2.5 in Japan caused by Siberian wildfires, Environ. Res. Lett., 10, 105001, https://doi.org/10.1088/17489326/10/10/105001, 2015.

Jacobson, M. Z.: Effects of biomass burning on climate, accounting for heat and moisture fluxes, black and brown carbon, and cloud absorption effects, J. Geophys. Res.-Atmos., 119, 89809002, https://doi.org/10.1002/2014JD021861, 2014.

Janssens-Maenhout, G., Crippa, M., Guizzardi, D., Dentener, F., Muntean, M., Pouliot, G., Keating, T., Zhang, Q., Kurokawa, J., Wankmüller, R., Denier van der Gon, H., Kuenen, J. J. P., Klimont, Z., Frost, G., Darras, S., Koffi, B., and Li, M.: HTAP_v2.2: a mosaic of regional and global emission grid maps for 2008 and 2010 to study hemispheric transport of air pollution, Atmos. Chem. Phys., 15, 11411-11432, https://doi.org/10.5194/acp-15-11411-2015, 2015.

Jen, C. N., Hatch, L. E., Selimovic, V., Yokelson, R. J., Weber, R., Fernandez, A. E., Kreisberg, N. M., Barsanti, K. C., and Goldstein, A. H.: Speciated and total emission factors of particulate organics from burning western US wildland fuels and their dependence on combustion efficiency, Atmos. Chem. Phys., 19, 1013-1026, https://doi.org/10.5194/acp-19-1013-2019, 2019.

Jethva, H. and Torres, O.: Satellite-based evidence of wavelengthdependent aerosol absorption in biomass burning smoke inferred from Ozone Monitoring Instrument, Atmos. Chem. Phys., 
11, 10541-10551, https://doi.org/10.5194/acp-11-10541-2011, 2011.

Jethva, H., Torres, O., and Ahn, C.: Global assessment of OMI aerosol single-scattering albedo using ground-based AERONET inversion, J. Geophys. Res.-Atmos., 119, 90209040, https://doi.org/10.1002/2014JD021672, 2014.

Jiang, Y., Lu, Z., Liu, X., Qian, Y., Zhang, K., Wang, Y., and Yang, X.-Q.: Impacts of global open-fire aerosols on direct radiative, cloud and surface-albedo effects simulated with CAM5, Atmos. Chem. Phys., 16, 14805-14824, https://doi.org/10.5194/acp-1614805-2016, 2016.

Jo, D. S., Park, R. J., Lee, S., Kim, S.-W., and Zhang, X.: A global simulation of brown carbon: implications for photochemistry and direct radiative effect, Atmos. Chem. Phys., 16, 3413-3432, https://doi.org/10.5194/acp-16-3413-2016, 2016.

Jolleys, M. D., Coe, H., McFiggans, G., Taylor, J. W., O’Shea, S. J., Le Breton, M., Bauguitte, S. J.-B., Moller, S., Di Carlo, P., Aruffo, E., Palmer, P. I., Lee, J. D., Percival, C. J., and Gallagher, M. W.: Properties and evolution of biomass burning organic aerosol from Canadian boreal forest fires, Atmos. Chem. Phys., 15, 3077-3095, https://doi.org/10.5194/acp-153077-2015, 2015.

Junghenn Noyes, K., Kahn, R., Sedlacek, A., Kleinman, L., Limbacher, J., and Li, Z.: Wildfire Smoke Particle Properties and Evolution, from Space-Based Multi-Angle Imaging, Remote Sens., 12, 769, https://doi.org/10.3390/rs12050769, 2020.

Keywood, M., Kanakidou, M., Stohl, A., Dentener, F., Grassi, G., Meyer, C. P., Torseth, K., Edwards, D., Thompson, A. M., Lohmann, U., and Burrows, J.: Fire in the air: biomass burning impacts in a changing climate, Crit. Rev. Env. Contr., 43, 4083, https://doi.org/10.1080/10643389.2011.604248, 2013.

Kim, Y., Sartelet, K., and Couvidat, F.: Modeling the effect of nonideality, dynamic mass transfer and viscosity on SOA formation in a 3-D air quality model, Atmos. Chem. Phys., 19, 1241-1261, https://doi.org/10.5194/acp-19-1241-2019, 2019.

Kleinman, L. I., Sedlacek III, A. J., Adachi, K., Buseck, P. R., Collier, S., Dubey, M. K., Hodshire, A. L., Lewis, E., Onasch, T. B., Pierce, J. R., Shilling, J., Springston, S. R., Wang, J., Zhang, Q., Zhou, S., and Yokelson, R. J.: Rapid evolution of aerosol particles and their optical properties downwind of wildfires in the western US, Atmos. Chem. Phys., 20, 13319-13341, https://doi.org/10.5194/acp-20-13319-2020, 2020.

Konovalov, I. B., Beekmann, M., Richter, A., Burrows, J. P., and Hilboll, A.: Multi-annual changes of NOx emissions in megacity regions: nonlinear trend analysis of satellite measurement based estimates, Atmos. Chem. Phys., 10, 8481-8498, https://doi.org/10.5194/acp-10-8481-2010, 2010.

Konovalov, I. B., Beekmann, M., Kuznetsova, I. N., Yurova, A., and Zvyagintsev, A. M.: Atmospheric impacts of the 2010 Russian wildfires: integrating modelling and measurements of an extreme air pollution episode in the Moscow region, Atmos. Chem. Phys., 11, 10031-10056, https://doi.org/10.5194/acp-11-100312011, 2011.

Konovalov, I. B., Beekmann, M., D’Anna, B., and George, C.: Significant light induced ozone loss on biomass burning aerosol: Evidence from chemistry-transport modeling based on new laboratory studies, Geophys. Res. Lett., 39, L17807, https://doi.org/10.1029/2012GL052432, 2012.
Konovalov, I. B., Berezin, E. V., Ciais, P., Broquet, G., Beekmann, M., Hadji-Lazaro, J., Clerbaux, C., Andreae, M. O., Kaiser, J. W., and Schulze, E.-D.: Constraining $\mathrm{CO}_{2}$ emissions from open biomass burning by satellite observations of co-emitted species: a method and its application to wildfires in Siberia, Atmos. Chem. Phys., 14, 10383-10410, https://doi.org/10.5194/acp-14-103832014, 2014.

Konovalov, I. B., Beekmann, M., Berezin, E. V., Petetin, H., Mielonen, T., Kuznetsova, I. N., and Andreae, M. O.: The role of semi-volatile organic compounds in the mesoscale evolution of biomass burning aerosol: a modeling case study of the 2010 mega-fire event in Russia, Atmos. Chem. Phys., 15, 1326913297, https://doi.org/10.5194/acp-15-13269-2015, 2015.

Konovalov, I. B., Berezin, E. V., Ciais, P., Broquet, G., Zhuravlev, R. V., and Janssens-Maenhout, G.: Estimation of fossil-fuel $\mathrm{CO} 2$ emissions using satellite measurements of "proxy" species, Atmos. Chem. Phys., 16, 13509-13540, https://doi.org/10.5194/acp-16-13509-2016, 2016.

Konovalov, I. B., Beekmann, M., Berezin, E. V., Formenti, P., and Andreae, M. O.: Probing into the aging dynamics of biomass burning aerosol by using satellite measurements of aerosol optical depth and carbon monoxide, Atmos. Chem. Phys., 17, 45134537, https://doi.org/10.5194/acp-17-4513-2017, 2017a.

Konovalov, I. B., Lvova, D. A., and Beekmann, M.: Estimation of the elemental to organic carbon ratio in biomass burning aerosol using AERONET retrievals, Atmosphere, 8, 122, https://doi.org/10.3390/atmos8070122, 2017b.

Konovalov, I. B., Lvova, D. A., Beekmann, M., Jethva, H., Mikhailov, E. F., Paris, J.-D., Belan, B. D., Kozlov, V. S., Ciais, P., and Andreae, M. O.: Estimation of black carbon emissions from Siberian fires using satellite observations of absorption and extinction optical depths, Atmos. Chem. Phys., 18, 1488914924, https://doi.org/10.5194/acp-18-14889-2018, 2018.

Konovalov, I. B., Beekmann, M., Golovushkin, N. A., and Andreae, M. O.: Nonlinear behavior of organic aerosol in biomass burning plumes: a microphysical model analysis, Atmos. Chem. Phys., 19, 12091-12119, https://doi.org/10.5194/acp-19-120912019, 2019.

Kroll, J. H., Ng, N. L., Murphy, S. M., Flagan, R. C., and Seinfeld, J. H.: Secondary organic aerosol formation from isoprene photooxidation, Environ. Sci. Technol., 40, 1869-1877, https://doi.org/10.1021/es0524301, 2006.

Kumar, N. K., Corbin, J. C., Bruns, E. A., Massabó, D., Slowik, J. G., Drinovec, L., Močnik, G., Prati, P., Vlachou, A., Baltensperger, U., Gysel, M., El-Haddad, I., and Prévôt, A. S. H.: Production of particulate brown carbon during atmospheric aging of residential wood-burning emissions, Atmos. Chem. Phys., 18, 17843-17861, https://doi.org/10.5194/acp-18-178432018, 2018.

Lack, D. A. and Cappa, C. D.: Impact of brown and clear carbon on light absorption enhancement, single scatter albedo and absorption wavelength dependence of black carbon, Atmos. Chem. Phys., 10, 4207-4220, https://doi.org/10.5194/acp10-4207-2010, 2010.

Laing, J. R., Jaffe, D. A., and Hee, J. R.: Physical and optical properties of aged biomass burning aerosol from wildfires in Siberia and the Western USA at the Mt. Bachelor Observatory, Atmos. Chem. Phys., 16, 15185-15197, https://doi.org/10.5194/acp-1615185-2016, 2016. 
Lambe, A. T., Onasch, T. B., Massoli, P., Croasdale, D. R., Wright, J. P., Ahern, A. T., Williams, L. R., Worsnop, D. R., Brune, W. H., and Davidovits, P.: Laboratory studies of the chemical composition and cloud condensation nuclei $(\mathrm{CCN})$ activity of secondary organic aerosol (SOA) and oxidized primary organic aerosol (OPOA), Atmos. Chem. Phys., 11, 8913-8928, https://doi.org/10.5194/acp-11-8913-2011, 2011.

Laskin, A., Laskin, J., and Nizkorodov, S. A., Chemistry of atmospheric brown carbon: Chem. Rev., 115, 4335-4382, https://doi.org/10.1021/cr5006167, 2015.

Lelieveld, J., Pozzer, A., Pöschl, U., Fnais, M., Haines, A., and Münzel, T., Loss of life expectancy from air pollution compared to other risk factors: a worldwide perspective, Cardiovasc. Res., https://doi.org/10.1093/cvr/cvaa025, 2020.

Levelt, P. F., Hilsenrath, E., Leppelmeier, G. W., van den Oord, G. H. J., Bhartia, P. K., Tamminen, J., de Haan, J. F., and Veefkind, J. P.: Science objectives of the ozone monitoring instrument, IEEE T. Geosci. Remote, 44, 1199-1208, https://doi.org/10.1109/TGRS.2006.872336, 2006.

Levin, E. J. T., McMeeking, G. R., Carrico, C. M., Mack, L. E., Kreidenweis, S. M., Wold, C. E., Moosmuller, H., Arnott, W. P., Hao, W. M., Collett, J. L., and Malm, W. C., Biomass burning smoke aerosol properties measured during Fire Laboratory at Missoula Experiments (FLAME), J. Geophys. Res., 115, D18210, https://doi.org/10.1029/2009jd013601, 2010.

Levy, R. C., Remer, L. A., Kleidman, R. G., Mattoo, S., Ichoku, C., Kahn, R., and Eck, T. F.: Global evaluation of the Collection 5 MODIS dark-target aerosol products over land, Atmos. Chem. Phys., 10, 10399-10420, https://doi.org/10.5194/acp-10-103992010, 2010.

Levy, R. C., Mattoo, S., Munchak, L. A., Remer, L. A., Sayer, A. M., Patadia, F., and Hsu, N. C.: The Collection 6 MODIS aerosol products over land and ocean, Atmos. Meas. Tech., 6, 29893034, https://doi.org/10.5194/amt-6-2989-2013, 2013.

Levy, R. and Hsu, C.: MODIS Atmosphere L2 Aerosol Product, NASA MODIS Adaptive Processing System, Goddard Space Flight Center, USA, available at: https://doi.org/10.5067/MODIS/MYD04_L2.006, 2015.

Li, C., He, Q., Schade, J., Passig, J., Zimmermann, R., Meidan, D., Laskin, A., and Rudich, Y.: Dynamic changes in optical and chemical properties of tar ball aerosols by atmospheric photochemical aging, Atmos. Chem. Phys., 19, 139-163, https://doi.org/10.5194/acp-19-139-2019, 2019.

Lim, C. Y., Hagan, D. H., Coggon, M. M., Koss, A. R., Sekimoto, K., de Gouw, J., Warneke, C., Cappa, C. D., and Kroll, J. H.: Secondary organic aerosol formation from the laboratory oxidation of biomass burning emissions, Atmos. Chem. Phys., 19, 1279712809, https://doi.org/10.5194/acp-19-12797-2019, 2019.

Liu, D., Whitehead, J., Alfarra, M. R., Reyes-Villegas, E., Spracklen, D. V., Reddington, C. L., Kong, S., Williams, P. I., Ting, Y.-C., Haslett, S., Taylor, J. W., Flynn, M. J., Morgan, W. T., McFiggans, G., Coe, H., and Allan, J. D.: Blackcarbon absorption enhancement in the atmosphere determined by particle mixing state, Nat. Geosci., 10, 184-188, https://doi.org/10.1038/ngeo2901, 2017.

Liu, S., Aiken, A. C., Arata, C., Dubey, M. K., Stockwell, C. E., Yokelson, R. J., Stone, E. A., Jayarathne, T., Robinson, A. L., DeMott, P. J., and Kreidenweis, S. M.: Aerosol single scattering albedo dependence on biomass combustion efficiency: Lab- oratory and field studies, Geophys. Res. Lett., 41, 742-748, https://doi.org/10.1002/2013GL058392, 2014.

Lu, Zi., Streets, D. G., Winijkul, E., Yan, F., Chen, Y., Bond, T. C., Feng, Y., Dubey, M. K., Liu, S., Pinto, J. P., and Carmichael, G. R.: Light absorption properties and radiative effects of primary organic aerosol emissions, Environ. Sci. Technol., 49, 48684877, https://doi.org/10.1021/acs.est.5b00211, 2015.

Lu, Z., Liu, X., Zhang, Z., Zhao, C., Meyer, K., Rajapakshe, C., Wu, C., Yang, Z., and Penner, J. E.: Biomass smoke from southern Africa can significantly enhance the brightness of stratocumulus over the southeastern Atlantic Ocean, P. Natl. Acad. Sci. USA, 115, 2924-2929, https://doi.org/10.1073/pnas.1713703115, 2018.

Mailler, S., Menut, L., Khvorostyanov, D., Valari, M., Couvidat, F., Siour, G., Turquety, S., Briant, R., Tuccella, P., Bessagnet, B., Colette, A., Létinois, L., Markakis, K., and Meleux, F.: CHIMERE-2017: from urban to hemispheric chemistrytransport modeling, Geosci. Model Dev., 10, 2397-2423, https://doi.org/10.5194/gmd-10-2397-2017, 2017.

Majdi, M., Turquety, S., Sartelet, K., Legorgeu, C., Menut, L., and Kim, Y.: Impact of wildfires on particulate matter in the EuroMediterranean in 2007: sensitivity to some parameterizations of emissions in air quality models, Atmos. Chem. Phys., 19, 785812, https://doi.org/10.5194/acp-19-785-2019, 2019.

Matsui, H., Koike, M., Kondo, Y., Oshima, N., Moteki, N., Kanaya, Y., Takami, A., and Irwin, M.: Seasonal variations of Asian black carbon outflow to the Pacific: contribution from anthropogenic sources in China and biomass burning sources in Siberia and Southeast Asia, J. Geophys. Res.-Atmos., 118, 9948-9967, https://doi.org/10.1002/jgrd.50702, 2013.

May, A. A., Levin, E. J. T., Hennigan, C. J., Riipinen, I., Lee, T., Collett Jr., J. L., Jimenez, J. L., Kreidenweis, S. M., and Robinson, A. L.: Gas-particle partitioning of primary organic aerosol emissions: 3. Biomass burning, J. Geophys. Res.-Atmos., 118, 11327-11338, https://doi.org/10.1002/jgrd.50828, 2013.

May, A. A., McMeeking, G. R., Lee, T., Taylor, J. W., Craven, J. S., Burling, I., Sullivan, A. P., Akagi, S., Collett, J. L., Flynn, M., Coe, H., Urbanski, S. P., Seinfeld, J. H., Yokelson, R. J., and Kreidenweis, S. M.: Aerosol emissions from prescribed fires in the United States: A synthesis of laboratory and aircraft measurements, J. Geophys. Res.-Atmos., 119, 11826-11849, https://doi.org/10.1002/2014JD021848, 2014.

May, A. A., Lee, T., McMeeking, G. R., Akagi, S., Sullivan, A. P., Urbanski, S., Yokelson, R. J., and Kreidenweis, S. M.: Observations and analysis of organic aerosol evolution in some prescribed fire smoke plumes, Atmos. Chem. Phys., 15, 6323-6335, https://doi.org/10.5194/acp-15-6323-2015, 2015.

Mazzoni, D., Logan, J. A., Diner, D., Kahn, R. A., Tong, L., and Li, Q.: A data-mining approach to associating MISR smoke plume heights with MODIS fire measurements, Remote Sens. Environ., 107, 138-148, https://doi.org/10.1016/j.rse.2006.08.014, 2007.

McClure, C. D., Lim, C. Y., Hagan, D. H., Kroll, J. H., and Cappa, C. D.: Biomass-burning-derived particles from a wide variety of fuels - Part 1: Properties of primary particles, Atmos. Chem. Phys., 20, 1531-1547, https://doi.org/10.5194/acp20-1531-2020, 2020.

McMeeking, G. R., Kreidenweis, S. M., Baker, S., Carrico, C. M., Chow, J. C., Collett, J. L., Hao, W. M., Holden, A. S., Kirchstetter, T. W., Malm, W. C., Moosmuller, H., Sullivan, A. P., and 
Wold, C. E.: Emissions of trace gases and aerosols during the open combustion of biomass in the laboratory, J. Geophys. Res., 114, D19210, https://doi.org/10.1029/2009jd011836, 2009.

Menut, L., Bessagnet, B., Khvorostyanov, D., Beekmann, M., Blond, N., Colette, A., Coll, I., Curci, G., Foret, G., Hodzic, A., Mailler, S., Meleux, F., Monge, J.-L., Pison, I., Siour, G., Turquety, S., Valari, M., Vautard, R., and Vivanco, M. G.: CHIMERE 2013: a model for regional atmospheric composition modelling, Geosci. Model Dev., 6, 981-1028, https://doi.org/10.5194/gmd-6-981-2013, 2013.

Menut, L.: CHIMERE: A multi-scale chemistry-transport model for atmospheric composition analysis and forecast, available at: https://www.lmd.polytechnique.fr/chimere/, last access: 30 October 2020.

Menut, L.: OPTSIM: A numerical tool for gas and particles radiative properties modeling, available at: https://www.lmd. polytechnique.fr/optsim/, last access: 9 January 2021.

Mikhailov, E. F., Mironova, S., Mironov, G., Vlasenko, S., Panov, A., Chi, X., Walter, D., Carbone, S., Artaxo, P., Heimann, M., Lavric, J., Pöschl, U., and Andreae, M. O.: Long-term measurements (2010-2014) of carbonaceous aerosol and carbon monoxide at the Zotino Tall Tower Observatory (ZOTTO) in central Siberia, Atmos. Chem. Phys., 17, 14365-14392, https://doi.org/10.5194/acp-17-14365-2017, 2017.

Mok, J., Krotkov, N. A., Arola, A., Torres, O., Jethva, H., Andrade, M., Labow, G., Eck, T. F., Li, Z., Dickerson, R. R., Stenchikov, G. L., Osipov, S., and Ren, X.: Impacts of brown carbon from biomass burning on surface UV and ozone photochemistry in the Amazon Basin, Sci. Rep.-UK, 6, 36940, https://doi.org/10.1038/srep36940, 2016.

Morgan, W. T., Allan, J. D., Bauguitte, S., Darbyshire, E., Flynn, M. J., Lee, J., Liu, D., Johnson, B., Haywood, J., Longo, K. M., Artaxo, P. E., and Coe, H.: Transformation and ageing of biomass burning carbonaceous aerosol over tropical South America from aircraft in situ measurements during SAMBBA, Atmos. Chem. Phys., 20, 5309-5326, https://doi.org/10.5194/acp20-5309-2020, 2020.

NASA EarthData portal team: EarthData data portal, available at: https://earthdata.nasa.gov, last access 9 January 2021.

NCEP: NCEP FNL Operational Model Global Tropospheric Analyses, continuing from July 1999, available at: https://rda.ucar.edu/ datasets/ds083.2/, https://doi.org/10.5065/D6M043C6 (last access: 1 April 2020), 2017.

Nenes, A., Pandis, S. N., and Pilinis, C.: ISORROPIA: A new thermodynamic model for inorganic multicomponent atmospheric aerosols, Aquatic Geochem., 4, 123-152, https://doi.org/10.1023/A:1009604003981, 1998.

Omar, A. H., Winker, D. M., Vaughan, M. A., Hu, Y., Trepte, C. R., Ferrare, R. A., Lee, K. P., Hostetler, C. A., Kittaka, C., Rogers, R. R., and Kuehn, R. E.: The CALIPSO Automated Aerosol Classification and Lidar Ratio Selection Algorithm, J. Atmos. Ocean. Tech., 26, 1994-2014, https://doi.org/10.1175/2009JTECHA1231.1, 2009.

Oris, F., Asselin, H., Ali, A., Finsinger, W., and Bergeron, Y.: Effect of increased fire activity on global warming in the boreal forest, Environ. Rev., 22, 206-219, https://doi.org/10.1139/er-20130062, 2014.

Park, R. J., Kim, M. J., Jeong, J. I., Youn, D., and Kim, S.: A contribution of brown carbon aerosol to the aerosol light absorption and its radiative forcing in East Asia, Atmos. Environ., 44, 14141421, 2010.

Péré, J. C., Bessagnet, B., Mallet, M., Waquet, F., Chiapello, I., Minvielle, F., Pont, V., and Menut, L.: Direct radiative effect of the Russian wildfires and its impact on air temperature and atmospheric dynamics during August 2010, Atmos. Chem. Phys., 14, 1999-2013, https://doi.org/10.5194/acp-14-1999-2014, 2014.

Petrenko, M., Kahn, R., Chin, M., Soja, A., Kucsera, T., and Harshvardhan: The use of satellite-measured aerosol optical depth to constrain biomass burning emissions source strength in the global model GOCART, J. Geophys. Res., 117, D18212, https://doi.org/10.1029/2012JD017870, 2012.

Petters, M. D. and Kreidenweis, S. M.: A single parameter representation of hygroscopic growth and cloud condensation nucleus activity, Atmos. Chem. Phys., 7, 1961-1971, https://doi.org/10.5194/acp-7-1961-2007, 2007.

Petters, M. D., Carrico, C. M., Kreidenweis, S. M., Prenni, A. J., DeMott, P. J., Collett, J. L., and Moosmuller, H.: Cloud condensation nucleation activity of biomass burning aerosol, J. Geophys. Res., 114, D22205, https://doi.org/10.1029/2009JD012353, 2009.

Pokhrel, R. P., Beamesderfer, E. R., Wagner, N. L., Langridge, J. M., Lack, D. A., Jayarathne, T., Stone, E. A., Stockwell, C. E., Yokelson, R. J., and Murphy, S. M.: Relative importance of black carbon, brown carbon, and absorption enhancement from clear coatings in biomass burning emissions, Atmos. Chem. Phys., 17, 5063-5078, https://doi.org/10.5194/acp-17-5063-2017, 2017.

Press, W. H., Teukolsky, S. A., Vetterling, W. T., and Flannery, B. P.: Numerical Recipes, 2nd edition, Cambridge University Press, Cambridge, 1992.

Reddington, C. L., Spracklen, D. V., Artaxo, P., Ridley, D. A., Rizzo, L. V., and Arana, A.: Analysis of particulate emissions from tropical biomass burning using a global aerosol model and long-term surface observations, Atmos. Chem. Phys., 16, 1108311106, https://doi.org/10.5194/acp-16-11083-2016, 2016.

Reid, J. S., Koppmann, R., Eck, T. F., and Eleuterio, D. P.: A review of biomass burning emissions part II: intensive physical properties of biomass burning particles, Atmos. Chem. Phys., 5, 799825, https://doi.org/10.5194/acp-5-799-2005, 2005a.

Reid, J. S., Eck, T. F., Christopher, S. A., Koppmann, R., Dubovik, O., Eleuterio, D. P., Holben, B. N., Reid, E. A., and Zhang, J.: A review of biomass burning emissions part III: intensive optical properties of biomass burning particles, Atmos. Chem. Phys., 5, 827-849, https://doi.org/10.5194/acp-5-827-2005, 2005b.

Robinson, A. L., Donahue, N. M., Shrivastava, M. K., Weitkamp, E. A., Sage, A. M., Grieshop, A. P., Lane, T. E., Pierce, J. R., and Pandis, S. N.: Rethinking organic aerosols: Semivolatile emissions and photochemical aging, Science, 315, 1259-1262, https://doi.org/10.1126/science.1133061, 2007.

Sakamoto, K. M., Allan, J. D., Coe, H., Taylor, J. W., Duck, T. J., and Pierce, J. R.: Aged boreal biomass-burning aerosol size distributions from BORTAS 2011, Atmos. Chem. Phys., 15, 16331646, https://doi.org/10.5194/acp-15-1633-2015, 2015.

Saleh, R., Hennigan, C. J., McMeeking, G. R., Chuang, W. K., Robinson, E. S., Coe, H., Donahue, N. M., and Robinson, A. L.: Absorptivity of brown carbon in fresh and photo-chemically aged biomass-burning emissions, Atmos. Chem. Phys., 13, 76837693, https://doi.org/10.5194/acp-13-7683-2013, 2013. 
Saleh, R., Robinson, E. S., Tkacik, D. S., Ahern, A. T., Liu, S., Aiken, A. C., Sullivan, R. C., Presto, A. A., Dubey, M. K., Yokelson, R. J., Donahue, N. M., and Robinson, A. L.: Brownness of organics in aerosols from biomass burning linked to their black carbon content, Nat. Geosci., 7, 647-650, https://doi.org/10.1038/ngeo2220, 2014.

Saleh, R., Marks, M., Heo, J., Adams, P. J., Donahue, N. M., and Robinson, A. L.: Contribution of brown carbon and lensing to the direct radiative effect of carbonaceous aerosols from biomass and biofuel burning emissions, J. Geophys. Res.-Atmos., 120, 10285-10296, 2015.

Salomonson, V. V., Barnes, W. L., Maymon, P. W., Montgomery, H. E., and Ostrow, H.: MODIS: advanced facility instrument for studies of the Earth as a system, IEEE T. Geosci. Remote, 27, 145-153, 1989.

Samset, B. H., Stjern, C. W., Andrews, E., Kahn, R. A., Myhre, G., Schulz, M., and Schuster, G. L.: Aerosol absorption: progress towards global and regional constraints, Curr. Clim. Change Rep., 4, 65-83, 2018.

Sand, M., Berntsen, T., von Salzen, K., Flanner, M., Langner, J., and Victor, D.: Response of Arctic temperature to changes in emissions of short-lived climate forcers, Nat. Clim. Change, 6 , 286-289, https://doi.org/10.1038/nclimate2880, 2015.

Schepaschenko, D., McCallum, I., Shvidenko, A., Steffen, F., Kraxner, F., and Obersteiner, M.: A new hybrid land cover dataset for Russia: a methodology for integrating statistics, remote sensing and in-situ information, J. Land Use Sci., 6, 245-259, 2011.

Schmidt, H. C., Derognat, C., Vautard, R., and Beekmann, M.: A comparison of simulated and observed ozone mixing ratios for the summer of 1998 in western Europe, Atmos. Environ., 35, 6277-6297, https://doi.org/10.1016/S1352-2310(01)004514, 2001.

Schulze, E.-D., Wirth, C., Mollicone, D., von Lüpke, N., Ziegler, W., Achard, F., Mund, M., Prokushkin, A., and Scherbina, S.: Factors promoting larch dominance in central Siberia: fire versus growth performance and implications for carbon dynamics at the boundary of evergreen and deciduous conifers, Biogeosciences, 9, 1405-1421, https://doi.org/10.5194/bg-9-1405-2012, 2012.

Selimovic, V., Yokelson, R. J., McMeeking, G. R., and Coefield, S.: In situ measurements of trace gases, PM, and aerosol optical properties during the $2017 \mathrm{NW}$ US wildfire smoke event, Atmos. Chem. Phys., 19, 3905-3926, https://doi.org/10.5194/acp19-3905-2019, 2019.

Shi, S., Cheng, T., Gu X., Guo, H., Wu, Y., and Wang, Y.: Biomass burning aerosol characteristics for different vegetation types in different aging periods, Environ. Int., 126, 504-511, https://doi.org/10.1016/j.envint.2019.02.073, 2019.

Shiraiwa, M., Li, Y., Tsimpidi, A. P., Karydis, V. A., Berkemeier, T., Pandis, S. N., Lelieveld, J., Koop, T., and Pöoschl, U.: Global distribution of particle phase state in atmospheric secondary organic aerosols, Nat. Commun., 8, 15002, https://doi.org/10.1038/ncomms15002, 2017.

Shrivastava, M., Easter, R., Liu, X., Zelenyuk, A., Singh, B., Zhang, K., Ma, P-L, Chand, D., Ghan, S., Jimenez, J. L., Zhang, Q., Fast, J., Rasch, P., and Tiitta, P.: Global transformation and fate of SOA: Implications of low volatility SOA and gas phase fragmentation reactions, J. Geophys. Res.-Atmos., 120, 4169-4195, https://doi.org/10.1002/2014JD022563, 2015.
Shrivastava, M., Cappa, C., Fan, J., Goldstein, A., Guenther, A., Jimenez, J., Kuang, C., Laskin, A., Martin, S., Ng, N., Petaja, T., Pierce, J., Rasch, P., Roldin, P., Seinfeld, J., Shilling, J., Smith, J., Thornton, J., Volkamer, R., Wang, J., Worsnop, D., Zaveri, R., Zelenyuk, A., and Zhang, Q.: Recent advances in understanding secondary organic aerosol: Implications for global climate forcing, Rev. Geophys., 55, 509-559, https://doi.org/10.1002/2016RG000540, 2017.

Sitnov, S. A., Mokhov, I. I., Gorchakov, G. I., Dzhola, A. V.: Smoke haze over the European part of Russia in the summer of 2016: A link to wildfires in Siberia and atmospheric circulation anomalies, Russ. Meteorol. Hydrol., 42, 518, https://doi.org/10.3103/S1068373917080052, 2017.

Sitnov, S. A., Mokhov, I. I., and Likhosherstova, A. A.: Exploring large-scale blackcarbon air pollution over Northern Eurasia in summer 2016 using MERRA-2 reanalysis data, Atmos. Res., 235, 104763, https://doi.org/10.1016/j.atmosres.2019.104763, 2020.

Skamarock, W. C., Klemp, J. B., Dudhia, J., Gill, D. O., Barker, D. M., Duda, M. G., Huang, X.-Y., Wang, W., and Powers, J. G.: A Description of the advanced research WRF version 3, NCAR Tech. Notes-475CSTR, Boulder, Colorado, USA, 113 pp., 2008.

Sofiev, M., Ermakova, T., and Vankevich, R.: Evaluation of the smoke-injection height from wild-land fires using remote-sensing data, Atmos. Chem. Phys., 12, 1995-2006, https://doi.org/10.5194/acp-12-1995-2012, 2012.

Sofiev, M., Vankevich, R., Ermakova, T., and Hakkarainen, J.: Global mapping of maximum emission heights and resulting vertical profiles of wildfire emissions, Atmos. Chem. Phys., 13, 7039-7052, https://doi.org/10.5194/acp-13-7039-2013, 2013.

Song, C., Zaveri, R. A., Alexander, M. L., Thornton, J. A., Madronich, S., Ortega, J. V., Zelenyuk, A., Yu, X.-Y., Laskin, A., and Maughan, D. A.: Effect of hydrophobic primary organic aerosols on secondary organic aerosol formation from ozonolysis of $\alpha$-pinene, Geophys. Res. Lett., 34, L20803, https://doi.org/10.1029/2007GL030720, 2007.

Stromatas, S., Turquety, S., Menut, L., Chepfer, H., Péré, J. C., Cesana, G., and Bessagnet, B.: Lidar signal simulation for the evaluation of aerosols in chemistry transport models, Geosci. Model Dev., 5, 1543-1564, https://doi.org/10.5194/gmd-5-1543-2012, 2012.

Sumlin, B. J., Pandey, A., Walker, M. J., Pattison, R. S., Williams, B. J., and Chakrabarty, R. K.: Atmospheric photooxidation diminishes light absorption by primary brown carbon aerosol from biomass burning, Environ. Sci. Tech. Lett., 4, 540-545, https://doi.org/10.1021/acs.estlett.7b00393, 2017.

Taylor, J. W., Wu, H., Szpek, K., Bower, K., Crawford, I., Flynn, M. J., Williams, P. I., Dorsey, J., Langridge, J. M., Cotterell, M. I., Fox, C., Davies, N. W., Haywood, J. M., and Coe, H.: Absorption closure in highly aged biomass burning smoke, Atmos. Chem. Phys., 20, 11201-11221, https://doi.org/10.5194/acp-20-112012020, 2020.

Thornberry, T., Froyd, K. D., Murphy, D. M., Thomson, D. S., Anderson, B. E., Thornhill, K. L., and Winstead, E. L.: Persistence of organic carbon in heated aerosol residuals measured during Tropical Composition Cloud and Climate Coupling (TC4), J. Geophys. Res., 115, D00J02, https://doi.org/10.1029/2009jd012721, 2010. 
Tiitta, P., Leskinen, A., Hao, L., Yli-Pirilä, P., Kortelainen, M., Grigonyte, J., Tissari, J., Lamberg, H., Hartikainen, A., Kuuspalo, K., Kortelainen, A.-M., Virtanen, A., Lehtinen, K. E. J., Komppula, M., Pieber, S., Prévôt, A. S. H., Onasch, T. B., Worsnop, D. R., Czech, H., Zimmermann, R., Jokiniemi, J., and Sippula, O.: Transformation of logwood combustion emissions in a smog chamber: formation of secondary organic aerosol and changes in the primary organic aerosol upon daytime and nighttime aging, Atmos. Chem. Phys., 16, 13251-13269, https://doi.org/10.5194/acp-16-13251-2016, 2016.

Tsimpidi, A. P., Karydis, V. A., Pozzer, A., Pandis, S. N., and Lelieveld, J.: ORACLE 2-D (v2.0): an efficient module to compute the volatility and oxygen content of organic aerosol with a global chemistry-climate model, Geosci. Model Dev., 11, 33693389, https://doi.org/10.5194/gmd-11-3369-2018, 2018.

Toon, O. and Ackerman, T.: Algorithms for the calculation of scattering by stratified spheres, Appl. Optics, 20, 3657-3660, 1981.

Torres, O. O.: OMI/Aura Near UV Aerosol Optical Depth and Single Scattering Albedo 1-orbit L2 Swath 1324km V003, Greenbelt, MD, USA, Goddard Earth Sciences Data and Information Services Center (GES DISC), https://doi.org/10.5067/Aura/OMI/DATA2004, 2006.

Torres, O., Tanskanen, A., Veihelmann, B., Ahn, C., Braak, R., Bhartia, P. K., Veefkind, P., and Levelt, P.: Aerosols and surface UV products from Ozone Monitoring Instrument observations: An overview, J. Geophys. Res., 112, D24S47, https://doi.org/10.1029/2007JD008809, 2007.

Torres, O., Ahn, C., and Chen, Z.: Improvements to the OMI near-UV aerosol algorithm using A-train CALIOP and AIRS observations, Atmos. Meas. Tech., 6, 3257-3270, https://doi.org/10.5194/amt-6-3257-2013, 2013.

Tosca, M. G., Randerson, J. T., and Zender, C. S.: Global impact of smoke aerosols from landscape fires on climate and the Hadley circulation, Atmos. Chem. Phys., 13, 5227-5241, https://doi.org/10.5194/acp-13-5227-2013, 2013.

Tsigaridis, K. and Kanakidou, M.: The Present and Future of Secondary Organic Aerosol Direct Forcing on Climate, Current Climate Change Reports, 4, 1-15, https://doi.org/10.1007/s40641018-0092-3, 2018.

Vaden, T. D., Imre, D., Beránek, J., Shrivastava, M., and Zelenyuk, A.: Evaporation kinetics and phase of laboratory and ambient secondary organic aerosol, P. Natl. Acad. Sci. USA, 108, 21902195, https://doi.org/10.1073/pnas.1013391108, 2011.

Vakkari, V., Beukes, J. P., Dal Maso, M., Aurela, M., Josipovic, M., and van Zyl, P. G.: Major secondary aerosol formation in southern African open biomass burning plumes, Nat. Geosci., 11, 580-583, https://doi.org/10.1038/s41561-018-0170-0, 2018.

van der Werf, G. R., Randerson, J. T., Giglio, L., van Leeuwen, T. T., Chen, Y., Rogers, B. M., Mu, M., van Marle, M. J. E., Morton, D. C., Collatz, G. J., Yokelson, R. J., and Kasibhatla, P. S.: Global fire emissions estimates during 1997-2016, Earth Syst. Sci. Data, 9, 697-720, https://doi.org/10.5194/essd-9-697-2017, 2017.

Wang, R., Balkanski, Y., Boucher, O., Ciais, P., Schuster, G. L., Chevallier, F., Samset, B. H., Liu, J., Piao, S., Valari, M., and Tao, S., Estimation of global black carbon direct radiative forcing and its uncertainty constrained by observations: J. Geophys. Res., 121, 5948-5971, https://doi.org/10.1002/2015JD024326, 2016.

Wang, X., Heald, C. L., Sedlacek, A. J., de Sá, S. S., Martin, S. T., Alexander, M. L., Watson, T. B., Aiken, A. C., Springston, S.
R., and Artaxo, P.: Deriving brown carbon from multiwavelength absorption measurements: method and application to AERONET and Aethalometer observations, Atmos. Chem. Phys., 16, 12733 12752, https://doi.org/10.5194/acp-16-12733-2016, 2016.

Wang, X., Heald, C. L., Liu, J., Weber, R. J., Campuzano-Jost, P., Jimenez, J. L., Schwarz, J. P., and Perring, A. E.: Exploring the observational constraints on the simulation of brown carbon, Atmos. Chem. Phys., 18, 635-653, https://doi.org/10.5194/acp-18635-2018, 2018.

Warneke, C., Bahreini, R., Brioude, J., Brock, C. A., de Gouw, J. A., Fahey, D. W., Froyd, K. D., Holloway, J. S., Middlebrook, A., Miller, L., Montzka, S., Murphy, D. M., Peischl, J., Ryerson, T. B., Schwarz, J. P., Spackman, J. R., and Veres, P.: Biomass burning in Siberia and Kazakhstan as an important source for haze over the Alaskan Arctic in April 2008, Geophys. Res. Lett., 36, L02813, https://doi.org/10.1029/2008GL036194, 2009.

Wild, O., Zhu, X., and Prather, J.: Fast-J: accurate simulation of the in- and below-cloud photolysis in tropospheric chemical models, J. Atmos. Chem., 37, 245-282, 2000.

Wong, J. P. S., Nenes, A., and Weber, R. J.: Changes in light absorptivity of molecular weight separated brown carbon due to photolytic aging, Environ. Sci. Technol., 51, 8414-8421, https://doi.org/10.1021/acs.est.7b01739, 2017.

Wong, J. P. S., Tsagkaraki, M., Tsiodra, I., Mihalopoulos, N., Violaki, K., Kanakidou, M., Sciare, J., Nenes, A., and Weber, R. J.: Atmospheric evolution of molecular-weight-separated brown carbon from biomass burning, Atmos. Chem. Phys., 19, 73197334, https://doi.org/10.5194/acp-19-7319-2019, 2019.

Wu, C., Wu, D., and Yu, J. Z.: Quantifying black carbon light absorption enhancement with a novel statistical approach, Atmos. Chem. Phys., 18, 289-309, https://doi.org/10.5194/acp-18-2892018, 2018.

Yasunari, T., Kim, K.-M., Da Silva, A., Hayasaki, M., Akiyama, M., Murao, N.: Extreme air pollution events in Hokkaido, Japan, traced back to early snowmelt and large-scale wildfires over East Eurasia: Case studies, Sci. Rep.-UK, 8, 6413, https://doi.org/10.1038/s41598-018-24335-w, 2018.

Yokelson, R. J., Crounse, J. D., DeCarlo, P. F., Karl, T., Urbanski, S., Atlas, E., Campos, T., Shinozuka, Y., Kapustin, V., Clarke, A. D., Weinheimer, A., Knapp, D. J., Montzka, D. D., Holloway, J., Weibring, P., Flocke, F., Zheng, W., Toohey, D., Wennberg, P. O., Wiedinmyer, C., Mauldin, L., Fried, A., Richter, D., Walega, J., Jimenez, J. L., Adachi, K., Buseck, P. R., Hall, S. R., and Shetter, R.: Emissions from biomass burning in the Yucatan, Atmos. Chem. Phys., 9, 5785-5812, https://doi.org/10.5194/acp-9-57852009, 2009.

Zhang, A., Wang, Y., Zhang, Y., Weber, R. J., Song, Y., Ke, Z., and Zou, Y.: Modeling the global radiative effect of brown carbon: a potentially larger heating source in the tropical free troposphere than black carbon, Atmos. Chem. Phys., 20, 1901-1920, https://doi.org/10.5194/acp-20-1901-2020, 2020.

Zhang, L., Gong, S., Padro, J., and Barrie, L.: A size-segregated particle dry deposition scheme for an atmospheric aerosol module, Atmos. Environ., 35, 549-560, 2001.

Zhang, L., Henze, D. K., Grell, G. A., Carmichael, G. R., Bousserez, N., Zhang, Q., Torres, O., Ahn, C., Lu, Z., Cao, J., and Mao, Y.: Constraining black carbon aerosol over Asia using OMI aerosol absorption optical depth and the adjoint of GEOS-Chem, Atmos. 
Chem. Phys., 15, 10281-10308, https://doi.org/10.5194/acp-1510281-2015, 2015.

Zhang, Y., Huang, J.-P., Henze, D. K., and Seinfeld, J. H.: Role of isoprene in secondary organic aerosol formation on a regional scale, J. Geophys. Res.-Atmos., 112, D20207, https://doi.org/10.1029/2007JD008675, 2007.

Zhong, M. and Jang, M.: Dynamic light absorption of biomass-burning organic carbon photochemically aged under natural sunlight, Atmos. Chem. Phys., 14, 1517-1525, https://doi.org/10.5194/acp-14-1517-2014, 2014.
Zhou, S., Collier, S., Jaffe, D. A., Briggs, N. L., Hee, J., Sedlacek III, A. J., Kleinman, L., Onasch, T. B., and Zhang, Q.: Regional influence of wildfires on aerosol chemistry in the western US and insights into atmospheric aging of biomass burning organic aerosol, Atmos. Chem. Phys., 17, 2477-2493, https://doi.org/10.5194/acp-17-2477-2017, 2017. 